\title{
Estimador Neural de Velocidade Para Motores de Indução Trifásicos
}

Tese apresentada à Escola de Engenharia de São Carlos da Universidade de São Paulo, sendo parte dos requisitos para obtenção do título de Doutor em Engenharia Elétrica.

Orientador: Prof. Dr. Ivan Nunes da Silva

São Carlos 

Dedico este trabalho com carinho e estima à minha esposa Cláudia pelo incentivo e paciência durante as pesquisas, estudos e elaboração desse trabalho. E ao meu pai Evaldo pelo incentivo aos meus estudos. 


\section{Agradecimentos}

Este trabalho teve a colaboração de diversas pessoas e instituições. Elencar todos os nomes e contribuições é uma tarefa árdua, havendo a possibilidade de deixar alguém sem o devido reconhecimento expresso nessas linhas. Desde já me desculpo por alguma omissão. Sendo dever de ofício e tradição atrevo-me a tentar.

Ao Prof. Dr. Ivan Nunes da Silva pelos seus ensinamentos em sistemas inteligentes, pelas sugestões no decorrer do desenvolvimento deste trabalho, pelo apoio na elaboração dos projetos de solicitação de recursos para construção de uma bancada experimental encaminhados à FAPESP e pela revisão dos artigos publicados.

Aos colegas Eng. MSc. Antônio Vanderlei Ortega, Eng. Dr. Rogério Andrade Flauzino, Eng. MSc. Danilo Hernane Spatti, Eng. MSc. Wesley Fernando Usida, Eng. Dr. Claudionor Francisco do Nascimento, Eng. MSc. Edimilson Sanagiotti, Eng. Marcelo Suetake, Eng. Sérgio Ferreira da Silva, Eng. Cristiano Minotti e demais colegas pelas inúmeras contribuições ao trabalho.

Aos técnicos de laboratório da Universidade Estadual Paulista (UNESP/FEB/DEE) Eng. Edson Oshiro, Helton Roberto Gonzáles, Manoel Rodrigues Porcino da Silva, Osmar Luis Matinelli e ao técnico de laboratório da Universidade de São Paulo (USP/EESC/SEL) Rui Bertho pelo auxílio na construção da bancada de testes desenvolvida neste trabalho.

Ao CNPq (Conselho Nacional de Desenvolvimento Científico e Tecnológico) pelo auxílio financeiro concedido no período de realização deste trabalho, na forma de bolsa de estudos sem a qual o mesmo não seria possível (Processo $n^{\circ}$. $142326 / 2005-4)$. 
À FAPESP (Fundação de Apoio a Pesquisa do Estado de São Paulo), pelo auxílio financeiro concedido no período de realização deste trabalho, na forma de projetos de pesquisa, os quais viabilizaram a construção de uma estrutura de ensaio de máquinas elétricas e a validação dos modelos computacionais propostos (Processos n. 03/11353-0 e 06/56093-3).

À Escola de Engenharia de São Carlos (EESC/USP) que acolheu este trabalho de doutorado, através da destinação de espaço físico e apoio administrativo, traduzindo assim a grandiosidade da instituição e visão de futuro. 
Uma mente que se abre para uma nova idéia, jamais retornará ao seu tamanho original.

Albert Einstein.

Porque Dele e por meio Dele, e para Ele são todas as coisas. Glória, pois, a Ele eternamente. Amém.

Romanos 11,36. 


\title{
Resumo
}

\begin{abstract}
GOEDTEL, A. (2007). Estimador Neural de Velocidade Para Motores de Indução Trifásicos. Tese (Doutorado) - Escola de Engenharia de São Carlos, Universidade de São Paulo, 2007.
\end{abstract}

Este trabalho apresenta uma estratégia para a estimativa de velocidade do motor de indução trifásico baseada em redes neurais artificiais utilizando medidas de variáveis primárias como tensão e corrente. $\mathrm{O}$ uso de motores de indução trifásicos é uma constante em diversos setores industriais e de grande importância no cenário energético nacional. A maioria das metodologias de controle, partida e especificação destes motores é fundamentada nas medidas de velocidade no eixo. Entretanto, a medida direta da velocidade compromete o sistema de controle e acionamento diminuindo sua robustez e aumentando o custo de implementação. Resultados de simulação e de ensaios experimentais para validação da proposta são também apresentados.

Palavras chave: Motor de indução trifásico, estimador de velocidade, redes neurais artificiais. 


\begin{abstract}
GOEDTEL, A. (2007). Speed Neural Estimator for the Three-Phase Induction Motors. Thesis (Doctorate Degree) - Escola de Engenharia de São Carlos, Universidade de São Paulo, 2007.
\end{abstract}

This work presents an approach to estimate speed in induction motors based on artificial neural networks and using measurement of primary variables like voltage and current. The use of induction motors is very common in many industrial sectors and plays an important role in the national energetic scene. The methodologies used in control, start up and dimensioning of these motors are based on measure of the speed variable. However, the direct measure of this variable compromises the system control and start up of the machine, reducing its robustness and increasing the implementation costs. Simulation results and experimental data are presented to validate the proposed approach.

Keywords: Three-phase induction motors, speed estimator, artificial neural networks. 


\title{
Lista de Siglas e Abreviaturas
}

\author{
$\mathrm{CA}=$ Corrente Alternada \\ $\mathrm{CC}=$ Corrente Contínua \\ $\mathrm{CV}=$ Controle Vetorial \\ CDT $=$ Controle Direto de Torque \\ DTC = Direct Torque Control \\ FFT = Fast Fourier Transform \\ IFFT = Interpolated Fast Fourier Transform \\ IFOC = Indirect Field Oriented Control \\ LN = Lógica Nebulosa \\ MCA = Máquina de Corrente Alternada \\ MCC = Máquina de Corrente Contínua \\ MIT = Motor de Indução Trifásico \\ PWM $=$ Pulse Width Modulation \\ RNA $=$ Redes Neurais Artificiais
}




\section{Lista de Figuras}

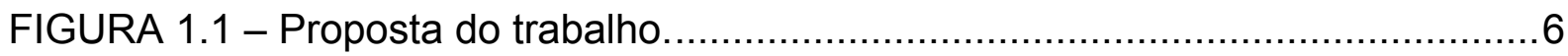

FIGURA 3.1 - A arquitetura perceptron multicamadas. .....................................25

FIGURA 3.2 - Diagrama esquemático da rede perceptron.....................................26

FIGURA 4.1 - Esquema experimental para simulação de cargas. ...........................46

FIGURA 4.2 - Quadro de comando: (a) vista frontal; (b) detalhe da conexão. .........49

FIGURA 4.3 - Quadro de comando: (a) disposição dos variadores de tensão no painel; (b) disposição dos variadores de tensão na parte posterior do painel frontal; (c) ligação dos variadores de tensão ao barramento do quadro de comando; (d) detalhe construtivo do variador de tensão utilizado no quadro de comando. 50

FIGURA 4.4 - Diagrama em blocos da operação do gerador CC. 52

FIGURA 4.5 - Seção de um semicondutor do tipo p submetido a um campo elétrico e magnético. 52

FIGURA 4.6 - Sensor Hall de corrente com realimentação do sinal de saída. .........55

FIGURA 4.7 - Transformação de corrente em tensão. ..........................................56

FIGURA 4.8 - Condicionamento de sinal do sensor Hall....................................57

FIGURA 4.9 - Diagrama de conexão elétrica. ......................................................59

FIGURA 4.10 - Diagrama de conexão interna ao quadro de comando. ...................60

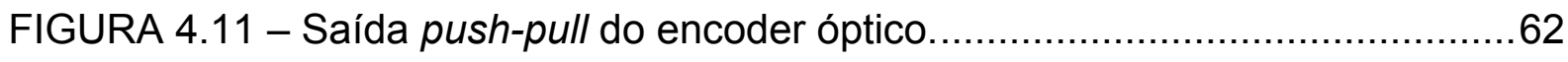

FIGURA 4.12 - Vista do conjunto: condicionamento de sinal do encoder óptico e fonte de alimentação. 
FIGURA 4.13 - Estrutura metálica: (a) Fixação das máquinas e (b) fixação do encoder. 65

FIGURA 4.14 - Elemento de fixação: (a) extensão do eixo do MIT, (b) Acoplamento elástico do encoder, (c) acoplamento elástico das demais máquinas, (d) acoplamento do MIT com o torquímetro girante utilizando acoplamento elástico.

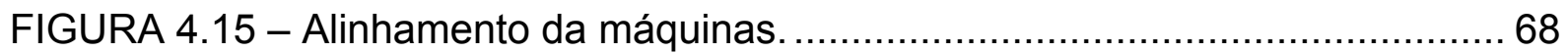

FIGURA 4.16 - Estrutura de ensaios de máquinas elétricas rotativas. ................... 68

FIGURA 4.17 - Carga da máquina de corrente contínua...................................... 69

FIGURA 5.1 - Diagrama esquemático representando as configurações de entradassaídas usadas para simular o MIT.

FIGURA 5.2 - Diagrama em blocos da metodologia. 74

FIGURA 5.3 - (a) Estrutura de treinamento e teste da RNA e (b) detalhe do bloco para o cálculo do valor eficaz utilizando Matlab/Simulink. 76

FIGURA 5.4 - Curvas de simulação do MIT as quais representam as diversas situações de carga e a faixa tensão de operação (NBR7094/1996). 77

FIGURA 5.6 - Estimativa de velocidade na faixa 1 (200V-206V) e $1 \mathrm{Nm}$ de conjugado de carga em regime permanente.

FIGURA 5.7 - Estimativa de velocidade na faixa 1 (200V-206V) e $5 \mathrm{Nm}$ de conjugado de carga em regime permanente.

FIGURA 5.8 - Estimativa de velocidade na faixa 2 (204V-216V) e $3 \mathrm{Nm}$ de conjugado de carga em regime permanente. 82

FIGURA 5.9 - Estimativa de velocidade na faixa 2 (204V-216V) e $5 \mathrm{Nm}$ de conjugado de carga em regime permanente. 
FIGURA 5.10 - Estimativa de velocidade na faixa $3(214 \mathrm{~V}-224 \mathrm{~V})$ e $5 \mathrm{Nm}$ de conjugado de carga em regime permanente

FIGURA 5.11 - Estimativa de velocidade na faixa $3(214 \mathrm{~V}-226 \mathrm{~V})$ e $3 \mathrm{Nm}$ de conjugado de carga em regime permanente 83

FIGURA 5.12 - Estimativa de velocidade na faixa 4 (224V-236V) e $5 \mathrm{Nm}$ de conjugado de carga em regime permanente 84

FIGURA 5.13 - Estimativa de velocidade na faixa $4(224 \mathrm{~V}-236 \mathrm{~V})$ e $3 \mathrm{Nm}$ de conjugado de carga em regime permanente. .84

FIGURA 5.14 - Estimativa de velocidade na faixa 5 (234V-240V) e $1 \mathrm{Nm}$ de conjugado de carga em regime permanente. 85

FIGURA 5.15 - Estimativa de velocidade na faixa 5 (234V-240V) e $3 \mathrm{Nm}$ de conjugado de carga em regime permanente 85

FIGURA 5.16 - Estrutura de ensaios. 88

FIGURA 5.17 - Sensores Hall de corrente e tensão da máquina CC. 88

FIGURA 5.18 - Estimativa de velocidade na faixa 1 (200V-206V) e 2,5 Nm de conjugado de carga em regime permanente através do processo de bivalidação. 90

FIGURA 5.19 - Medidas de tensão, corrente e velocidade. 91

FIGURA 5.20 - Estimativa de velocidade na faixa 1 (200V-206V) e 2,5 Nm de conjugado de carga em regime permanente através do processo de bivalidação modificado. 92

FIGURA 5.21 - Estimativa de velocidade na faixa 1 (200V-206V) e $5 \mathrm{Nm}$ de conjugado de carga em regime permanente através do processo de bivalidação modificado. 93 
FIGURA 5.22 - Estimativa de velocidade na faixa 2 (204V-216V) e $3 \mathrm{Nm}$ de conjugado de carga em regime permanente através do processo de bivalidação modificado. 94

FIGURA 5.23 - Estimativa de velocidade na faixa 2 (204V-216V) e $5 \mathrm{Nm}$ de conjugado de carga em regime permanente através do processo de bivalidação modificado. 94

FIGURA 5.24 - Estimativa de velocidade na faixa $3(214 \mathrm{~V}-226 \mathrm{~V})$ e $1 \mathrm{Nm}$ de conjugado de carga em regime permanente através do processo de bivalidação modificado. 95

FIGURA 5.25 - Estimativa de velocidade na faixa 3 (214V-226V) e $3,8 \mathrm{Nm}$ de conjugado de carga em regime permanente através do processo de bivalidação modificado. 95

FIGURA 5.26 - Estimativa de velocidade na faixa 4 (224V-236V) e $5,5 \mathrm{Nm}$ de conjugado de carga em regime permanente através do processo de bivalidação modificado. 96

FIGURA 5.27 - Estimativa de velocidade na faixa 4 (224V-236V) e 3,5 Nm de conjugado de carga em regime permanente através do processo de bivalidação modificado. 96

FIGURA 5.28 - Estimativa de velocidade na faixa 5 (234V-240V) e $1 \mathrm{Nm}$ de conjugado de carga em regime permanente através do processo de bivalidação modificado. 97

FIGURA 5.29 - Estimativa de velocidade na faixa 5 (234V-240V) e $6 \mathrm{Nm}$ de conjugado de carga em regime permanente através do processo de bivalidação modificado. 97 
FIGURA 5.30 - Estimativa de velocidade na faixa $3(214 \mathrm{~V}-226 \mathrm{~V})$ e $1 \mathrm{Nm}$ de conjugado de carga em regime permanente através do processo de bivalidação modificado e o modelo de referência. 100

FIGURA 5.31 - Estimativa de velocidade na faixa $3(214 \mathrm{~V}-226 \mathrm{~V})$ e $2 \mathrm{Nm}$ de conjugado de carga em regime permanente através do processo de bivalidação modificado e o modelo de referência. 101

FIGURA 5.32 - Estimativa de velocidade na faixa $3(214 \mathrm{~V}-226 \mathrm{~V})$ e $3 \mathrm{Nm}$ de conjugado de carga em regime permanente através do processo de bivalidação modificado e o modelo de referência. 101

FIGURA 5.33 - Estimativa de velocidade na faixa $3(214 \mathrm{~V}-226 \mathrm{~V})$ e $4 \mathrm{Nm}$ de conjugado de carga em regime permanente através do processo de bivalidação modificado e o modelo de referência. 102

FIGURA 5.34 - Estimativa de velocidade na faixa $3(214 \mathrm{~V}-226 \mathrm{~V})$ e $5 \mathrm{Nm}$ de conjugado de carga em regime permanente através do processo de bivalidação modificado e o modelo de referência. 102

FIGURA 5.35 - Estimativa de velocidade na faixa $3(214 \mathrm{~V}-226 \mathrm{~V})$ e $6 \mathrm{Nm}$ de conjugado de carga em regime permanente através do processo de bivalidação modificado e o modelo de referência. 103 


\section{Lista de Tabelas}

TABELA 5.1 - Parâmetros do MIT. 73

TABELA 5.2 - Faixas de tensão e índice da estrutura neural. 78

TABELA 5.3 - Erro médio e desvio padrão entre as velocidades real e estimada no eixo do motor de indução trifásico. 86

TABELA 5.4 - Erro médio e desvio padrão recalculado entre as velocidades real e estimada no eixo do motor de indução trifásico. 87

TABELA 5.5 - Parâmetros da rede neural artificial proposta. 87

TABELA 5.6 - Erro médio e desvio padrão entre as velocidades real e estimada no eixo do motor de indução trifásico. 98

TABELA 5.7 - Erro médio e desvio padrão entre as velocidades real e estimada no eixo do motor de indução trifásico para o estimador neural e o modelo de referência. 103 


\section{SUMÁRIO}

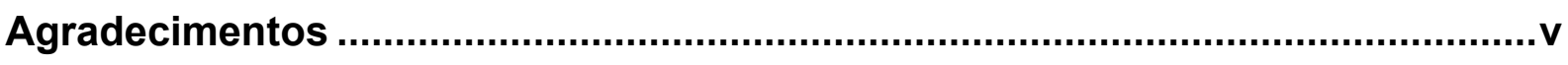

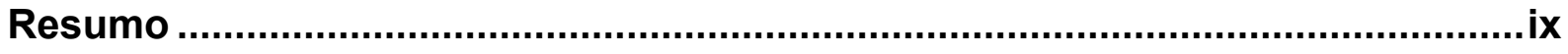

Abstract

Lista de Siglas e Abreviaturas ..........................................................................ii

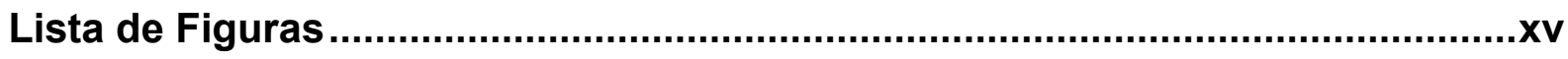

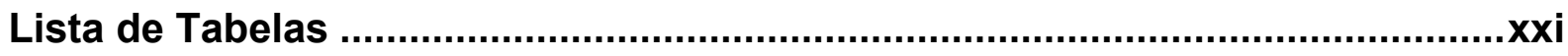

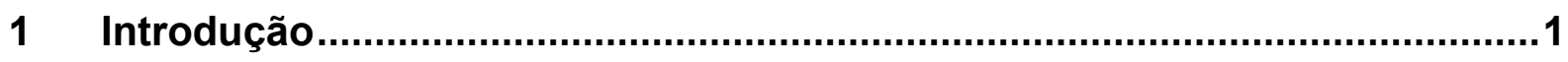

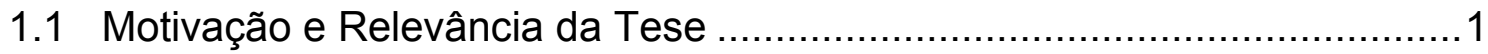

1.2 Objetivos e Justificativas da Tese ....................................................

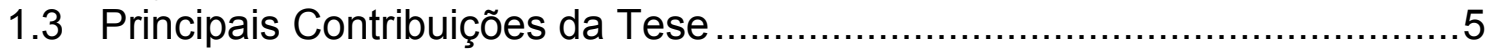

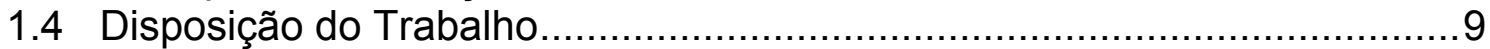

2 Aspectos Relacionados ao Controle e à Estimação Paramétrica do Motor de Indução Trifásico ..............................................................................11

2.1 Aspectos Relacionados ao Controle do MIT ......................................12

2.2 Aspectos Relacionados à Estimação Paramétrica do MIT .......................17

3 Fundamentos e Conceitos de Inteligência Computacional ...........................23

3.1 Fundamentos das Redes Neurais Artificiais ........................................23

3.1.1 A Rede Perceptron Multicamadas ............................................24

3.1.2 Algoritmo de Treinamento da Rede Perceptron ..........................25

3.1.3 Algoritmo de Levenberg-Marquardt ........................................... 31

3.1.4 Algoritmo de Levenberg Regularizado ..................................... 34

3.2 O Processo de Validação Cruzada (Crossvalidation)...............................35

3.3 As Redes Neurais Artificiais Aplicadas em Máquinas Elétricas Rotativas.38 
4 Desenvolvimento de Uma Estrutura de Ensaios de Máquinas Elétricas

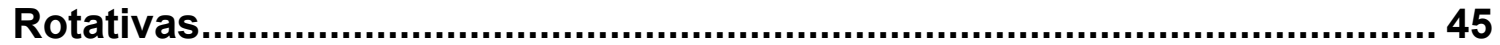

4.1 Aspectos Relacionados à Máquina CC …….................................... 50

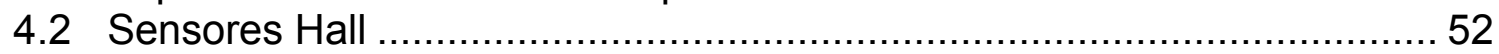

4.2.1 Sensores Hall de Corrente ....................................................... 53

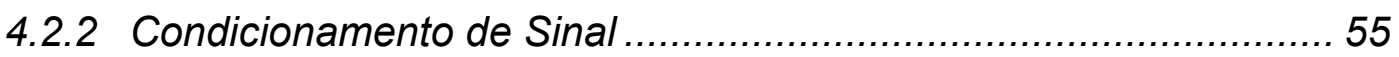

4.2.3 Sensores Hall de Tensão...................................................... 58

4.2.4 Sensores Hall: Aplicação ........................................................ 59

4.3 Encoder Óptico e Seu Condicionamento de Sinal .................................. 60

4.4 Bancada de Ensaios: Acoplando as Máquinas ....................................... 64

4.4.1 Estrutura Metálica da Bancada de Ensaios ................................... 65

4.4.2 Montagem do Conjunto Completo ............................................. 66

5 Uma Contribuição aos Estimadores de Velocidade Utilizando Redes

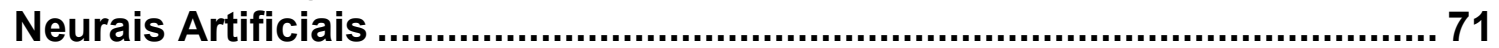

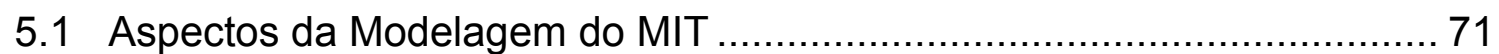

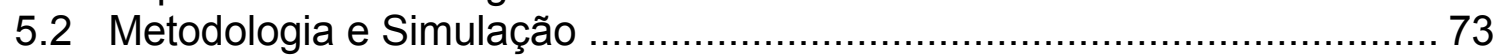

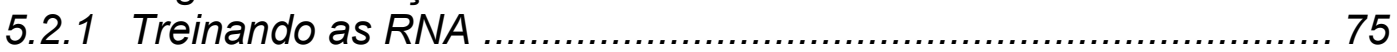

5.2.2 Resultados de Simulação: Validação Cruzada ............................... 80

5.2.3 Resultados Experimentais .................................................... 88

5.2.4 Resultados da Bi-Validação Cruzada ......................................... 89

5.2.5 O Processo de Bi-Validação Cruzada Modificado ......................... 91

5.3 Estudo Comparativo Entre RNA e Modelo de Referência ........................ 98

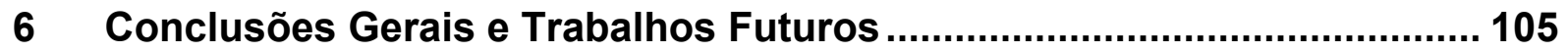

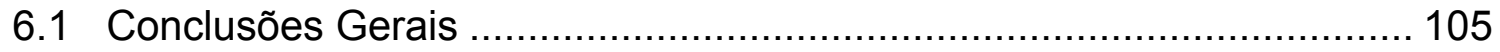

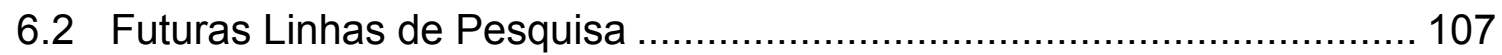

6.3 Publicações Relativas ao Trabalho.................................................... 108

Referências Bibliográficas ....................................................................... 113

Apêndice A 



\section{Introdução}

\subsection{Motivação e Relevância da Tese}

Os Motores de Indução Trifásicos (MIT) são usados em muitos setores industriais, sendo o principal elemento para converter energia elétrica em mecânica motriz. Suas principais características se fundamentam no baixo custo e robustez.

As aplicações destes motores podem ser divididas em dois grandes grupos: o primeiro grupo é aquele em que o motor trabalha sempre à mesma velocidade, ou seja, uma vez dada sua partida, não há elemento de controle sobre sua velocidade ou regime de operação. O segundo grupo, por sua vez, é aquele onde os processos em que os motores estão acoplados necessitam a aplicação de uma metodologia de controle de velocidade (escalar ou vetorial).

A velocidade nos eixos dos motores de indução pode ser medida com encoders ópticos, resolvers eletromagnéticos ou tacogeradores baseados em motores de corrente contínua sem escovas. Entretanto, o uso destes dispositivos eletromecânicos apresenta certa limitação em sua aplicação, tais como o aumento do custo do dispositivo de partida, redução da robustez mecânica, baixa imunidade ao ruído, alteração da inércia da máquina, além de exigir especial atenção em ambientes hostis (VAS, 1998).

O uso de técnicas sensorless se encontra principalmente em aplicações de alto desempenho como Controle Vetorial (CV) e Controle Direto de Torque (CDT). As principais metodologias empregadas originam-se em estimadores de malha aberta com monitoramento de corrente e tensão do estator, observadores de estado, 
sistemas de referência com modelos adaptativos e estimadores baseados em sistemas inteligentes, os quais advêm principalmente das Redes Neurais Artificiais (RNA) e Lógica Nebulosa (LN) (VAS, 1998).

Outras questões que envolvem a partida e especificação do motor de indução também utilizam a velocidade como variável primária. Dois métodos de partida se destacam por sua simplicidade, robustez e baixo custo. O primeiro método é o da partida com chave estrela-triângulo e o segundo com autotransformador.

Estes métodos, apesar de serem simples em sua implementação, possuem algumas limitações em sua operacionalidade. Por exemplo, se houver mudança na chave de ligação de estrela para triângulo ou mudança de tap no autotransformador enquanto a carga estiver acelerando, o transitório de corrente pode se igualar ao de uma partida direta anulando o efeito do método de partida.

Os motores elétricos são considerados os maiores consumidores de energia elétrica e principais conversores de energia elétrica em mecânica, conforme demonstram as pesquisas citadas ao longo deste trabalho. O MIT é o motor mais vendido e instalado no setor industrial, pois suas características de baixo custo de aquisição e robustez traduzem as necessidades dos processos produtivos.

Entretanto, não há consenso sobre um método genérico para estimação de velocidade visando atender às diversas necessidades para sistemas a laço aberto ou controle realimentado; quais sejam: i) regime permanente ou regime transitório, ii) alimentação senoidal ou não-senoidal, iii) variações paramétricas observadas ao longo de sua operação devido à temperatura, iv) variações paramétricas observadas ao longo de sua operação em regime transitório, v) variações de carga, vi) variação de tensão de alimentação, e vii) esforço computacional envolvido nesta estimativa. 
A prova desta afirmativa está na busca incessante de métodos para estimar velocidade e outros parâmetros como fluxo eletromagnético, resistências de rotor e estator, torque de carga etc, ao longo de mais de duas décadas de pesquisa, registrados e divulgados em importantes periódicos de circulação nacional e internacional.

Assim, a principal motivação deste trabalho está no desenvolvimento de uma metodologia que estime a velocidade do motor de indução trifásico, considerando uma grande faixa de operação de alimentação e conjugado de carga, do transitório ao regime permanente. A simplicidade computacional e a robustez frente à variação de parâmetros de alimentação e alteração de carga no eixo são questões de grande relevância na estimativa de velocidade. Ainda, de forma complementar, é de fundamental importância considerar as variações de parâmetros internos da máquina, tais como resistência do rotor e estator com a elevação da temperatura.

\subsection{Objetivos e Justificativas da Tese}

Esta tese tem por objetivo o desenvolvimento de um método robusto para estimativa de velocidade em motores de indução trifásico, do transitório ao regime permanente, para aplicações típicas como determinação do rendimento e eficiência energética, partida e controle.

Em termos de eficiência energética, no trabalho de El-lbiary (2003) é proposto um método alternativo e de baixo custo para determinação da eficiência energética de um motor de indução instalado numa planta industrial. O autor propõe o uso de medidas de tensão, corrente e potência de entrada, resistência de estator e a velocidade no rotor. Em Damasceno et al. (2002), os autores sugerem dois 
métodos para determinação do rendimento do motor. Em ambos os métodos há a necessidade de medida de velocidade no eixo do motor, além da medição de potência elétrica.

No trabalho de Goedtel (2003) foi proposto um estimador de conjugado de carga para motores de indução trifásicos baseado em redes neurais artificiais. 0 estimador tem como entrada medidas de tensão e corrente eficaz e velocidade no eixo. A saída da estrutura neural é o conjugado de carga aplicado ao eixo do motor. Em Goedtel et al. (2004 e 2006b) foi proposta uma estrutura neural em cascata no sentido de eliminar o sensor de velocidade e reduzir o custo da implementação da proposta de Goedtel (2003).

Alguns métodos de partida de máquinas elétricas, muito utilizados na indústria, requerem o conhecimento da velocidade do motor de indução para o instante exato da comutação dos contatores. Conforme as considerações sobre métodos de partida no manual de um fabricante nacional de motores, espera-se que a velocidade atinja entre $90 \%$ e $95 \%$ de sua rotação nominal para comutar da posição estrela para triângulo num MIT.

Desta forma, há a necessidade de medir (ou estimar) a velocidade do MIT com o objetivo de determinar o exato, ou aproximado, instante de comutação da chave (GOEDTEL et al., 2006). Atualmente, esta comutação é feita de forma manual com a intervenção do operador ou através de um circuito temporizador. Entretanto, a imprecisão destes métodos (manual ou temporizado) pode acarretar valores de pico de corrente de linha muito próximos aos verificados na partida direta.

Em Goedtel et al. (2006) foi proposto um estimador de velocidade para comutação estrela-triângulo em motores de indução trifásicos. Quando o motor atinge $90 \%$ de sua velocidade nominal o controle acionava o contator responsável 
pela ligação em triângulo e desligava o contator responsável pela ligação em estrela. Após este instante o estimador de velocidade deixava de atuar no processo, pois sua função já havia se encerrado.

Diversas variáveis que envolvem a dinâmica elétrica e mecânica do MIT são objeto de estudos. Dentre as variáveis elétricas, citam-se as resistências de rotor e estator, as indutâncias de rotor, estator e magnetização, além do fluxo eletromagnético. Entre as variáveis mecânicas o torque de carga e o torque eletromagnético são de grande importância no controle do MIT. A velocidade, outra variável mecânica, é de especial interesse em algoritmos de controle, tais como controle vetorial indireto, controle direto de torque e controle por escorregamento controlado.

Observa-se, através das diversas referências apresentadas neste trabalho, a constante pesquisa por metodologias que estimem a velocidade do motor de indução trifásico, do transitório ao regime permanente, com um erro baixo e com reduzido esforço computacional. O desenvolvimento de um modelo (ou metodologia) simples e robusto, que atenda as necessidades da indústria em relação ao controle e partida destas máquinas, é um dos objetivos de diversos centros de pesquisa espalhados pelo mundo e atestado pelas diversas publicações em mais de duas décadas.

\subsection{Principais Contribuições da Tese}

A proposta desta tese é contribuir com as pesquisas na área de estimadores paramétricos para o motor de indução. Em especial, propõe-se um estimador de velocidade para o motor de indução trifásico com medidas primárias de tensão e 
corrente de estator numa multi-estrutura dividida pela tensão de alimentação da máquina. A FIGURA 1.1 ilustra a proposta deste trabalho.

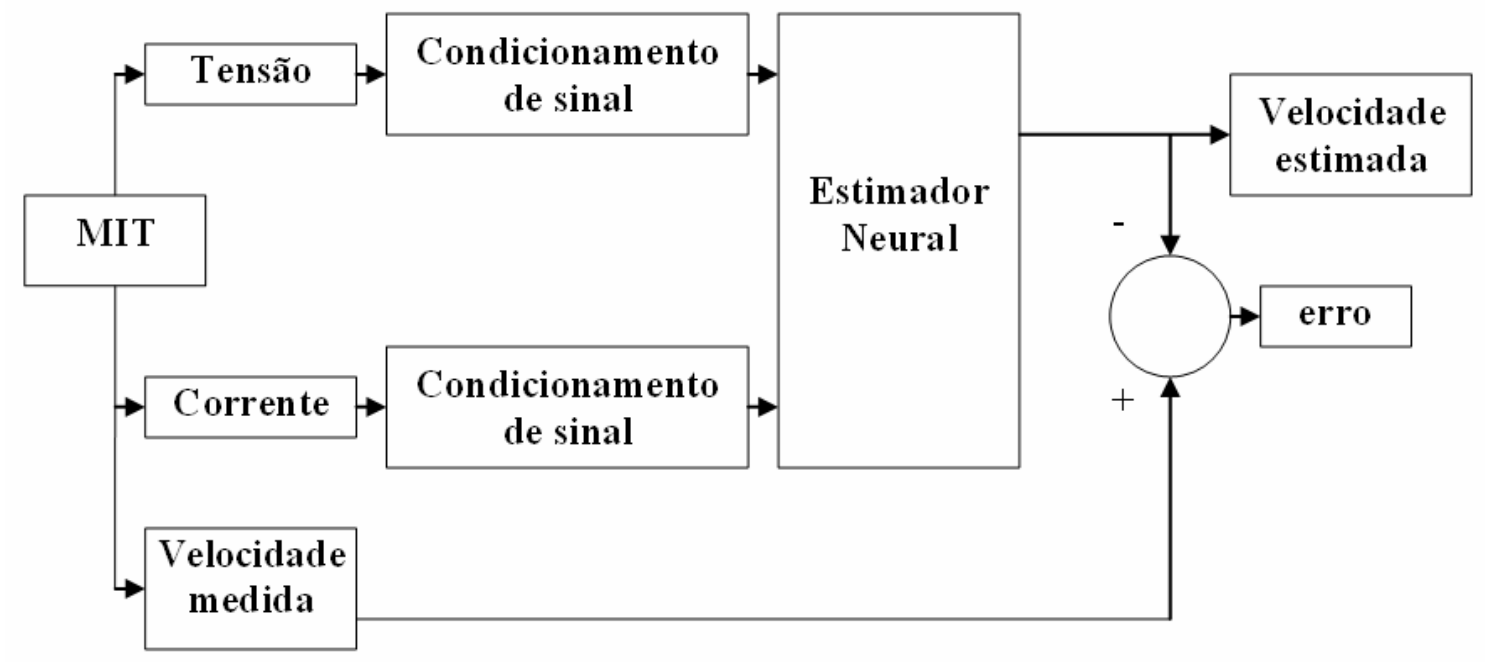

FIGURA 1.1 - Proposta do trabalho.

Na FIGURA 1.1 a tensão e a corrente são medidas com sensores Hall e a velocidade medida com encoder óptico. Ao MIT são impostas situações de carga e alimentação (sub-tensão e sobretensão) encontradas nos ambientes produtivos. O condicionamento de sinais, descrito nos blocos acima, calcula o valor eficaz do sinal e faz a conversão Analógica/Digital (A/D). A estrutura neural, após treinamento supervisionado, estima o valor da velocidade no eixo do MIT. Este sinal é comparado com o sinal de velocidade medido, devidamente condicionado, gerando o sinal de erro; ou seja, a diferença entre sinal medido e estimado.

Dentro da proposta desta tese, assume-se a divisão por faixas de tensão. Logo, tem-se uma estrutura neural para cada faixa de tensão considerada e obedecendo aos limites de operação da máquina de indução impostos pela NBR 7094/1996. Há então uma multi-estrutura neural operando para estimar a velocidade do motor de indução trifásico. O trabalho de Goedtel (2003) utilizou esta multiestrutura, por faixa de tensão, para estimar torque de carga. 
Através da pesquisa à literatura, percebe-se a necessidade de conectar a realidade física de um sistema dinâmico multivariável e variante no tempo, que é o caso da maioria das máquinas elétricas - em especial o motor de indução trifásico com um sistema de baixo custo computacional para realizar a estimação paramétrica.

Apresenta-se neste trabalho, no sentido de completar a proposta de um estimador de velocidade para o motor de indução trifásico, uma modificação no método de validação cruzada; a saber: o método de bi-validação cruzada e o método de bi-validação cruzada modificado.

O método da validação cruzada (crossvalidation) é muito utilizado para validar uma estrutura neural. Após o processo de treinamento da rede neural artificial, alguns dados os quais são chamados de teste, são apresentados à estrutura neural e verifica-se a capacidade da rede em generalizar soluções.

A partir do modelo físico do sistema (ONG, 1997; KRAUSE el tal, 2002) foi possível gerar os dados de treinamento da estrutura neural proposta neste trabalho. Dividiu-se em faixas de tensão e diferentes valores de conjugado de carga conforme Goedtel (2003). As simulações geraram dados suficientes para o treinamento da rede neural e sua validação.

O método de bi-validação proposto apresenta dados experimentais à rede neural treinada com dados de simulação. Tem-se com isso uma segunda etapa de validação da mesma rede. Os resultados de generalização obtidos demonstram que em regime permanente o valor estimado e o valor real (medido na bancada de ensaios) são muito próximos e com erro muito baixo. Entretanto, em regime transitório, o erro entre o valor estimado e valor real são elevados. 
Em tal situação, insere-se uma modificação no método de bi-validação cruzado. O modelo do sistema, o qual é responsável por gerar os dados de treinamento, não contempla todos os aspectos relacionados à dinâmica da máquina; a saber: a saturação eletromagnética, o efeito pelicular, variação dos parâmetros com a temperatura e as perdas por atrito e ventilação. De forma complementar, os dados obtidos por meio de simulação não contemplam as imperfeições dos sensores envolvidos na aquisição dos dados reais; a citar: ruídos, deriva térmica, respostas não-lineares em algumas faixas de operação.

Desta forma, no sentido de superar as diferenças entre modelo e realidade física, propõe-se uma modificação no método de bi-validação. A proposta deste trabalho, no sentido de contemplar o regime permanente e transitório, consiste em re-treinar a estrutura neural inserindo um pequeno número de dados experimentais no conjunto de treinamento e validá-la novamente, com dados experimentais.

Esta modificação contribui também com as pesquisas na área de redes neurais artificiais uma vez que a indisponibilidade de dados de treinamento torna a aplicação desta metodologia proibitiva. Entretanto, a partir do modelo do sistema, gera-se dados de simulação e insere-se uma pequena quantidade de dados experimentais no conjunto de treinamento.

Tais dados foram obtidos através de uma estrutura de ensaios de máquinas elétricas projetada e desenvolvida no período deste trabalho de doutorado com financiamento da FAPESP. Descreve-se também, de forma detalhada, a construção desta estrutura. A metodologia experimental foi proposta no ano de 2003 (projeto FAPESP) e não havia na época estrutura similar descrita na literatura. 


\subsection{Disposição do Trabalho}

Uma breve introdução envolvendo os aspectos da estimativa de parâmetros do MIT e as propostas do trabalho são apresentados neste capítulo.

No Capítulo 2 são apresentados os pontos principais envolvidos com a estimação de velocidade e outros parâmetros do motor de indução.

No Capítulo 3 são apresentados os principais aspectos relacionados às redes neurais artificiais utilizadas nos métodos desenvolvidos.

No Capítulo 4 é apresentado, de forma sistemática, o desenvolvimento de uma estrutura de ensaios para máquinas elétricas que se caracteriza por sua flexibilidade e baixo custo, a qual pode ser aplicada em diversas pesquisas correlatas.

No Capítulo 5 é apresentado o estimador neural de velocidade proposto, a metodologia de bi-validação cruzada e a bi-validação cruzada modificada. Resultados experimentais são também apresentados para validar a proposta.

No Capítulo 6, realizam-se as considerações finais da tese; enfatizando as conclusões relativas ao estimador de velocidade proposto, os métodos de validação, as principais publicações realizadas e as propostas de trabalhos futuros que darão continuidade à esta pesquisa. 


\section{Aspectos Relacionados ao Controle e à Estimação Paramétrica do Motor de Indução Trifásico}

A necessidade crescente de busca por processos mais racionais e econômicos no que tange à utilização eficiente da energia elétrica tem implicado na realização de estudos detalhados para a otimização das técnicas de manufatura, os quais visam também a adequada conservação da energia elétrica. Dentro deste contexto, os motores elétricos se tornaram elementos indispensáveis na maioria dos processos que envolvem os setores produtivos, pois os mesmos destacam-se como o principal elemento de conversão de energia elétrica em mecânica motriz.

Como conseqüência, essas máquinas elétricas passaram, e tendem a continuar passando, por melhorias que atendem as necessidades emergentes dos processos produtivos por sua importância energética dentro do cenário nacional. Como mencionado na revista Eletricidade Moderna (Abril, 2000), cerca de $49 \%$ da energia elétrica produzida no Brasil é destinada ao setor industrial, donde estima-se que $50 \%$ deste montante seja destinado ao consumo por motores elétricos.

Mais recentemente, conforme mencionado no trabalho de Lu et al. (2006), estima-se que dois terços do total de energia elétrica produzida nos Estado Unidos é consumida por sistemas acionados por motores elétricos.

Especial atenção deve ser dada aos motores de indução, os quais são destacados pela sua simplicidade construtiva e principalmente pelo menor custo. Entre os motores de indução, o Motor de Indução com Rotor em Gaiola (MIRG) merece um maior destaque, cujas características marcantes são atribuídas à sua robustez, longa vida útil e quase ausência de manutenção, característica esta que o 
torna mais atraente, especialmente no preço (VAS, 1998; ASHRAFZADEH et al., 2002; ONG, 1997).

Desta forma, frente à necessidade de racionalização do uso da energia elétrica associada aos sistemas de controle e partida destes motores com o menor custo possível, faz-se uso de metodologias chamadas sensorless. Tais metodologias, cuja tradução literal é "sem sensor", se baseiam em medidas primárias de variáveis como tensão e corrente do enrolamento de estator, as quais são mais simples para medição e de menor custo associado. Logo, a expressão "sem sensor" se relaciona a ausência do sensor da variável de interesse e não a ausência total de outros sensores.

A proposta desta tese vem ao encontro das necessidades da indústria e das pesquisas recentes, uma vez que propõe um método alternativo para a estimativa de velocidade do MIT utilizando RNA com medidas (no estator) de tensão e corrente da partida ao regime permanente. O modelo proposto é genérico e pode ser usado em sistemas que trabalhem com velocidade constante ou variável, alimentação senoidal ou PWM (Pulse Width Modulation), pois a entrada do sistema é o valor eficaz destas variáveis. Nos tópicos a seguir serão discutidos os principais problemas envolvidos com a estimativa paramétrica do motor de indução trifásico.

\subsection{Aspectos Relacionados ao Controle do MIT}

O controle de velocidade e torque dos motores elétricos tem sido objeto de estudos e pesquisas nas últimas décadas. Com a evolução e diminuição dos custos dos semicondutores, a tendência é o uso destes em larga escala para o controle dos motores (VAS, 1998). Conforme Bimal K. Bose, "Power semiconductor device is the 
heart and the soul of modern power electronics apparatus..."(BOSE, 1997). A tendência mais recente se baseia no uso de tecnologias sensorless, as quais usam medidas de variáveis primárias como tensão e corrente para estimar velocidade, torque e fluxo eletromagnético no motor (VAS, 1998; CRUZ \& PAREDES, 2003; BOSE, 1997).

As técnicas de controle das máquinas de indução podem ser classificadas em dois grupos; a saber, as escalares e as vetoriais. As técnicas consideradas escalares são baseadas em modelos de regime permanente, tal como Volt/Hertz, apresentando fraco desempenho dinâmico (JACOBINA \& LIMA, 2002).

Algumas das questões que envolvem o baixo desempenho dinâmico são as aplicações em baixas velocidades devido à influência da resistência de estator e o escorregamento necessário para a produção de torque. Além disso, o comportamento não-linear dos inversores "fonte de tensão por modulação de pulso" (PWM-VSI) contribuem também para o desempenho inadequado dos sistemas de controle baseado na relação V/f para freqüências inferiores a 3Hz (MUÑOZ-GARCIA et al., 1998). No trabalho de Munoz-Garcia et al. (1998) foi proposto um novo esquema para compensação da resistência de estator e freqüência que exige mínimo conhecimento dos parâmetros do motor. Com isso houve melhora significativa no desempenho dinâmico do controle do MIT através do uso da relação não-linear entre torque e velocidade.

O segundo grupo de estratégias para o controle da máquina de indução são os controles baseados na orientação de campo. Estes controladores são normalmente referenciados na literatura e na indústria como controladores vetoriais (vector controllers), pois eles controlam a amplitude e a fase da excitação de alimentação (ac excitation). O controle vetorial de correntes e tensões resultam num 
controle de orientação espacial do fluxo eletromagnético na máquina normalmente chamado por orientação de campo (NOVOTNY \& LIPO, 1996).

O princípio da orientação por campo (ou campo orientado) foi concebido por Blaschke num dos primeiros trabalhos publicados a este respeito no ano de 1972. Tal princípio pode ser explicado pelo funcionamento da máquina de corrente contínua de excitação independente, onde o fluxo magnético produzido pelo enrolamento de campo e o fluxo magnético produzido pelo enrolamento de armadura encontram-se em quadratura. Estes campos são desacoplados e estacionários entre eles (BLASCHKE, 1972). O controle vetorial procura recriar esta ortogonalidade entre as componentes no MIT de forma a controlar a corrente que gera o torque de maneira independente da corrente que produz o fluxo magnético. Conforme Leonhard (1991 - pp. 16), Blaschke utilizou a dedução matemática e a intuição formulando uma teoria geral para o controle das máquinas de Corrente Alternada (CA), a qual pode ser utilizada em qualquer inversor e máquina $\mathrm{CA}$.

Nas estratégias de campo orientado o controle é feito por meio de valores da amplitude e fase das componentes dq da grandeza. Tais estratégias podem ser escolhidas conforme o fluxo para a excitação magnética da máquina e de acordo com o tipo de variável empregada no controle do conjugado eletromagnético. A excitação magnética pode ser feita através do fluxo estatórico, do fluxo rotórico ou do fluxo de entreferro (JACOBINA \& LIMA, 2002).

No caso de máquinas de indução, o controle por orientação de fluxo de rotor é usualmente aplicado, apesar de ser possível à implementação o controle por orientação de fluxo do estator e fluxo de magnetização. No controle por orientação de fluxo de rotor há duas implementações para obtenção do módulo e o ângulo espacial do fasor espacial do fluxo concatenado de rotor; a saber: direto e indireto. 
Quando o controle por orientação de campo é chamado direto (direct rotor-fluxoriented control), então o fluxo magnético é medido diretamente utilizando sensores de efeito Hall, bobinas exploratórias (search coils), enrolamento de estator com derivação (tap), entre outras. O fluxo também pode ser calculado através dos modelos de fluxo. Tem-se, desta forma, o controle indireto por orientação de campo (indirect rotor-flux-oriented control), no qual o módulo do fasor espacial do fluxo concatenado de rotor é obtido através do monitoramento das correntes de estator e velocidade do rotor (VAS, 1990, pp. 124-125).

É importante perceber que o uso de sensores para medição de fluxo de forma direta implica no desmonte do motor para inserção dos dispositivos no entreferro da máquina. Por outro lado, a estimativa de fluxo através dos modelos de fluxo requerem as medidas de corrente de estator e velocidade do rotor.

Este trabalho contribui com as pesquisas no controle por orientação por fluxo indireto, uma vez que propõe um estimador de velocidade, substituindo assim o sensor de velocidade no controle vetorial indireto por um estimador de velocidade. Para tanto, utiliza-se sensores de corrente e tensão, os quais podem alimentar os modelos de fluxo; ou seja, sem a introdução de novos sensores.

Há duas formas básicas de controle instantâneo de torque em sistemas de acionamento das máquinas CA (ac drives) utilizado em aplicações de alta performance; a saber, controle vetorial (direto ou indireto) e controle direto de torque (Direct Torque Control - DTC). O DTC foi introduzido no Japão por Takahashi e também na Alemanha por Depenbrock na década de 80 (VAS, 1998). Conforme Lins (2001) a estratégia DTC é caracterizada pelo controle direto do vetor de fluxo de estator e do torque eletromagnético. Diversas novas técnicas para o DTC foram 
estudadas, desenvolvidas e implementadas desde o primeiro acionamento DTC implementado por Takahashi (LINS, 2001).

As vantagens do DTC é a redução das oscilações do fluxo de estator e do torque eletromagnético. Outra questão importante é que a escolha otimizada dos chaveamentos representa a redução na freqüência de chaveamento do inversor e, por conseguinte, redução das perdas. Outra vantagem deste tipo de controle é o reduzido esforço computacional e reduzida sensibilidade à variação paramétrica do MIT (VAS, 1998; LINS, 2001).

No recente trabalho de Castoldi (2006), foi elencado de forma sistemática as vantagens e desvantagens do uso do DTC. As vantagens são as seguintes: i) ausência de módulos de geração de modulação, ii) ausência de circuitos e estratégias de desacoplamento, iii) necessidade de poucos controladores, iv) necessidade de apenas do setor e não da posição do fluxo e v) mínimo tempo de resposta. Na contra-partida, as desvantagens são as seguintes: i) pode apresentar problemas de partida e operação em baixa velocidade, ii) requer estimação de fluxo como no controle por orientação por campo, iii) freqüência de chaveamento no inversor é variável e iv) pode apresentar oscilações de torque. (CASTOLDI, 2006).

A maioria das metodologias de controle, as quais são realimentadas, necessita do valor da velocidade de rotor no seu algoritmo, seja para atuar diretamente sobre ela ou para estimar outras variáveis por meio de modelos como o fluxo magnético. Este trabalho também contribui com estas abordagens, pois apresenta um estimador de velocidade que pode ser utilizado para aplicações de controle a partir de medidas primárias de corrente e tensão. 


\subsection{Aspectos Relacionados à Estimação Paramétrica do MIT}

Conforme Jacobina e Lima (2002), “... a estimação de parâmetros é uma das tarefas mais importante nos sistemas de acionamento estático, pois nos seus resultados é baseado o cálculo dos controladores de corrente, fluxo, conjugado, velocidade ou posição...".

O bom desempenho dos controladores aplicados ao motores de indução está relacionado com a eficiente estimativa de parâmetros do motor (resistência de rotor/estator, indutância de estator/rotor, velocidade, torque e fluxo eletromagnético), valores estes que devem entrar no algoritmo de controle dependendo da estratégia adotada.

Essas estratégias de controle saíram dos laboratórios de pesquisa diretamente para a indústria e são aplicados em diversos processos produtivos. Entretanto, há uma busca por melhor desempenho e menor custo de tais dispositivos controladores a exemplo de pesquisas recentes (VAS, 1998; KARANAYIL et al., 2002; CIRRINCIONE \& PUCCI, 2003; CIRSTEA \& DINU, 2001; KIM et al. 2001; FURTUNATO et al., 2001; KIM et al., 2003; LIXIN \& RAHAN, 2001).

A título de exemplificação dos problemas encontrados nas estratégias de controle, faz-se menção a alguns trabalhos. Em Ashrafzadeh (2002) é descrito que o cálculo do escorregamento para a estratégia de Controle Indireto por Orientação de Campo (IFOC - Indirect Field Orientation Control) é dependente da temperatura e da saturação eletromagnética.

Em Xepapas et al. (2003), enuncia-se que o Sistema de Modelo de Referência Adaptativo (MRAS - Model-Reference Adaptative Systems) apresenta boa performance na estimativa de velocidade em uma vasta faixa de operação, mas 
sofrem de grande influência na variação de parâmetros, tornando a estimativa pobre para baixas velocidades. No sentido de melhorar o desempenho do MRAS, Campbell e Sumner $(2000 ; 2002)$ propuseram um estimador para a resistência do estator usando redes neurais artificiais cujas entradas eram a velocidade e a corrente do motor.

O filtro de Kalman estendido é citado na literatura como um método para estimativa de velocidade do motor de indução (VAS, 1998; XEPAPAS et al., 2003; VAS, 1999). Conforme (XEPAPAS et al., 2003), o filtro de Kalman apresenta desvantagens inerentes, tais como influência de ruído, o esforço computacional, além da falta de um critério claro para desenvolvimento e sintonização. Em López et al. (2006) os autores apresentam os observadores de modo deslizantes adaptativos e o filtro de Kalman conforme pesquisa dos autores na literatura. Entretanto, os autores fazem ressalvas ao uso destes estimadores, pois os mesmos necessitam do conhecimento dos parâmetros do motor e carecem pelo alto custo computacional, sendo estes os seus maiores inconvenientes (LÓPEZ et al., 2006).

É sugerido em (VAS, 1999) o uso de lógica nebulosa (Fuzzy Logic) para sintonizar o filtro de Kalman estendido. Quando observadores são usados para sistemas não lineares, é necessário o uso de sua forma estendida, mas os observadores estendidos são computacionalmente intensivos, conforme Vas (1999).

O método baseado na análise espectral das harmônicas de corrente estima a velocidade do rotor através das harmônicas de corrente, as quais advêm das saliências mecânicas e magnéticas do rotor, que são independentes dos parâmetros do motor e cujas amplitudes são independentes da freqüência da alimentação conforme Hurst e Habetler (1996). 
Alguns trabalhos apresentam esquemas baseados na teoria das saliências. Esta metodologia é fundamentada na injeção de um sinal de alta freqüência na bobina de estator de forma a detectar as saliências magnéticas produzidas num rotor desenhado sob encomenda (custom designed machine rotor). No mesmo trabalho, um estimador de posição também é apresentado, considerando um motor de linha convencional (HOLTZ, 1998).

Na mesma linha de pesquisa o trabalho de Aielo et al. (2005) apresentou um método para estimar as componentes espectrais do sinal de corrente de estator para determinar a velocidade do MIT utilizando uma transformada Z-Chirp. Os autores apresentaram resultados experimentais (pp. 1816) de medidas de velocidade, sendo que foram comparados os resultados medidos através de encoder óptico com a Transformada Z-Chirp e a FFT (Fast Fourier Transform) para o MIT operando a freqüência de $50 \mathrm{~Hz}$ e diferentes situações de carga.

Nesta tese, além das situações adversas de carga a uma freqüência de alimentação constante do enrolamento de estator apresentados em Aielo et al. (2005), submete-se o estimador a situações diversas de tensão de alimentação.

Mais recentemente, no trabalho de Shi et al. (2006), os autores apresentaram uma nova abordagem para a tecnologia sensorless na estimativa de velocidade do motor de indução combinando a transformada de Hilbert na demodulação do sinal de corrente com a IFFT (Interpolated Fast Fourier Transform).

Há avanços nesta linha de trabalho para estimativas de parâmetros utilizando análise espectral, considerando a boa performance em velocidades muito baixas (menor que 10\% da rotação nominal). No trabalho de Xepapas et al. (2003), os autores concluem que os métodos baseados nesta metodologia apresentam boa 
performance em baixas velocidades, mas, em contrapartida, necessitam de esquemas sofisticados de hardware e software para medida e filtragem da corrente.

No trabalho de Xepapas et al. (2003), após apresentarem as características de diversos métodos sensorless, os autores propõem o uso de observadores de modo deslizante para estimar a velocidade, fluxo do rotor e torque do motor de forma eficiente usando técnicas de observadores de modo deslizante não-lineares.

Em grande parte das aplicações nas quais são utilizados motores de indução trifásicos há pouco conhecimento do comportamento da carga que está sendo acoplada ao eixo. A partir da análise prática e matemática, demonstra-se que, motores de indução trifásicos trabalhando superdimensionados apresentam diminuição do fator de potência e uma diminuição do rendimento. Por outro lado, motores de indução trifásicos trabalhando de maneira subdimensionada apresentam um sobre aquecimento e uma drástica redução na sua vida útil (DIAS \& LOBOSCO, 1988; ONG, 1997).

Em Goedtel (2003) foi desenvolvida uma metodologia para estimar conjugado nos eixos dos motores utilizando os princípios da abordagem sensorless. No referido trabalho foi desenvolvido um modelo matemático do motor de indução baseado em Ong (1997) e Krause et al. (2002). As variáveis primárias da máquina, tais como tensão, corrente e velocidade, geradas na simulação, proporcionaram o treinamento da estrutura baseada em redes neurais artificiais. Os resultados de generalização se mostraram satisfatórios quando se mostra à estrutura neural um novo padrão de dados de tensão, corrente e velocidade que não participaram do treinamento, produzindo erro menor que 5\% para uma ampla faixa de estimativa.

Tais resultados obtidos em Goedtel (2003) podem ser aplicados de forma direta em diversos setores industriais, pois é possível estimar o conjugado exigido 
pela carga acoplado ao eixo do motor. Uma das aplicações desta metodologia proposta é a classificação de cargas (DIAS \& LOBOSCO, 1988). Através da estimativa de conjugado é possível substituir os torquímetros girantes que são caros e cuja instalação necessita o deslocamento físico longitudinal entre o motor e a máquina. Além disso, o alto torque de partida exigido por algumas cargas exige o superdimensionamento do elemento sensor que implica na diminuição de sua sensibilidade.

Um outro aspecto relevante é que os torquímetros girantes devem ser alinhados cuidadosamente ao eixo do motor para que não sofram flexões, as quais podem comprometer a sua vida útil. Assim sendo, a instalação deste sistema tornase normalmente moroso e caro (BRITO, 1994). Outra aplicação para o trabalho desenvolvido em Goedtel (2003) consiste na realimentação do sinal de torque estimado num sistema de controle.

O estimador de velocidade proposto neste trabalho pode também ser aplicado diretamente na proposta de Goedtel (2003), uma vez que elimina o sensor de velocidade e assim contribui para esta linha de pesquisa. Tal abordagem foi também inserida em aplicações recentes (GOEDTEL et al., 2004, GOEDTEL et al., 2006b).

Desta forma, a abordagem proposta nesta tese, associada com Goedtel (2003), pode contribuir para sistemas de controle de alto desempenho, uma vez que leva em consideração o conjugado de carga no regime transitório e no regime permanente.

De acordo com os trabalhos de Marino et. al. (2004) e Murat et. al. (2004), o conhecimento do conjugado de carga é uma necessidade dos controles de alto 
desempenho, onde a aplicação da metodologia proposta neste trabalho para fins de controle é uma perspectiva promissora de pesquisa em trabalhos futuros.

Outras aplicações de metodologias sensorless para partida e especificação da máquina de indução estão apresentadas em Goedtel (2003) e Goedtel et al. (2006a). 


\section{Fundamentos e Conceitos de Inteligência Computacional}

\subsection{Fundamentos das Redes Neurais Artificiais}

Os sistemas baseados em Inteligência Computacional (IC) têm se desenvolvidos como uma abordagem promissora e flexível que podem ser aplicados em diversos tipos de problemas de engenharia. Entre as ferramentas que constituem a IC se destacam as redes neurais artificiais, as quais foram utilizadas nesta tese, sendo apresentados os aspectos envolvidos com as mesmas nos tópicos seguintes.

Atualmente, as RNA representam um domínio de pesquisa multidisciplinar em diversas áreas: física, matemática, engenharia, psicologia, neurofisiologia, biologia, etc. Os princípios fundamentais das redes neurais artificiais são baseados na modelagem biológica de processos neurofisiológicos, cognitivos e comportamentais. A utilização de RNA na solução de problemas complexos e variados é baseado no funcionamento do cérebro humano, que tem capacidade de resolver, de forma rápida e satisfatória, problemas mal definidos e que exigem um grande esforço computacional.

Sistemas baseados em RNA possuem elevadas taxas de computação por utilizarem um número elevado de elementos processadores simples com alta taxa de conectividade entre si. Resumindo, as redes neurais artificiais podem ser caracterizadas como modelos computacionais, com propriedades particulares, cujas principais características são definidas como segue:

(i) Capacidade intrínseca de operação em paralelo. 
(ii) Não necessidade de conhecimento a priori de eventuais modelos matemáticos que descrevem o comportamento de determinada aplicação.

(iii) Sistemas inspirados no cérebro humano.

(iv) Habilidade de aprender a partir da experiência.

A arquitetura de redes neurais artificiais utilizadas no desenvolvimento deste trabalho é a rede Perceptron multicamadas. Uma descrição sucinta dessa arquitetura é apresentada na próxima subseção.

\subsubsection{A Rede Perceptron Multicamadas}

A rede Perceptron multicamadas é aquela em que os neurônios são organizados em camadas. A característica principal das redes em camadas é a presença de uma ou mais camadas escondidas que são responsáveis pela extração e armazenamento de conhecimentos associados a alguma aplicação específica.

Neste tipo de rede, o fluxo de dados (informações) das entradas para as saídas segue estritamente em uma única direção, isto é, existem apenas ligações entre as saídas dos nós de um nível inferior para as entradas dos nós de um nível superior, não existindo conexões entre os elementos de um mesmo nível. Redes em camadas são utilizadas em várias aplicações, tais como: aproximação de funções, reconhecimento de padrões, otimização de sistemas, controle de processos, entre outras.

A ilustração de uma rede Perceptron multicamadas com duas camadas escondidas é apresentada na FIGURA 3.1. 


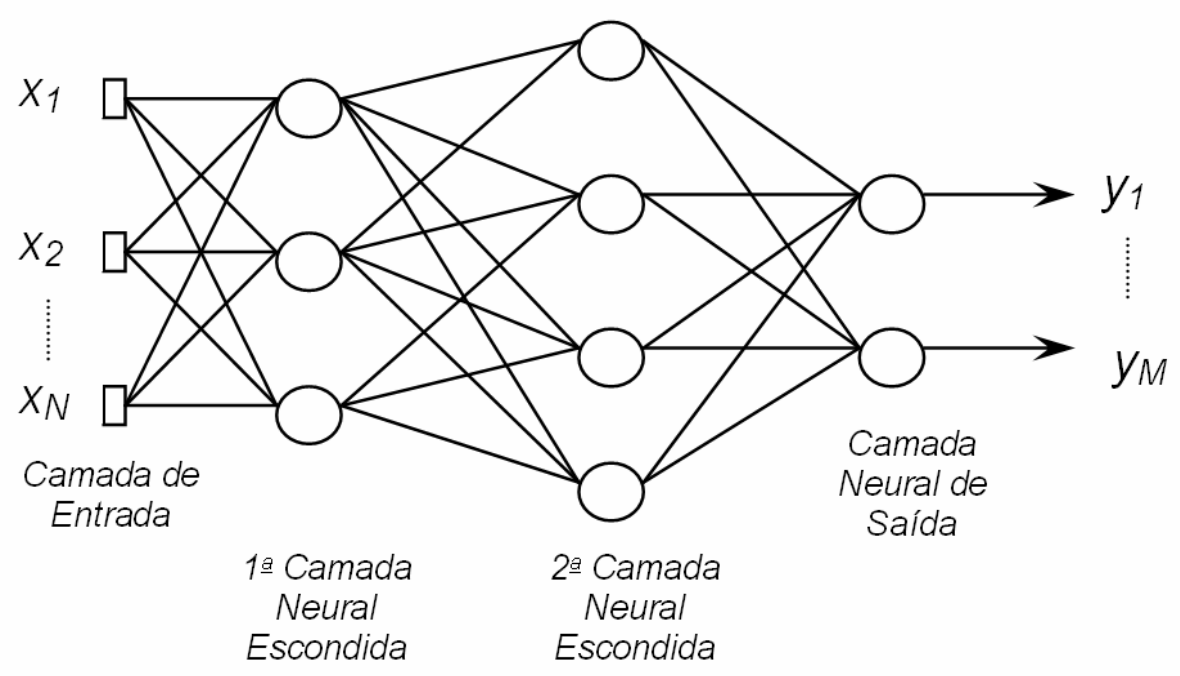

FIGURA 3.1 - A arquitetura perceptron multicamadas.

A partir da FIGURA 3.1, observa-se que os nós da camada de entrada da rede fornecem as informações (vetores de entrada), as quais constituem os sinais de entrada, que serão aplicados aos neurônios da segunda camada ( $1^{a}$ camada neural). Os sinais de saída da segunda camada são utilizados como entradas para a terceira camada $\left(2^{a}\right.$ camada neural). Finalmente, o conjunto de sinais de saída apresentados pelos neurônios da camada de saída reflete a resposta final da rede em relação ao vetor de entrada fornecido pelos nós fontes da primeira camada.

O treinamento ou processo de aprendizagem de uma rede neural artificial consiste em ajustar os pesos sinápticos (matriz de pesos $\boldsymbol{W}$ ) de forma que a aplicação de um conjunto de entradas produza um conjunto de saídas desejadas.

\subsubsection{Algoritmo de Treinamento da Rede Perceptron}

O treinamento supervisionado das redes neurais artificiais do tipo perceptron utilizadas nesta pesquisa é baseado no algoritmo de aprendizagem backpropagation (Haykin, 1999). 
Apresenta-se à rede um vetor de entrada (exemplo) que é propagado camada a camada. A saída produzida pela rede é então comparada com a saída desejada para o respectivo vetor de entrada, e a diferença entre ambas as saídas é calculada e o erro de saída da rede é então produzido. Este sinal de erro é retropropagado com o objetivo de ajustar os pesos sinápticos de forma que a saída produzida pela rede esteja próxima da saída desejada. Este processo é repetido para todos os vetores de entrada da rede até que o erro quadrático médio das saídas da rede esteja num valor aceitável.

A derivação do algoritmo backpropagation para redes Perceptron com uma única camada escondida é realizada conforme a notação apresentada na FIGURA 3.2.

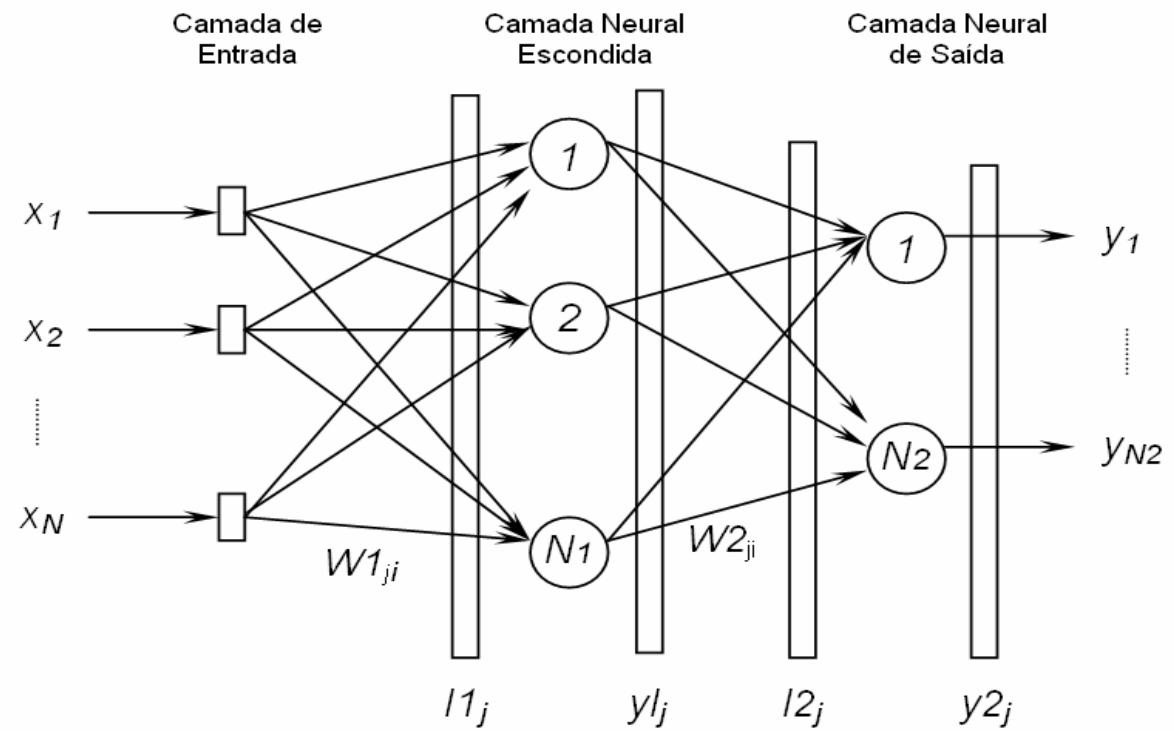

FIGURA 3.2 - Diagrama esquemático da rede perceptron.

A partir da FIGURA 3.2, adota-se a seguinte convenção:

i) O parâmetro $N$ especifica o número de variáveis que constitui cada vetor de entrada.

ii) O parâmetro $N_{1}$ especifica a quantidade de neurônios utilizados na camada neural escondida. 
iii) O parâmetro $N_{2}$ especifica o número de variáveis que constitui cada vetor de saída, e também indica a quantidade de neurônios utilizados na camada neural de saída.

iv) O vetor $\boldsymbol{x}=\left[x_{1}, x_{2}, \ldots, x_{N}\right]^{\top}$ denota o vetor de entrada da rede.

v) O vetor $\boldsymbol{y}=\left[y_{1}, y_{2}, \ldots, y_{N}\right]^{\top}$ denota o vetor de saída da rede.

vi) O símbolo $W l_{j i}$ fornece o valor do peso sináptico conectando ao j-ésimo neurônio da camada $(I)$ ao i-ésimo neurônio da camada $(I-1)$.

vii) $O$ símbolo $l_{j}$ fornece o valor correspondente à entrada ponderada do $j$ ésimo neurônio da camada $(I)$, ou seja:

$$
\begin{aligned}
& I 1_{j}=\sum_{i=0}^{N} W 1_{j i} \cdot x_{i} ; j=1 . . N 1 \\
& I 2_{j}=\sum_{i=0}^{N} W 2_{j i} \cdot y 1_{i} ; j=1 . . N 2
\end{aligned}
$$

viii) O símbolo $y l_{j}$ fornece o valor correspondente à saída do j-ésimo neurônio da camada $(I)$, ou seja:

$$
\begin{aligned}
& y 1_{j}=\mathrm{g}\left(/ 1_{j}\right) ; j=1 . . N_{1} \\
& y 2_{j}=\mathrm{g}\left(/ 2_{j}\right) ; j=1 . . N_{2}
\end{aligned}
$$

As funções Erro Quadrático $\{E(k)\}$ e Erro Quadrático Médio $\left\{E_{M}\right\}$, as quais são utilizadas como critérios de desempenho e de parada do processo de treinamento, são definidas por:

\section{i) Erro Quadrático}

Esta função fornece o valor instantâneo da soma dos erros quadráticos (em relação ao k-ésimo padrão de treinamento) de todos os neurônios da camada de saída da rede, ou seja: 


$$
E(k)=\frac{1}{2} \sum_{j=1}^{N 2}\left(d_{j}(k)-y 2_{j}(k)\right)^{2}
$$

onde $d_{j}(k)$ é o valor da saída desejada do neurônio $j$ em relação ao $k$-ésimo padrão de entrada.

\section{ii) Erro Quadrático Médio}

O erro quadrático médio é obtido a partir da soma dos erros quadráticos relativos a todos os padrões de entrada utilizados no conjunto de treinamento da rede, ou seja:

$$
E_{M}=\frac{1}{p} \sum_{k=1}^{p} E(k)
$$

onde o parâmetro $p$ especifica o número de padrões de treinamento ou a quantidade de vetores de entrada.

Assim, o objetivo do processo de aprendizagem, utilizando o algoritmo backpropagation, consiste em ajustar as matrizes de pesos $\boldsymbol{W} \mathbf{1}$ e $\boldsymbol{W} \mathbf{2}$ da rede a fim de minimizar a função $E_{M}$. $O$ processo de ajuste dos pesos pode ser dividido em duas fases como descrito a seguir:

\section{FASE 1 - AJUSTE DOS PESOS DOS NEURÔNIOS DA CAMADA DE SAÍDA}

O ajuste dos pesos dos neurônios da camada de saída ( $2^{\mathrm{a}}$ camada neural) é feita a partir da minimização da função erro quadrático em relação aos pesos $W 2_{j j}$. Utilizando a regra da diferenciação em cadeia, tem-se:

$$
\begin{gathered}
\nabla E_{\left(W 2_{j i}\right)}=\frac{\partial E}{\partial W 2_{j i}}=\frac{\partial E}{\partial y 2_{j}} \cdot \frac{\partial y 2_{j}}{\partial I 2_{j}} \cdot \frac{\partial I 2_{j}}{\partial W 2_{j i}} \\
\frac{\partial I 2_{j}}{\partial W 2_{j i}}=y 1_{i}
\end{gathered}
$$




$$
\begin{gathered}
\frac{\partial y 2_{j}}{\partial I 2_{j}}=g^{\prime}\left(I 2_{j}\right) \\
\frac{\partial E}{\partial y 2_{j}}=-\left(d_{j}-y 2_{j}\right)
\end{gathered}
$$

Substituindo (3.8), (3.9) e (3.10) em (3.7), obtém-se:

$$
\frac{\partial E}{\partial W 2_{j i}}=-\left(d_{j}-y 2_{j}\right) \cdot g^{\prime}\left(/ 2_{j}\right) \cdot y 1_{i}
$$

Logo, o ajuste deverá ser feito na direção oposta ao gradiente a fim de minimizar a função erro quadrático, ou seja:

$$
\begin{gathered}
\Delta W 2_{j i}=-\eta \cdot \frac{\partial E}{\partial W 2_{j i}} \\
\Delta W 2_{j i}=-\eta \cdot \delta 2_{j} \cdot y 1_{i}
\end{gathered}
$$

ou ainda:

$$
\Delta W 2_{j i}(t+1)=\Delta W 2_{j i}(t)+\eta \cdot \delta 2_{j} \cdot y 1_{i}
$$

onde $\eta$ é uma constante que determina a taxa de aprendizagem do algoritmo backpropagation, e $\delta 2_{j}$ denota o gradiente local sendo auto-definido por:

$$
\delta 2_{j}=\left(d_{j}-y 2_{j}\right) \cdot g^{\prime}\left(12_{j}\right)
$$

\section{FASE 2 - AJUSTE DOS PESOS DOS NEURÔNIOS DA CAMADA}

\section{INTERMEDIÁRIA}

O ajuste dos pesos dos neurônios da camada intermediária ( $1^{\mathrm{a}}$ camada neural) é feito normalmente a partir da função erro quadrático em relação aos pesos $W 1_{j i}$ Utilizando a regra de diferenciação em cadeia, tem-se:

$$
\nabla E_{\left(W 1_{j i}\right)}=\frac{\partial E}{\partial W 1_{j i}}=\frac{\partial E}{\partial y 1_{j}} \cdot \frac{\partial y 1_{j}}{\partial I 1_{j}} \cdot \frac{\partial l 1_{j}}{\partial W 1_{j i}}
$$




$$
\begin{gathered}
\frac{\partial I 1_{j}}{\partial W 1_{j i}}=x_{i} \\
\frac{\partial y 1_{j}}{\partial I 1_{j}}=g^{\prime}\left(I 1_{j}\right) \\
\frac{\partial E}{\partial y 1_{j}}=\sum_{k=1}^{N 2} \frac{\partial E}{\partial I 2_{k}} \cdot \frac{\partial I 2_{k}}{\partial y 1_{j}} \\
\frac{\partial E}{\partial y 1_{j}}=\sum_{k=1}^{N 2} \frac{\partial E}{\partial I 2_{k}} \cdot W 2_{k j}
\end{gathered}
$$

Inserindo o resultado da multiplicação de (3.17) por (3.18) em (3.19), tem-se:

$$
\frac{\partial E}{\partial y 1_{j}}=-\sum_{k=1}^{N 2} \delta 2_{k} \cdot W 2_{k j}
$$

Substituindo (3.16), (3.17) e (3.18) em (3.15), tem-se:

$$
\frac{\partial E}{\partial W 1_{j}}=\left(-\sum_{k=1}^{N 2} \delta 2_{k} \cdot W 2_{k j}\right) \cdot g^{\prime}\left(/ 1_{j}\right) \cdot x_{i}
$$

O ajuste deve ser feito na direção oposta ao gradiente. Então, a Equação (3.21) torna-se:

$$
\begin{aligned}
& \Delta W 1_{j i}=-\eta \cdot \frac{\partial E}{\partial W 1_{j i}} \\
& \Delta W 1_{j i}=-\eta \cdot \delta 1_{j} \cdot x_{i}
\end{aligned}
$$

ou ainda:

$$
W 1_{j i}(t+1)=W 1_{j i}(t)+\eta \cdot \delta 1_{j} \cdot x_{i}
$$

onde $\delta 1_{j}$ denota o gradiente local e é auto-definido por:

$$
\delta 1_{j}=g^{\prime}\left(/ 1_{j}\right) \cdot\left(\sum_{k=1}^{N 2} \delta 2_{k} \cdot W 2_{k j}\right)
$$


Assim, aplicam-se as Fase 1 e Fase 2 seqüencialmente até que o erro quadrático médio da rede atinja um valor aceitável que é estipulado em função de cada aplicação específica.

\subsubsection{Algoritmo de Levenberg-Marquardt}

Como descrito anteriormente, o algoritmo backpropagation ajusta os valores das matrizes de pesos $\boldsymbol{W} 1$ e $\boldsymbol{W} 2$ em relação à direção oposta do gradiente da função erro quadrático. Entretanto, a utilização deste algoritmo na prática tende a convergir muito lentamente, exigindo assim um elevado esforço computacional. Para contornar este problema, várias técnicas de otimização têm sido incorporadas ao algoritmo backpropagation a fim de reduzir o seu tempo de convergência e diminuir o esforço computacional exigido pelo mesmo. Dentre as técnicas de otimização mais utilizadas para este propósito destaca-se o algoritmo de Levenberg-Marquardt (HAGAN \& MENHAJ, 1994).

O algoritmo de Levenberg-Marquardt é uma técnica baseada no método dos mínimos quadrados para modelos não-lineares que pode ser incorporada ao algoritmo backpropagation a fim de aumentar a eficiência do processo de treinamento. Neste algoritmo as funções erro quadrático e erro quadrático médio fornecidas respectivamente nas Equações (3.5) e (3.6) podem ser expressas conjuntamente por:

$$
\begin{gathered}
V=\frac{1}{2 p} \cdot \sum_{k=1}^{p} \sum_{j=1}^{\mathrm{N} 2}\left[d_{j}(k)-y 2 j(k)\right]^{2} \\
V=\frac{1}{2 p} \cdot \sum_{k=1}^{p}(d(k)-\boldsymbol{y} 2(k))^{\top} \cdot(d(k)-\boldsymbol{y} 2(k)
\end{gathered}
$$




$$
V=\frac{1}{2 p} \cdot \sum_{k=1}^{p} \mathbf{e}^{\top}(k) \cdot \mathbf{e}(k)
$$

onde o termo $\{\boldsymbol{e}(k)=\boldsymbol{d}(k)-\boldsymbol{y} \mathbf{2}(k)\}$ denota o vetor erro em relação ao $k$-ésimo padrão de treinamento. Para um padrão $k$ específico o erro é dado por:

$$
V=\frac{1}{2} \mathbf{e}^{\top}(k) \cdot \mathbf{e}(k)
$$

Enquanto que o algoritmo backpropagation é um método de descida no gradiente da função erro quadrático, o algoritmo de Levenberg-Marquardt é uma aproximação do Método de Newton (BATTITI, 1992; FORESEE \& HAGAN, 1997). Neste método a minimização de uma função $V(z)$ em relação a um vetor paramétrico z é dada por:

$$
\Delta \mathbf{z}=-\left[\nabla^{2} V(\mathbf{z})\right]^{-1} \cdot \nabla V(\mathbf{z})
$$

onde $\nabla^{2} \boldsymbol{V}(\mathbf{z})$ denota a matriz Hessiana e $\nabla \boldsymbol{V}(\boldsymbol{z})$ é a matriz Jacobiana de $\boldsymbol{V}(\mathbf{z})$. Assumindo-se que $V(z)$ é uma função que executa soma de funções quadráticas da forma:

$$
V(\mathbf{z})=\sum_{i=1}^{\mathrm{N}} \mathbf{e}_{i}^{2}(\mathbf{z})
$$

Então, a partir da equação anterior, pode ser mostrado que:

$$
\begin{gathered}
\nabla V(z)=J^{\top}(z) \cdot e(z) \\
\nabla^{2} V(z)=J^{\top}(z) \cdot J(z)+s(z)
\end{gathered}
$$

onde $J(z)$ é a matriz Jacobiana definida por: 


$$
\boldsymbol{J}(\mathbf{z})=\left[\begin{array}{cccc}
\frac{\partial e_{1}(z)}{\partial z_{1}} & \frac{\partial e_{1}(z)}{\partial z_{2}} & \cdots & \frac{\partial e_{1}(z)}{\partial z_{N}} \\
\frac{\partial e_{2}(z)}{\partial z_{1}} & \frac{\partial e_{2}(z)}{\partial z_{2}} & \cdots & \frac{\partial e_{2}(z)}{\partial z_{N}} \\
\frac{\partial e_{N}(z)}{\partial z_{1}} & \frac{\partial e_{N}(z)}{\partial z_{2}} & \cdots & \frac{\partial e_{N}(z)}{\partial z_{N}}
\end{array}\right]
$$

e $\boldsymbol{s}(\mathbf{z})$ é uma função vetorial dada por:

$$
\boldsymbol{s}(\mathbf{z})=\sum_{i=1}^{N} \boldsymbol{e}_{i}(\mathbf{z}) \cdot \nabla^{2} \boldsymbol{e}_{i}(\mathbf{z})
$$

Inserindo-se os resultados de (3.31) e (3.32) em (3.29), obtém-se a equação iterativa do método de Newton, ou seja:

$$
\Delta z=\left[J^{T}(z) \cdot J(z)+s(z)\right]^{-1} \cdot J^{T}(z) \cdot e(z)
$$

No algoritmo de Levenberg-Marquardt a equação (3.35) é modificada da seguinte forma:

$$
\Delta \boldsymbol{z}=\left[\boldsymbol{J}^{T}(\mathbf{z}) \cdot \boldsymbol{J}(\mathbf{z})+\mu \boldsymbol{I}\right]^{-1} \cdot \boldsymbol{J}^{T}(\mathbf{z}) \cdot \mathbf{e}(\mathbf{z})
$$

onde $I$ é a matriz identidade e $\mu$ é um parâmetro que ajusta a taxa de convergência do algoritmo de Levenberg-Marquardt.

Portanto, a característica principal deste algoritmo é a computação da matriz Jacobiana. Para o processo de treinamento das redes neurais do tipo Perceptron utilizadas neste trabalho, e ilustrada na Figura 3.2, a matriz Jacobiana (3.33) passa então a ser re-escrita em função dos pesos sinápticos da rede, ou seja:

$$
J(W)=[J(W 1) \mid J(W 2)]_{(p) \times(N . N 1+N 1 . N 2)}
$$

onde:

$$
\begin{aligned}
\mathbf{W}= & {\left[\begin{array}{llllll}
\boldsymbol{W} 1 \mid \boldsymbol{W} 2
\end{array}\right]=\left[\begin{array}{lllll}
W 1_{1,1} \ldots W 1_{1, N} & W 1_{2,1} \ldots W 1_{2, N} & \ldots & W 1_{N_{1,1}} \ldots W 1_{N_{11, N}} \mid \\
W 2_{1,1} \ldots W 2_{1, N 1} & W 2_{2,1} \ldots W 2_{2, N 1} & \ldots & W 2_{N 2,1} \ldots W 2_{N 2, N 1}
\end{array}\right]_{(N . N 1+N 1 . N 2) \times(1)}^{\top} }
\end{aligned}
$$




$$
\begin{aligned}
& \boldsymbol{J}(\boldsymbol{W} 1)=\left[\begin{array}{llllll}
\frac{\partial \mathbf{e}(1)}{\partial W 1_{1,1}} \ldots \frac{\partial \mathbf{e}(1)}{\partial W 1_{1, N}} & \frac{\partial \mathbf{e}(1)}{\partial W 1_{2,1}} \ldots \frac{\partial \mathbf{e}(1)}{\partial W 1_{2, N}} & \cdots & \frac{\partial \mathbf{e}(1)}{\partial W 1_{N 1,1}} \ldots \frac{\partial \mathbf{e}(1)}{\partial W 1_{N 1, N}} \\
\frac{\partial \mathbf{e}(2)}{\partial W 1_{1,1}} \ldots \frac{\partial \mathbf{e}(2)}{\partial W 1_{1, N}} & \frac{\partial \mathbf{e}(2)}{\partial W 1_{2,1}} \ldots \frac{\partial \mathbf{e}(2)}{\partial W 1_{2, N}} & \cdots & \frac{\partial \mathbf{e}(2)}{\partial W 1_{N 1,1}} \ldots \frac{\partial \mathbf{e}(2)}{\partial W 1_{N 1, N}} \\
\frac{\partial \mathbf{e}(p)}{\partial W 1_{1,1}} \cdots \frac{\partial \mathbf{e}(p)}{\partial W 1_{1, N}} & \frac{\partial \mathbf{e}(p)}{\partial W 1_{2,1}} \cdots \frac{\partial \mathbf{e}(p)}{\partial W 1_{2, N}} & \cdots & \frac{\partial \mathbf{e}(p)}{\partial W 1_{N 1,1}} \cdots \frac{\partial \mathbf{e}(p)}{\partial W 1_{N 1, N}}
\end{array}\right]_{(p) \times(N \cdot N 1)} \\
& \boldsymbol{J}(\boldsymbol{W} 2)=\left[\begin{array}{cccccc}
\frac{\partial \mathbf{e}(1)}{\partial W 2_{1,1}} \ldots \frac{\partial \mathbf{e}(1)}{\partial W 2_{1, N 1}} & \frac{\partial \mathbf{e}(1)}{\partial W 2_{2,1}} \ldots \frac{\partial \mathbf{e}(1)}{\partial W 2_{2, N 1}} & \cdots & \frac{\partial \mathbf{e}(1)}{\partial W 2_{N 2,1}} \ldots \frac{\partial \mathbf{e}(1)}{\partial W 2_{N 2, N 1}} \\
\frac{\partial \mathbf{e}(2)}{\partial W 2_{1,1}} \ldots \frac{\partial \mathbf{e}(2)}{\partial W 2_{1, N 1}} & \frac{\partial \mathbf{e}(2)}{\partial W 2_{2,1}} \ldots \frac{\partial \mathbf{e}(2)}{\partial W 2_{2, N 1}} & \cdots & \frac{\partial \mathbf{e}(2)}{\partial W 2_{N 2,1}} \ldots \frac{\partial \mathbf{e}(2)}{\partial W 2_{N 2, N 1}} \\
\frac{\partial \mathbf{e}(p)}{\partial W 2_{1,1}} \cdots \frac{\partial \mathbf{e}(p)}{\partial W 2_{1, N 1}} & \frac{\partial \mathbf{e}(p)}{\partial W 2_{2,1}} \cdots \frac{\partial \mathbf{e}(p)}{\partial W 2_{2, N 1}} & \cdots & \frac{\partial \mathbf{e}(p)}{\partial W 2_{N 2,1}} \cdots \frac{\partial \mathbf{e}(p)}{\partial W 2_{N 2, N 1}}
\end{array}\right]_{(p) \times(N 1 . N 2)}
\end{aligned}
$$

A partir de (3.36), a equação iterativa do método de Levenberg-Marquardt para o ajuste dos pesos da rede passa a ser definida por:

$$
\Delta \boldsymbol{Z}=\left[\boldsymbol{J}^{\top}(\boldsymbol{W}) \cdot \boldsymbol{J}(\boldsymbol{W})+\mu I\right]^{-1} \boldsymbol{J}^{\top}(W) \cdot \mathbf{e}(W)
$$

onde $\mathbf{e}(\boldsymbol{W})=\left[e_{1}(\boldsymbol{W}), e_{2}(\boldsymbol{W}), \ldots, e_{p}(\boldsymbol{W})\right]^{\top}(p) \times(1)$ é o vetor erro (em relação à matriz $\left.\boldsymbol{W}\right)$ referente aos $p$-padrões de treinamento.

Finalmente, os elementos das matrizes $J(\boldsymbol{W} 1)$ e $J(\boldsymbol{W} 2)$ são obtidos seqüencialmente a partir das Fases 1 e 2 do algoritmo backpropagation apresentado na subseção anterior. Com estas modificações, comprova-se que o algoritmo de Levenberg-Marquardt se torna de 10 a 100 vezes mais rápido que o algoritmo backpropagation convencional.

\subsubsection{Algoritmo de Levenberg Regularizado}

Um dos problemas que ocorrem durante o treinamento de redes neurais do tipo Perceptron é denominado de overfitting. Quando acontece overfitting, o erro quadrático médio dos padrões de treinamento é muito pequeno, mas quando novos padrões (que não pertenciam ao conjunto de treinamento) são apresentados à rede, 
o erro torna-se muito grande. Este fato ocorre porque a rede memorizou apenas os padrões de treinamento, mas não conseguiu generalizar novas situações.

O problema do overfitting normalmente acontece quando a disponibilidade de dados usados no treinamento da rede é pequena. Um dos métodos para melhorar a generalização é a técnica de Levenberg regularizado, e que consiste em modificar a função erro quadrático médio da rede. A partir da equação (3.27), temse:

$$
V=\frac{1}{2 p} \cdot \sum_{k=1}^{p} \mathbf{e}^{\top}(k) \cdot \mathbf{e}(k)
$$

A generalização é melhorada se incluir também na Expressão (3.42) o erro quadrático médio dos pesos ( $\left.V_{\text {peso }}\right)$ que compõem a rede. Então, a nova função erro quadrático médio regularizado $\left(\mathrm{V}_{\mathrm{REG}}\right)$ é definida por:

$$
V_{R E G}=\gamma \cdot V+(1-\gamma) \cdot V_{\text {peso }}
$$

onde o parâmetro $\gamma$ especifica a taxa de desempenho, e o termo $V_{\text {peso }}$ é definido por:

$$
V_{p e s o}=\frac{1}{q} \sum_{j, i} W_{j i}
$$

onde $W_{j i}$ são os pesos da rede e $q$ é a quantidade total de pesos que compõem a rede. Portanto, a utilização da função (3.43) implica que os pesos da rede serão menores, e esta característica forçará que a resposta da rede seja suavizada e menos propensa ao overfitting.

\subsection{O Processo de Validação Cruzada (Crossvalidation)}

O aprendizado por retropropagação realiza o mapeamento entrada-saída através do ajuste de pesos sinápticos e limiares de uma rede perceptron de múltiplas camadas. 
O objetivo deste aprendizado é que a estrutura neural possa generalizar soluções após o processo de treinamento com dados que não participaram do treinamento (HAYKIN, 1999).

Seja um determinado processo (ou fenômeno) o qual possui um conjunto de dados descrevendo a relação entrada-saída das variáveis do sistema. $\mathrm{Na}$ sistemática de correlação das variáveis entre causa-efeito utilizando redes neurais artificiais, os dados devem ser divididos em dois grupos; a saber: i) dados de treinamento e ii) dados de teste.

Os dados de treinamento são aqueles utilizados para ajustar os pesos sinápticos da rede através de um algoritmo de aprendizado. Nesta tese se utiliza o algoritmo backpropagation. Os dados de teste, por sua vez, são usados para validar o modelo proposto e comprovar sua aplicabilidade no mapeamento entrada-saída do sistema em estudo.

Uma vez a rede treinada, com os pesos de cada conexão entre os neurônios ajustados, testa-se a rede para verificar sua capacidade de generalizar soluções. A partir da diferença entre os valores estimados pela RNA e o valor do conjunto de testes se estabelece o erro de generalização. O erro de generalização admissível é uma característica para cada sistema.

Conforme Abdelbar et al. (2005) o treinamento supervisionado com redes neurais alimentadas adiante (feedforward neural networks), tem por objetivo o mapeamento $f: R^{n} \rightarrow R^{m}$ baseado num conjunto de treinamento de exemplos representativos do sistema que são constituídos por $\mathrm{n}$ entradas e $\mathrm{m}$ saídas. A generalização acontece a partir do instante que a rede mapeia, de forma precisa, o conjunto de padrões que não fizeram parte do treinamento (ABDELBAR et al., 2005). 
O processo de validação cruzada (crossvalidation) é um método para seleção de modelos de acordo com a habilidade de predição. Suponha que um conjunto total com $n_{T}$ dados esteja disponível para a seleção de um modelo a partir de uma classe de modelos. O conjunto de dados é dividido em duas partes. A primeira parte contém $n_{c}$ dados utilizados no treinamento (ou ajuste do modelo) enquanto a segunda parte contém $n_{v}=n_{T}-n_{c}$ dados reservados para testar e validar o modelo; ou seja, testar a habilidade do modelo em generalizar soluções (SHAO, 1993).

No trabalho de Anders e Korn (1999, pp. 316) é descrito que o método de validação cruzada é a estratégia mais geral para seleção de modelos em redes neurais artificiais uma vez que não recai em suposições estatísticas e não é afetado por problemas de identificação referentes aos dados. Em princípio, todas as combinações de variáveis de entrada e camadas escondidas podem ser testadas.

Os modelos resultantes são repetidamente estimados por subconjuntos de observações e o modelo com o menor erro médio frente ao conjunto de teste é selecionado. Entretanto, a escolha segue no sentido de determinar a estrutura com menor número de neurônios nas camadas escondidas. Se uma rede com maior número de neurônios numa camada escondida apresentar um erro menor de generalização, então é aceito um aumento na estrutura neural e conseqüente aumento da complexidade computacional (ANDERS \& KORN, 1999).

O processo de validação cruzada foi utilizado nesta tese para determinar a menor estrutura neural com menor erro de generalização na estimativa de velocidade dos motores de indução trifásico com entradas de tensão e corrente.

Inicialmente, a estrutura neural foi treinada com dados de simulação do modelo do MIT. O processo de validação cruzada foi aplicada de forma a determinar 
a menor estrutura neural com o menor erro possível de generalização. Em seguida, frente à necessidade de determinar a robustez da rede em situações reais, dados experimentais foram apresentados à rede treinada com dados de simulação. Este processo de pré-validação e pós-validação é denominado, nesta tese, de bivalidação cruzada conforme descrito no Capítulo 5.

\subsection{As Redes Neurais Artificiais Aplicadas em Máquinas Elétricas Rotativas}

As redes perceptron multicamadas podem ser utilizadas nas mais variadas áreas de

conhecimento. No processamento de imagem e voz, robótica, identificação e controle, entre outras, principalmente pela sua característica como aproximadora universal de funções (BOSE \& LIANG, 1996).

$\mathrm{Na}$ área de máquinas elétricas o uso das redes neurais artificiais tem sido tema de pesquisas recentes. São vários os enfoques, tais como controle, estimativa de parâmetros e detecção de falhas, bem como determinação do comportamento de carga em regime permanente (BOSE,2007).

No trabalho de Kolla e Varatharasa (2000) a rede muticamada teve como entrada as três tensões e as três correntes de linha para determinar falhas no motor de indução assíncrono trifásico, a saber: sobrecarga, rotor bloqueado, alimentação com falta de fase, tensão de alimentação desbalanceada, falta de aterramento, sobre e subtensão de fase.

Por outro lado, Kukolj et al. (2000) faz uma comparação entre o controle do motor de corrente contínua usando as redes neurais artificiais, lógica nebulosa e o controle proporcional-integral tradicional. Já o trabalho de Campbell e Sumner (2000 e 2002) desenvolve um sistema de acionamento de alto desempenho para motores 
de indução usando a técnica sensorless, obtendo boa resposta dinâmica em relação ao conjugado e velocidade. Os resultados deste trabalho foram comparados com a técnica de controle vetorial indireto, onde a principal dificuldade na técnica tradicional é a correta sintonização dos parâmetros do controlador. Melhorias significativas foram conseguidas neste trabalho usando as redes neurais artificiais.

O trabalho de Bostanci et al. (1997), centrado na identificação dinâmica de cargas pelo ponto de vista das concessionárias, modela uma rede neural artificial para simular o comportamento do motor de indução. Segundo o autor, o motor de indução representa o aspecto mais importante da variação dinâmica de carga num sistema de potência. O artigo de Chatterjee et al. (2002) usa as redes neurais artificiais multicamadas para estimativa do conjugado em regime permanente, bem como fluxo e ângulo de fluxo para aplicação em controle.

Nessa combinação, as redes neurais artificiais se preocupam principalmente com o mapeamento de processos, o qual é feito através da utilização de elementos processadores que são especialistas em aprender o comportamento existente entre as variáveis de entradas e saídas dos respectivos processos. Além disso, uma das principais vantagens em se utilizar às abordagens baseadas nas redes neurais artificiais é a não necessidade de conhecimento prévio sobre eventuais modelos matemáticos que descrevem o comportamento dos processos a serem mapeados, pois tais modelos podem ainda ser desconhecidos, ou ainda, estarem mapeando os processos de forma inadequada ou particularizada. Assim, a aplicação de tais ferramentas em processos envolvidos com a identificação de máquinas elétricas rotativas fornece uma forma alternativa de mapear o comportamento existente entre as suas diversas variáveis de interesse. 
Por conseguinte, o motor de indução, seguramente o mais usado na indústria, tem características não-lineares em toda sua faixa de operação, da partida e frenagem ao regime permanente. Assim sendo, há a necessidade constante de pesquisar novas abordagens de identificação, otimização e controle, que possam ser eficientemente aplicadas nos processos envolvidos com a identificação do comportamento dinâmico dos motores de indução, contribuindo de forma efetiva para a geração de novos conhecimentos que implicarão em ganhos substanciais de eficiência e produtividade, bem como para a redução do desperdício de energia elétrica.

O uso de estimadores faz com que o custo dos dispositivos de controle e acionamento seja diminuído, pois utilizam medidas de variáveis primárias da máquina, como tensão e corrente, no lugar de medir a variável de forma direta. Essa é a base das tecnologias sensorless (VAS, 1998; VAS, 1999).

As principais aplicações de redes neurais artificiais em máquinas elétricas são observadas em diversos tópicos relacionados com esta área de pesquisa; a saber: i) identificação de parâmetros (elétricos e mecânicos), ii) controle de máquinas e iii) identificação de falhas em máquinas elétricas rotativas.

Diversos trabalhos estão utilizando redes neurais artificiais com sucesso para a estimativa de outras variáveis dos motores elétricos, tais como fluxo magnético do entreferro e na estimativa de parâmetros elétricos como resistências de rotor e estator (ASHRAFZADEH et al., 2002; CRUZ \& PAREDES, 2003; CAO \& LI, 2002; CIRRINCINCIONE et al., 2003; CAMPBELL et al., 2000; CAMPBELL \& SUMNER, 2002; KARANAYIL et al., 2002; KOLLA \& VARATHARASA, 2000; CIRRINCIONE \& PUCCI, 2003, BOSE, 2007); 
Em Ashrafzadeh et al. (2002), numa implementação do controle vetorial do motor de indução utilizando redes neurais artificiais para estimar escorregamento, foi observado pulsação de torque. Os autores utilizaram dados experimentais para retreinar a estrutura neural proposta eliminando a pulsação de torque indesejável. Um trecho da conclusão dos autores do trabalho Ashrafzadeh et al. (2002), é transcrita abaixo.

"Test results confirm that two stages of training are required to train the neural network, namely, an off-line training stage and another stage base on experimental testing of the neural network".

Um dos objetivos do trabalho desenvolvido em Ashrafzadeh et al. (2002), foi usar redes neurais artificiais para reduzir o esforço computacional do DSP (Digital Signal Processor). Desta forma o processador pode ser usado para outras tarefas reduzindo o custo do dispositivo. Conforme mencionado em Ashrafzadeh et al. (2002), a redução destes custos é especialmente interessante para a produção de dispositivos em larga escala.

Em Cruz e Paredes (2003) e Cao e Li (2002) foram desenvolvidos sistemas híbridos neuro-fuzzy. Em Cruz e Paredes (2003) o controlador PI (Proporcional Integral) foi sintonizado "on-line" através do sistema fuzzy. A rede neural, por sua vez, estimou a velocidade através de medidas de tensão e corrente. Em Cao e Li (2002) é mencionado que sistemas clássicos de controle direto de torque apresentam pouca precisão em baixas velocidades. Os autores propõem o uso de redes neurais artificiais para estimar velocidade e melhorar o desempenho do controlador. O sistema fuzzy é usado para regular a taxa de aprendizado do algoritmo backpropagation da rede neural artificial. 
Em Cirrincione et al. (2003) é proposta uma arquitetura neural autoorganizável para o controle direto de torque. Conforme os autores, com esta nova abordagem, transforma-se o problema de mapeamento e identificação de um sistema num sistema de reconhecimento de padrões. Testes experimentais validaram a proposta utilizando uma placa de DSP para implementar o controle do motor de indução.

Em Campbell et al. (2000) e Campbell e Sumner (2002) foram usadas redes neurais artificiais para estimar as mudanças na resistência do estator e velocidade do rotor. A estimativa do valor da resistência do estator é realimentada no algoritmo de controle melhorando o seu desempenho. É importante observar que os trabalhos de Campbell e Sumner são dos mesmos autores, tendo diferença de dois anos nas datas de publicação; 2000 e 2002 respectivamente, onde são apresentadas melhorias no segundo trabalho em relação ao primeiro. Em ambos os trabalhos, medidas experimentais foram realizadas para validar os modelos neurais.

Em Karanayil et al. (2002) é mencionado que a performance do controle vetorial indireto (Indirect Vector Control) depende da precisão da estimativa do fluxo de rotor através de medidas de corrente do estator. A precisão do controle é aumentada com o uso da medida da resistência do rotor que pode variar em até $100 \%$ com o aumento da temperatura. Os autores propõem o uso de redes neurais artificiais para estimar a resistência do rotor pelas dificuldades da medida direta da variável. Para validar a proposta o algoritmo do controle vetorial indireto e o estimador de resistência do rotor são implementados em uma placa de DSP baseado no processador TMS320C31 da Texas®. Os dados são medidos através de uma placa de aquisição e armazenados usando o software Labview®. 
Em Kolla e Varatharasa (2000) as redes neurais artificiais são utilizadas na predição de falhas em máquinas elétricas. Esta aplicação é de especial interesse para processos cuja parada deve ser planejada, ou nos processos que são considerados críticos como, por exemplo, em refinarias de petróleo.

No trabalho de Cirrincione e Pucci (2003) foi desenvolvido um estimador de velocidade usando redes neurais artificiais. O estimador foi implementado em controle direto de torque (DTC) e no controle por orientação de campo (Field Oriented Control - FOC). A metodologia foi empregada em experimentos práticos e ambos algoritmos de controle numa placa de DSP. Os autores concluem que a resposta do estimador em altas velocidades tem precisão mais elevada e finalizam as conclusões sugerindo que as pesquisas continuem para melhorar o desempenho em baixas velocidades.

Assim, uma das propostas principais desta tese consiste em utilizar redes neurais artificiais como ferramentas alternativas no processo de medida indireta de velocidade em motores de indução trifásicos a exemplo das pesquisas recentes.

Mais especificamente, propõem-se uma multi-estrutura neural dividida por faixas de tensão. Assim, o trabalho consegue maior flexibilidade e modularidade para operar em diversas condições de alimentação da máquina conforme foi proposto por Goedtel (2003) na estimativa de conjugado de carga.

No sentido de contribuir com os aspectos relacionados à validação dos modelos neurais propostos, propõem-se também, de forma complementar e com caráter inovador, duas modificações no processo de validação (crossvalidation). Para a experimentação das propostas apresentadas neste trabalho foi construída uma estrutura de ensaios de máquinas elétricas e seu detalhamento também é apresentado no próximo capítulo. 


\section{Desenvolvimento de Uma Estrutura de Ensaios de Máquinas Elétricas Rotativas}

A aplicação de redes neurais artificiais em diversos ramos do conhecimento envolve, em especial na engenharia, a experimentação prática para confrontar aspectos da modelagem matemática e os aspectos da dinâmica de cada processo. O confronto entre dados experimentais e teóricos é uma constante em diversos trabalhos publicados.

O projeto e desenvolvimento de uma estrutura de testes de máquinas elétricas se faz necessária para validar os modelos teóricos desta tese. Neste trabalho é feita a descrição sistemática da montagem de tal sistema, possibilitando a reprodução da estrutura em outros centros de pesquisa.

Assim, a descrição da construção dos diversos passos desta estrutura de ensaios, marcada pela flexibilidade e baixo custo, constitui-se uma contribuição desta tese de doutorado com o suporte financeiro da FAPESP. Cabe salientar que esta estrutura também servirá a outros trabalhos correlatos na área de máquinas elétricas.

A montagem da bancada de testes se constitui um dos módulos mais importantes desta tese de doutorado, pois a mesma possibilitará a aquisição de todos os sinais que envolvem à dinâmica das máquinas elétricas em estudo, tais como corrente, tensão, torque e velocidade do motor, tanto em regime transitório como permanente. A sua montagem implica na utilização de equipamentos que possibilitem essas medidas, tais como: placa de aquisição de dados, sensores e transdutores para as variáveis a serem medidas, motores elétricos, chaves, fios e fusíveis. 
Após a montagem da bancada de testes experimentais, realizam-se os processos que visam validar a mesma. Entre as diversas atividades executadas destacam-se a aferição e calibração de instrumentos e o desenvolvimento de rotinas para aquisição e tratamento de dados.

Os sensores de tensão e corrente foram calibrados conforme o padrão de um multímetro marca Agilent, modelo 34401A de 61/2 dígitos com precisão de $0,06 \%$ de precisão na faixa de $10 \mathrm{~Hz}$ a $20 \mathrm{kHz}$. O certificado de calibração e aferiação do multímetro foi fornecido pelo fabricante no ato da compra do equipamento com recursos da FAPESP.

A FIGURA 4.1 ilustra o diagrama em blocos da estrutura de ensaios proposta neste trabalho de doutorado. A linha pontilhada indica a implementação futura do trabalho.

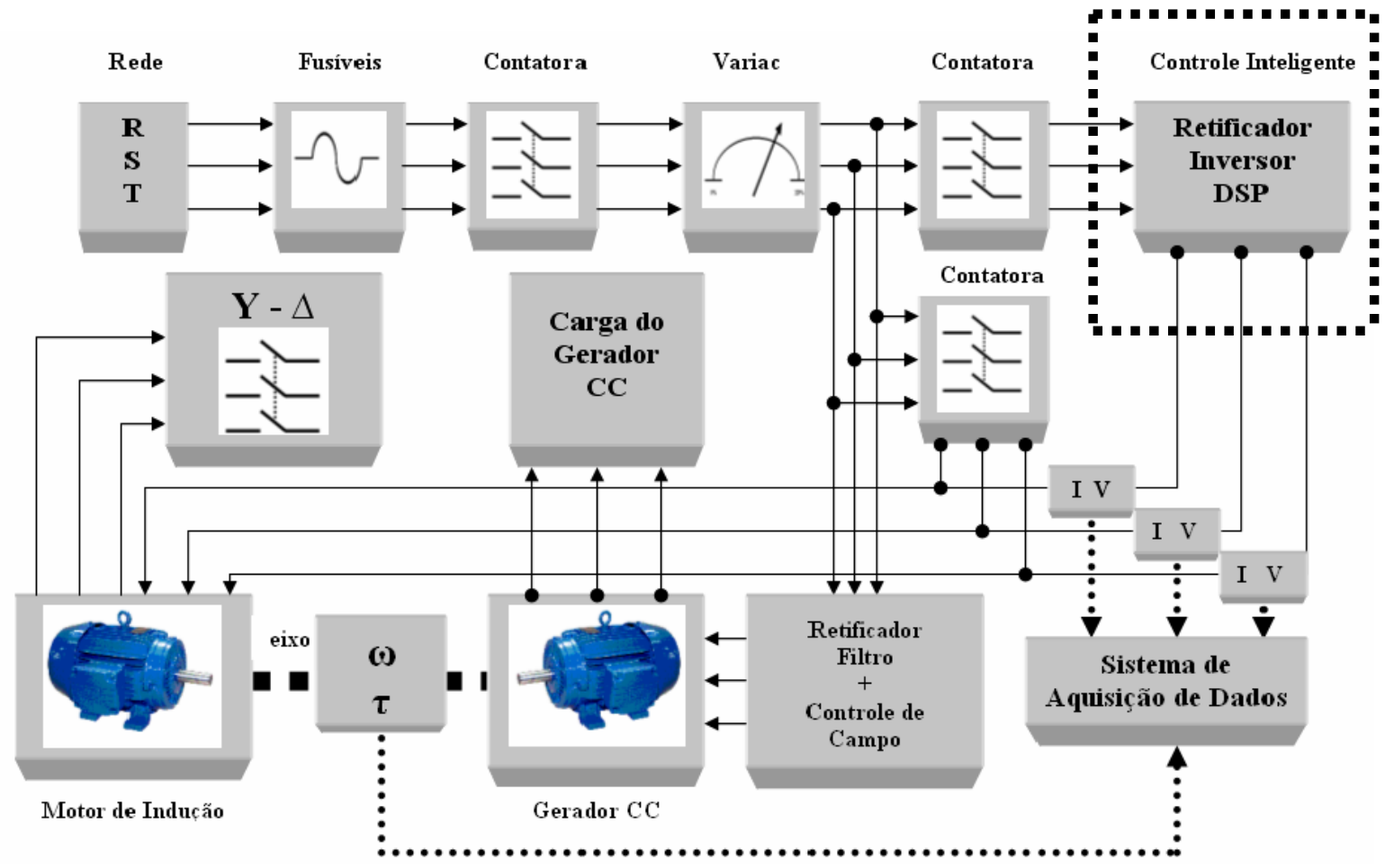

FIGURA 4.1 - Esquema experimental para simulação de cargas.

Como verificado na FIGURA 4.1, a simulação dos perfis de carga no eixo do motor de indução trifásico será realizado através da utilização de um gerador de 
corrente contínua que será acoplado ao eixo do mesmo. O gerador neste caso deve ter excitação independente do campo para permitir o controle da corrente do seu campo independente da carga acoplada ao gerador.

Consegue-se, desta forma, maior flexibilidade no controle desta máquina que, em última análise, simulará a carga imposta ao motor de indução. O circuito de controle é composto basicamente por uma fonte de Corrente Contínua (CC) de tensão variável aplicada ao enrolamento de campo.

Cabe salientar que o acoplamento de máquinas de corrente alternada em máquinas de corrente contínua para simulação de cargas é utilizado com freqüência em aulas de máquinas elétricas nas instituições de ensino, assim como em pesquisas recentes como mencionado em (CAMPBELL \& SUMNER, 2002; CIRRINCIONE e PUCCI, 2003; CIRRINCIONE e PUCCI, 2005; AIELO et al., 2005; CIRRINCIONE et al., 2006).

O ajuste do variac simula a variação de tensão da rede de alimentação. Este dispositivo é precedido dos fusíveis para proteção do circuito, bem como da contatora que energiza todo o sistema. Ainda na FIGURA 4.1 é descrita a estrutura de seleção do tipo de estratégia utilizada para controle e acionamento: i) direto ou ii) inversor de freqüência.

No esquema proposto, e ilustrado na FIGURA 4.1, há a possibilidade de partida direta do motor em estrela ou triângulo. O gerador de corrente contínua impõe o perfil de carga e o sistema de aquisição de dados armazena os dados provenientes dos transdutores de tensão, corrente, velocidade e torque.

Com estes dados é possível validar os modelos baseados em sistemas inteligentes, bem como criar um banco de dados de simulações que poderá ser 
usado em outras pesquisas ou no re-treinamento do sistema inteligente a exemplo de (ASHRAFZADEH, 2002).

Estudos adicionais quanto à geração de harmônicas para a rede elétrica, bem como do fator de potência, podem ser realizados acoplando à entrada da alimentação destes dispositivos nos respectivos transdutores de tensão e corrente por efeito Hall. Pode-se inferir desta forma a energia elétrica perdida no sistema de distribuição proveniente do setor industrial e também o rendimento do próprio dispositivo que apresenta perdas. Assim, a flexibilidade desta bancada permite vários estudos, beneficiando, desta forma, vários projetos de pesquisa.

Portanto, o primeiro passo na direção da validação dos modelos inteligentes desenvolvidos é a construção desta bancada de testes. Desta forma, o quadro de comando é peça fundamental para que a bancada de testes seja flexível para possibilitar diversos tipos de testes. A FIGURA 4.2(a) ilustra o quadro de comando projetado a partir do diagrama esquemático da FIGURA 4.1.

O quadro de comando é composto por uma estrutura metálica dentro da qual ficam alojados dispositivos de partida (chaves contatoras), fusíveis, chaves, variadores de tensão, mostradores de tensão, bornes entre outros.

A conexão externa do quadro, feita com bornes, difere das aplicações industriais. Quando um quadro é projetado para a partida de uma determinada máquina, suas conexões externas são feitas à base de barras de terminais. Os equipamentos utilizados são normalmente fixados sobre trilhos DIN*, os quais fazem parte do padrão industrial. Neste trabalho, optou-se pela conexão de bornes no painel frontal do quadro, pois os mesmos possibilitam um esquema flexível de conexão ao motor e sua rápida mudança quando necessário. A FIGURA 4.2 (b) 
Os variadores de tensão, também conhecidos como variacs, são monofásicos. Com esta configuração é possível simular as variações de tensão de linha, bem como os desequilíbrios de tensão entre as fases que são encontrados de forma freqüente no ambiente industrial. O desequilíbrio de tensões entre fases é produto do mau dimensionamento de condutores e principalmente pela distribuição não uniforme de cargas entre as fases da rede elétrica numa determinada planta. A experiência profissional dos membros do grupo de pesquisa mostra que isso é uma realidade muito presente em uma parte considerável das empresas. Desta forma, torna-se imprescindível o uso dos variadores monofásicos para simular o ambiente do setor produtivo. A FIGURA 4.3 mostra os variadores de tensão dispostos no painel, bem como detalhes internos do mesmo.

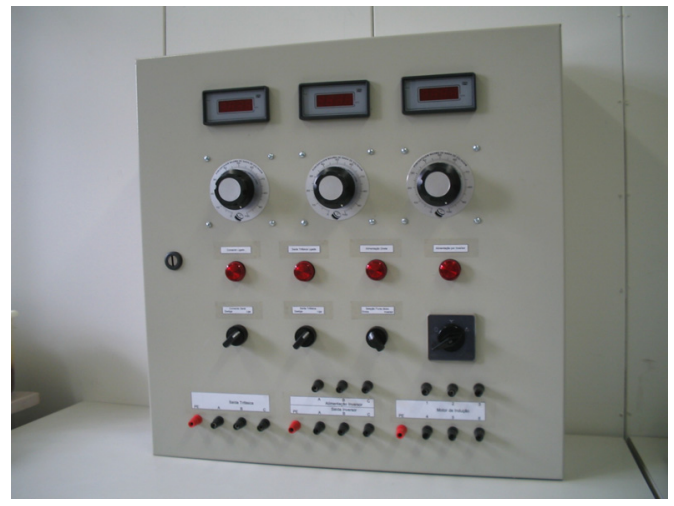

(a)

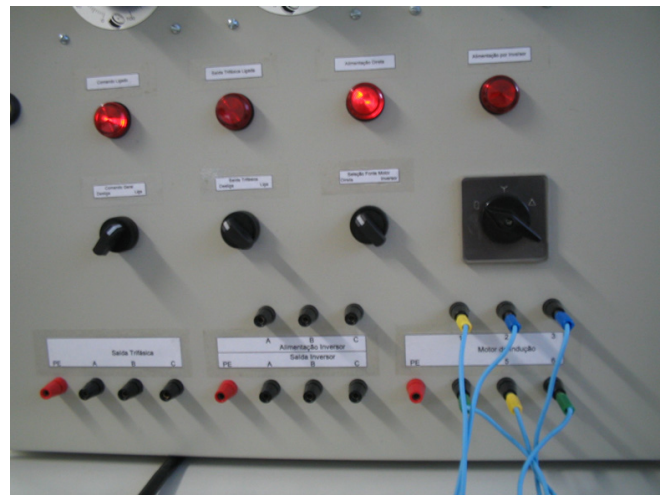

(b)

FIGURA 4.2 - Quadro de comando: (a) vista frontal; (b) detalhe da conexão.

Usa-se neste quadro de comando mostradores de tensão que indicam a tensão aplicada em cada uma das fases em relação ao neutro. Desta forma, é possível ajustar o variac e observar a respectiva variação de tensão de alimentação do motor.

O quadro de comando desenvolvido neste trabalho pode ser considerado uma contribuição na pesquisa e no ensino que envolvem máquinas elétricas. 0 
quadro é genérico no sentido de permitir diversos experimentos com motores elétricos e seus acionamentos.

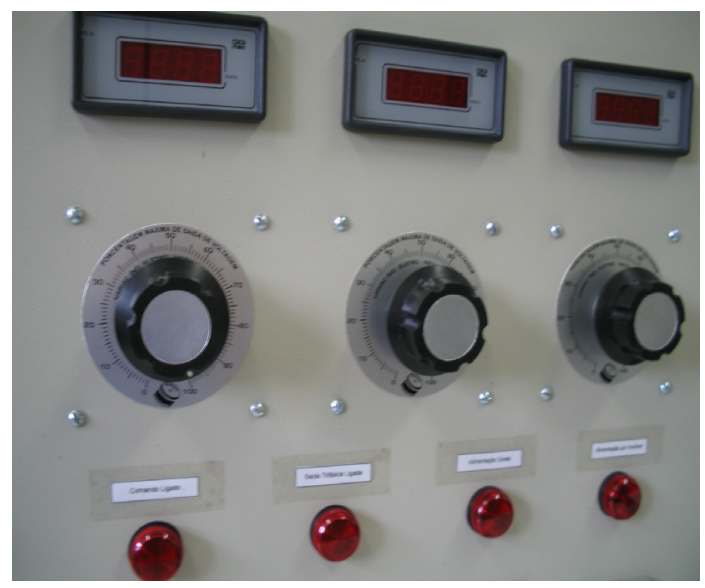

(a)

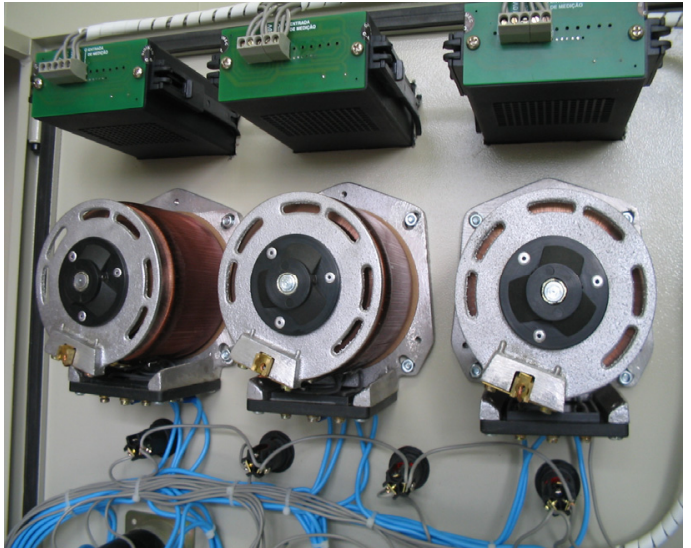

(c)

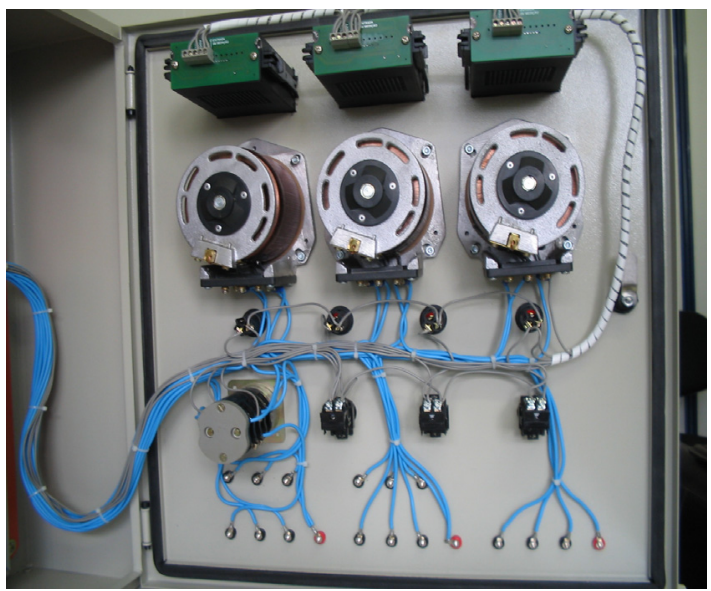

(b)

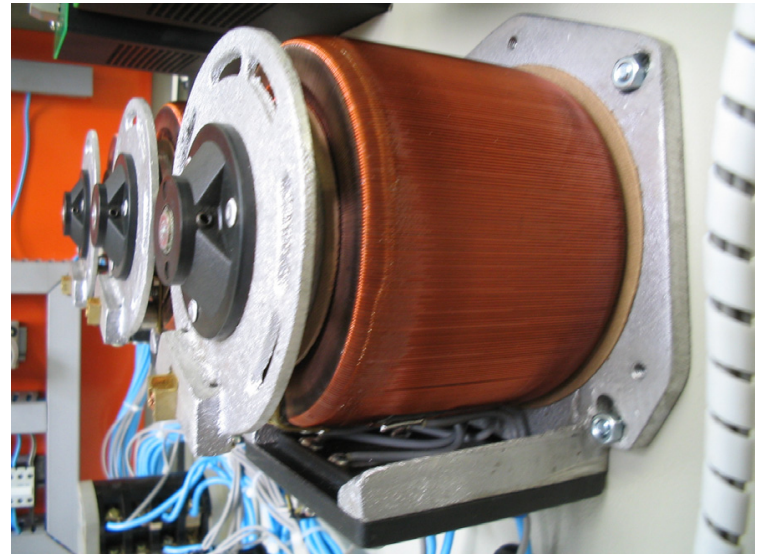

(d)

FIGURA 4.3 - Quadro de comando: (a) disposição dos variadores de tensão no painel; (b) disposição dos variadores de tensão na parte posterior do painel frontal;

(c) ligação dos variadores de tensão ao barramento do quadro de comando; (d) detalhe construtivo do variador de tensão utilizado no quadro de comando.

\subsection{Aspectos Relacionados à Máquina CC}

A Máquina de Corrente Contínua (MCC) foi uma das primeiras máquinas utilizadas em meios industriais, sendo considerada uma máquina bastante versátil. A sua velocidade pode ser facilmente controlada. A máquina de corrente contínua desenvolve torque nominal em todas as velocidades, ou seja, de rotor bloqueado à 
velocidade nominal (HUBERT, 1991). A máquina pode operar como motor ou gerador.

A máquina CC utilizada neste trabalho é a máquina de corrente contínua com excitação independente. Ela é composta por dois enrolamentos básicos: i) o enrolamento de campo e ii) o enrolamento de armadura. O enrolamento de campo está acoplado no estator e produz o fluxo eletromagnético que atravessa o enrolamento de armadura. O enrolamento de armadura está localizado no rotor e a corrente circulante nele produz a força contra-eletromotriz que atua no sentido de anular o fluxo produzido pelo enrolamento de campo. Desta forma, tem-se conjugado eletromagnético (torque) e giro do rotor.

Na estrutura de ensaios, a máquina de corrente contínua é utilizada como gerador de corrente contínua. O seu eixo é acoplado ao eixo do Motor de Indução Trifásico (MIT), tendo acoplado entre as duas máquinas um torquímetro girante. Quando a MCC está operando como geradora ela impõem um torque resistente no seu eixo. Este torque pode variar conforme a carga imposta ao gerador o qual está acoplado no enrolamento de armadura ou pela variação da tensão no enrolamento de campo. Consegue-se com isso a variação dinâmica do torque aplicado ao MIT. A FIGURA 4.4 ilustra um diagrama em blocos que descreve a atuação do sistema composto pela MCC e o MIT.

A modelagem eletromecânica da máquina de corrente contínua é encontrada em diversas referências da literatura pesquisada. No sentido de determinar os parâmetros desta máquina usada nos experimentos, diversos ensaios foram realizados na mesma conforme descrito em Oliveira et al. (2005). 


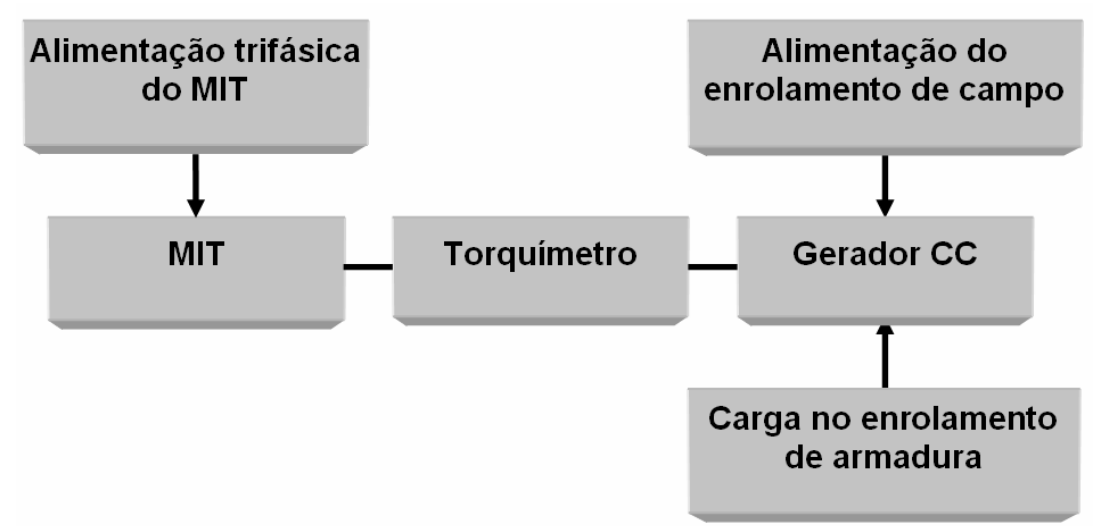

FIGURA 4.4 - Diagrama em blocos da operação do gerador CC.

\subsection{Sensores Hall}

Os materiais utilizados na manufatura de dispositivos de efeito Hall são semicondutores do tipo p ou do tino n. São exemplos típicos o arsenieto de Indium e Silício dopado conforme Coombs (1995).

A FIGURA 4.5 mostra a seção de um semicondutor dopado tipo p submetido a um campo magnético $B_{z}$ na direção do eixo $z$, e um campo elétrico $E_{x}$ na direção do eixo x. A corrente $\mathrm{I}_{\mathrm{x}}$ se desloca na direção do eixo $x$.

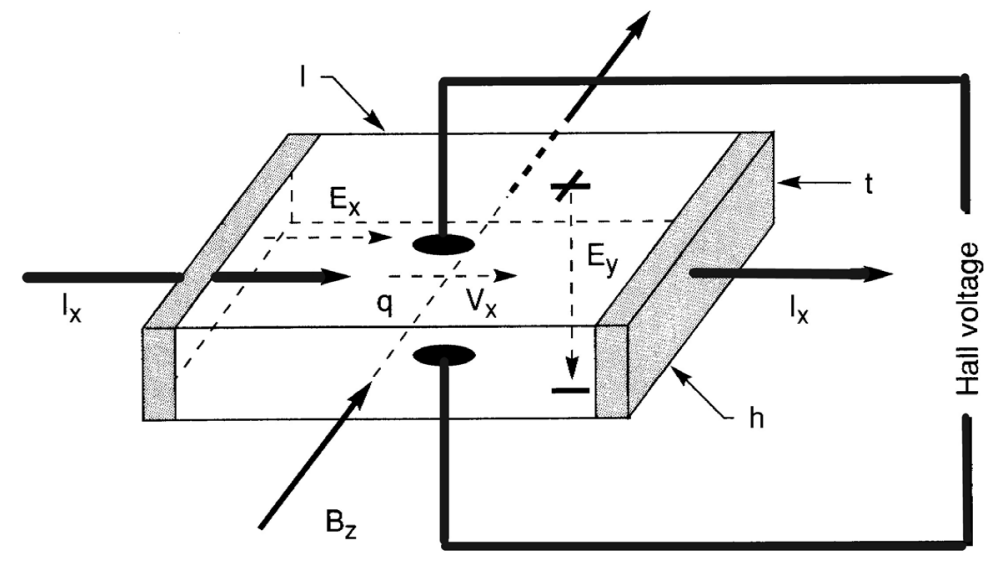

FIGURA 4.5 - Seção de um semicondutor do tipo p submetido a um campo elétrico e magnético.

Fonte: Coombs, 1995. 
As lacunas do semicondutor se deslocam na direção do eixo $x$ através do campo magnético as quais ficam submetidas à ação de uma força de origem magnética, resultando em polarização de cargas positivas no topo do semicondutor e de cargas negativas na face inferior da pastilha. Um campo elétrico $E_{y}$, conhecido como campo Hall, surge como conseqüência desta polarização de cargas elétricas (Coombs, 1994). A tensão de Hall pode ser calculada conforme Equação (4.1).

$$
V_{H}=\frac{R_{H}\left(I_{x} B_{z}\right)}{h}
$$

onde $R_{H}$ é o coeficiente de Hall (sendo negativo para semicondutores do tipo n) e $h$ é a dimensão paralela a $B_{z}$. Os sensores por efeito Hall são os responsáveis pela medida de tensão e corrente da alimentação dos motores conforme ilustrado na FIGURA 4.1 nos blocos denotado por "I V".

\subsubsection{Sensores Hall de Corrente}

Os sensores Hall são amplamente usados em diversas aplicações industriais. Outras alternativas tradicionais para a medida de corrente são os shunts e os dispositivos que funcionam pelo princípio da indução eletromagnética baseada na Lei de Faraday-Lenz.

$\mathrm{Na}$ primeira alternativa, os shunts são elementos resistivos nos quais circulam corrente, sendo termicamente estáveis dentro de sua faixa de operação. Entretanto, estes elementos aparecem como uma carga ao circuito e tem perda de calor por efeito Joule, além da inexistência de isolamento galvânico.

Na segunda alternativa, as medidas de corrente pelo princípio da indução eletromagnética têm como seus principais representantes os Transformadores de Corrente (TC) e alicates amperímetros. Nestes equipamentos há a desvantagem de 
medirem apenas corrente alternada, pois conforme foi postulado por Faraday-Lenz, a tensão induzida numa bobina de $\mathrm{N}$ espiras depende da variação de fluxo por intervalo de tempo. Há somente fluxo eletromagnético alternado se a corrente também for alternada. Justifica-se desta forma o uso dos sensores Hall na medida de corrente neste trabalho. Há também o aspecto que deve ser apresentado no que diz respeito à tendência de miniaturização dos componentes conseguido pelos fabricantes de sensores Hall.

Considerando que o gerador de corrente contínua acoplado ao eixo do motor de indução trifásico é uma carga dinâmica, tem-se então a necessidade da medida de corrente contínua nos terminais da máquina para efetuar seu controle. O sensor Hall de corrente propicia tal medida. Optou-se neste trabalho pelo uso de sensores Hall da marca LEM, cujos sensores já foram usados com sucesso no trabalho de Serni (1999) por apresentarem baixo ruído, ampla faixa de resposta em freqüência e classe de precisão inferior a $1 \%$.

Mais especificamente, usa-se neste projeto de pesquisa o sensor LAH - 25 NP com corrente nominal de $25 \mathrm{~A}$ eficaz e classe de precisão de $0,3 \%$. A saída da corrente é de 0-25 mA eficaz. A tecnologia usada neste sensor prevê realimentação do sinal de saída com a entrada através de um amplificador operacional e dois transistores em push-pull. A FIGURA 4.6 ilustra esta tecnologia.

É importante ressaltar que esta característica é muito importante neste trabalho (em termos de flexibilidade de trabalhos futuros), uma vez que há algumas metodologias para estimativa de rotação de máquinas elétricas que usam o conteúdo harmônico do sinal de corrente como fonte primária de dados, conforme descrito em Holtz (2002). 


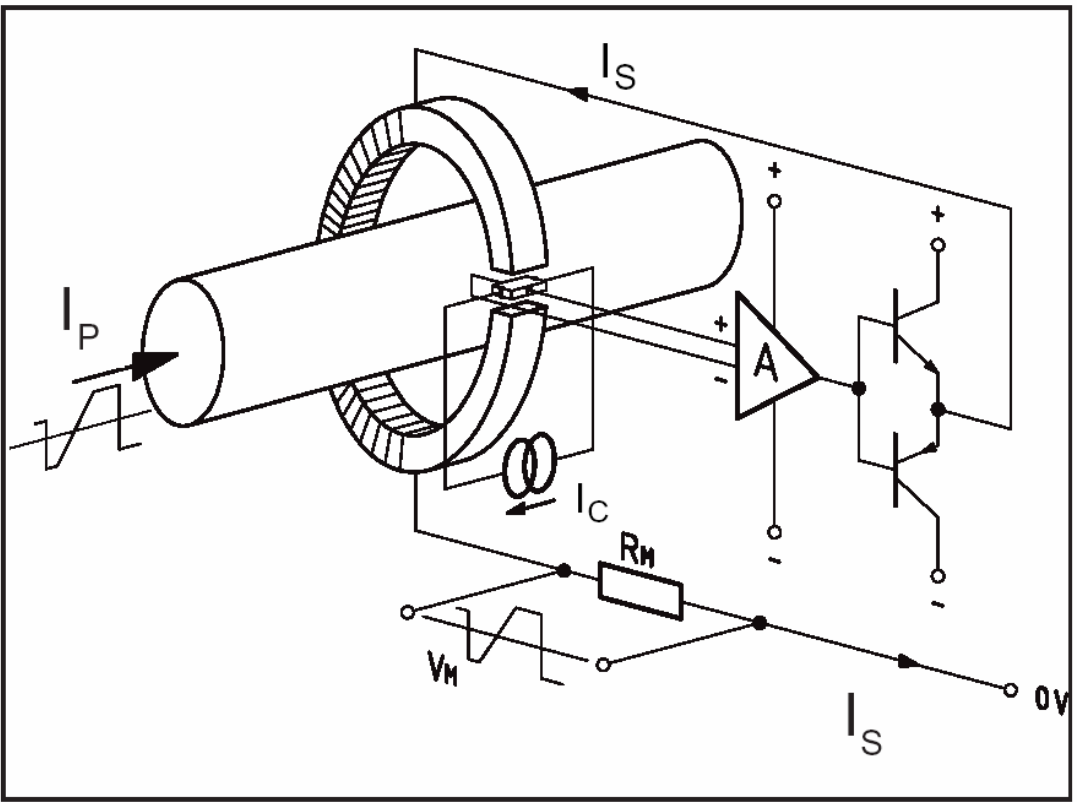

FIGURA 4.6 - Sensor Hall de corrente com realimentação do sinal de saída.

Fonte: Manual LEM

\subsubsection{Condicionamento de Sinal}

O condicionamento de sinal é definido como o tratamento dado ao sinal, na saída do transdutor, para deixá-lo condicionado a outros equipamentos. No caso do sensor Hall adotado, este tem saída em corrente enquanto a placa de aquisição de dados tem entrada em tensão. Desta forma acrescenta-se uma carga resistiva à saída do sensor Hall de forma a ter o sinal de tensão adequado à placa de aquisição. $A$ FIGURA 4.7 ilustra esta configuração. 


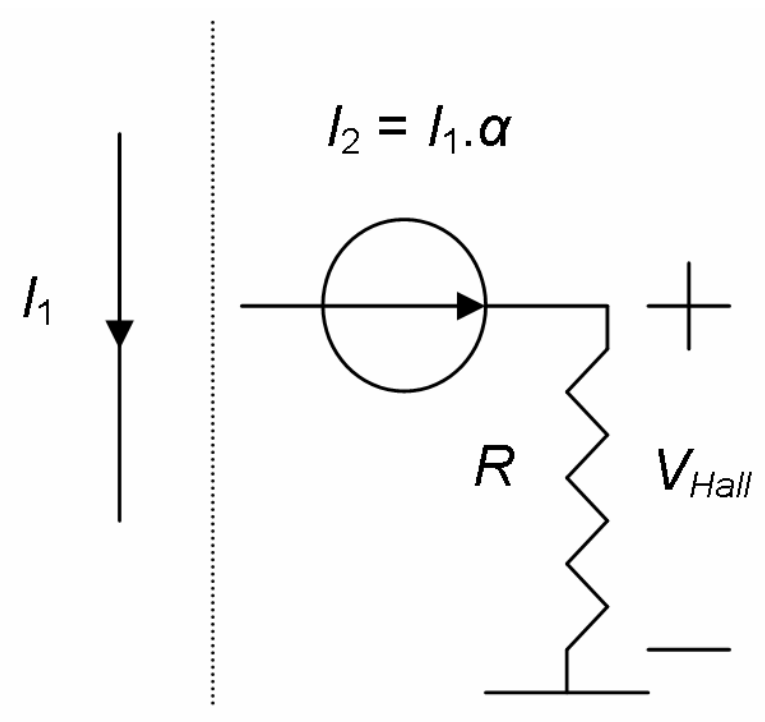

FIGURA 4.7 - Transformação de corrente em tensão.

onde $I_{1}$ é a corrente primária, $I_{2}$ é a corrente secundária (ou de saída) e $\alpha$ é a relação entre a corrente de primário e secundário.

Neste caso $\alpha$ tem a relação $1 / 1000$, ou seja, para cada Ampere na entrada tem-se $1 \mathrm{~mA}$ na saída. O resistor $R$ é escolhido com o valor de $100 \Omega$ conforme faixa sugerida pelo fabricante. Neste valor, tem-se também uma relação de 1/10 entre corrente $I_{1}$ e $V_{\text {Hall. }}$

Desta forma, a tensão eficaz de saída é de $2,5 \mathrm{~V}$ ou $3,536 \mathrm{Vp}$ (pico). A placa de aquisição escolhida para este trabalho trabalha com tensões de $+/-10$ Vpp. Optase então por inserir um amplificador operacional de ganho dois com conseqüente aumento da resolução do sinal de saída e, ainda, estar dentro da faixa de tolerância da placa de aquisição considerando surtos de corrente no primário. A FIGURA 4.8 ilustra o condicionamento proposto para o sensor Hall de corrente. 


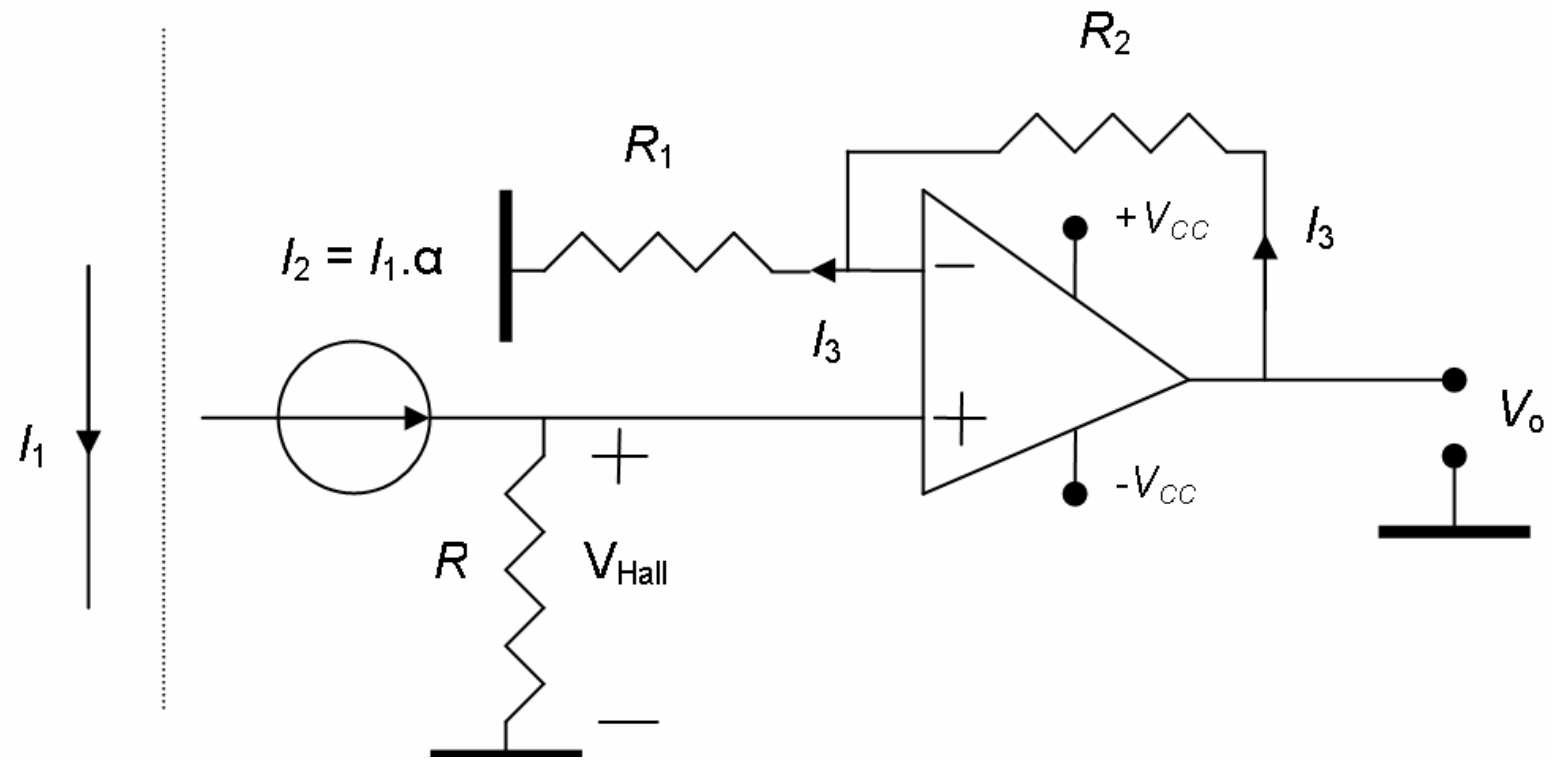

FIGURA 4.8 - Condicionamento de sinal do sensor Hall.

Considerando que há realimentação negativa, ou seja, há uma conexão entre a saída e a entrada $V_{(-)}$através do resistor $R_{2}$, tem-se então que $V_{(-)}=V_{(+)}$. A partir deste postulado, tem-se:

$$
V_{(+)}=I_{2} \cdot R=I_{1} \cdot \alpha \cdot R
$$

Se $V_{(-)}=V_{(+)}$então tem-se:

$$
I_{3}=\frac{V_{(+)}}{R_{1}}=\frac{I_{1} \cdot \alpha \cdot R}{R 1}
$$

Considerando que a corrente drenada das entradas do amplificador operacional deve ser muito baixa, da ordem de nano Ampere, então $I_{3}$ deve ser fornecida pela saída do dispositivo, confirmando assim a premissa inicial de realimentação negativa. Aplicando Kirchoff das malhas, tem-se:

$$
V_{o}=R_{2} \cdot I_{3}+V_{(+)}=R_{2} \cdot \frac{I_{1} \alpha R}{R_{1}}+I_{1} \cdot \alpha \cdot R=I_{1} \cdot \alpha \cdot R\left(\frac{R_{2}}{R_{1}}+1\right)
$$

Se $R_{2}=R_{1}$ então tem-se ganho dois. Deve ser notado que o esquema proposto é flexível o suficiente para servir como buffer de tensão, ou também chamado de seguidor de tensão, se $R_{2}$ igualar-se a zero. Desta forma, tem-se na 
saída do amplificador operacional a mesma tensão que a produzida pelo produto I.. .R.

O amplificador operacional escolhido foi o TL081, cuja entrada é JFet e como conseqüência drenando nano amperes de corrente. Este dispositivo, da Família TL08X, também possui saída para ajuste de off-set, banda de $3 \mathrm{MHz}$ para ganho unitário e slew rate típico de $13 \mathrm{~V} / \mu \mathrm{s}$. Desta forma, o amplificador operacional acompanha variações rápidas de tensão em sua entrada.

\subsubsection{Sensores Hall de Tensão}

Os modelos baseados em redes neurais que estimam parâmetros de motores elétricos têm como entradas a corrente e tensão eficazes. Desta forma, há a necessidade de medida de tensão de alimentação do motor. Seguindo as mesmas premissas da escolha do sensor de corrente, tais como portabilidade, tamanho reduzido e imunidade a ruído, opta-se pelo uso de um sensor Hall de tensão o qual é produzido também pela LEM.

O princípio de funcionamento é o mesmo do Hall de corrente, diferindo apenas que se deve transformar o sinal de tensão em corrente através da adição de um resistor externo R1 conforme FIGURA 4.9, a qual ilustra o diagrama de conexão

elétrica do sensor Hall de tensão. Na referida figura o resistor $\mathrm{RM}_{\mathrm{m}}$ representa a resistência de carga e Is a fonte de corrente regulada pela variação de tensão dos terminais $+\mathrm{HT}$ e $-\mathrm{HT}$. 


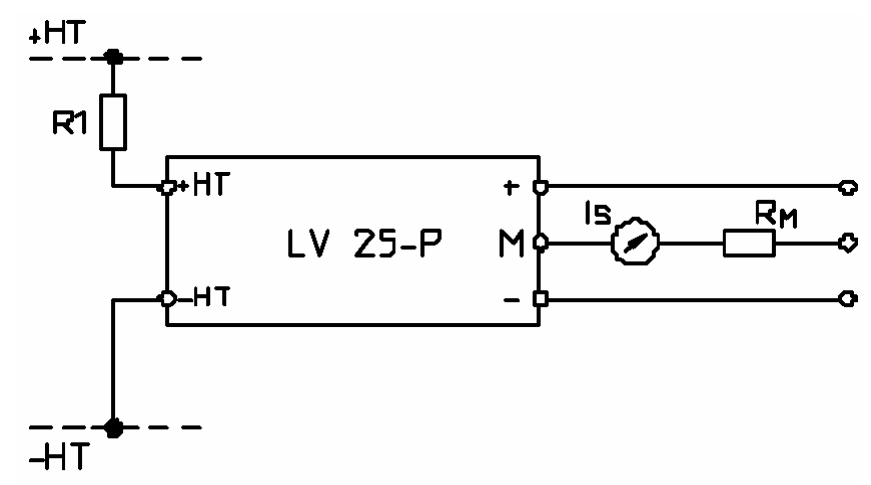

FIGURA 4.9 - Diagrama de conexão elétrica.

Fonte: Manual LEM

A taxa de conversão é de 1:2,5; ou seja, para cada miliampere na entrada tem-se 2,5 miliamperes na saída. As características do LV-20P constam do manual do componente. Deve ser observado que a saída tem a mesma escala (0-25 mA) do sensor Hall de corrente. Desta forma, utiliza-se o mesmo esquema de condicionamento de sinal usado no transdutor de corrente descrito na seção anterior.

\subsubsection{Sensores Hall: Aplicação}

Conforme mencionado anteriormente, o sensor Hall de corrente e tensão escolhido para uso neste projeto foi o LAH-25 NP e o LV-20P do fabricante LEM. O condicionamento de sinal foi feito utilizando o amplificador operacional TL081 com ajuste de offset.

Os sensores Hall de tensão e de corrente têm por objetivo instrumentar a máquina de corrente contínua e a máquina de corrente alternada (Motor de Indução Trifásico - MIT). Estes sensores são os pontos de partida das tecnologias sensorless e suas aplicações não se restringem às aplicações em máquinas elétricas. 
Neste trabalho, as tensões e corrente trifásicas, a tensão do enrolamento de armadura, a corrente do enrolamento de armadura, a tensão do enrolamento de campo e a corrente do enrolamento de campo são medidas por tais sensores. A FIGURA 4.1 ilustra a aplicação destes sensores no barramento da máquina de indução representado pelos blocos "I V". A FIGURA 4.10 mostra os sensores fixados na parte interna do painel de comando e monitorando o barramento da máquina de indução.

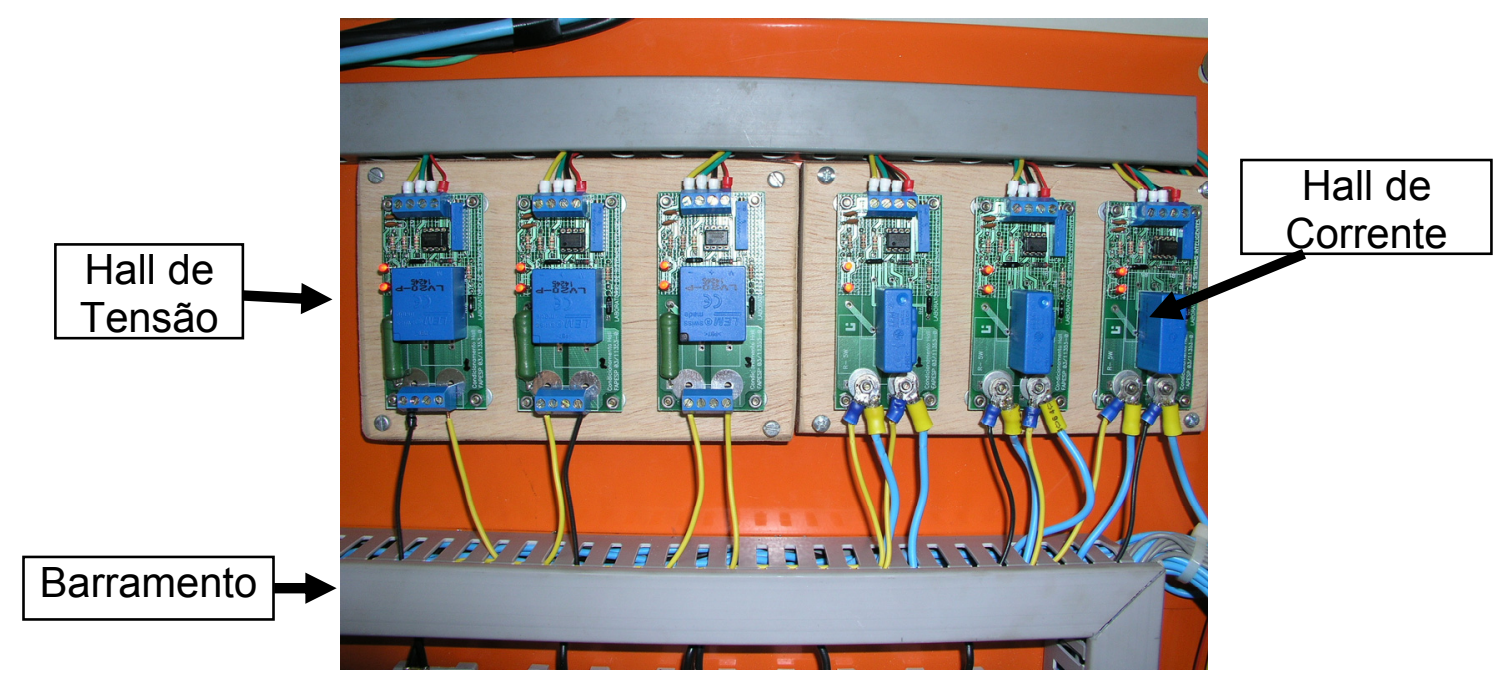

FIGURA 4.10 - Diagrama de conexão interna ao quadro de comando.

\subsection{Encoder Óptico e Seu Condicionamento de Sinal}

O encoder óptico é um dispositivo eletromecânico que transforma movimento numa seqüência de pulsos digitais. Pela contagem de um bit ou pela decodificação de um conjunto de bits, os pulsos podem ser convertidos em medida de posição relativa ou absoluta.

Os encoders possuem configuração linear ou rotativa, sendo a última mais comum. Os encoders ópticos rotativos são fabricados em duas formas básicas: i) o encoder absoluto e ii) o encoder óptico incremental. No encoder absoluto uma 
palavra (seqüência de bits) corresponde de forma unívoca à posição do eixo em relação à uma referência. Já no encoder incremental é produzida uma seqüência de pulsos cuja freqüência varia de forma proporcional à velocidade de giro do eixo.

Neste trabalho opta-se pelo uso do encoder óptico incremental, pois há a necessidade de medida da velocidade no eixo do motor de indução trifásico. O encoder adquirido com recursos financeiros da FAPESP foi o modelo T8-5800 do fabricante Kuebler. Destaca-se como característica importante deste equipamento o uso industrial dele, com tolerância a grandes esforços axiais e radiais, o que propicia uma maior vida útil deste aparelho. A saída do tipo push-pull aumenta a imunidade ao ruído. Foi escolhido o encoder com 2.000 pulsos por rotação com saída $A, \bar{A}, B, \bar{B}, Z$ e $\bar{Z}$.

O encoder óptico possui uma saída digital conforme o nível de tensão o qual ele é alimentado. Entretanto, cada saída possui dois transistores e quando um está acionado o outro está cortado. O sentido da corrente sobre a resistência de carga, tomando um mesmo ponto como referência, a deixa ora positiva e ora negativa. Com isso, tem-se um nível de tensão simétrico sobre a resistência praticamente igual a Vcc. Só não é igual à tensão de Vcc porque os transistores que estão conduzindo trabalham de forma saturada e sobre eles há uma queda de tensão chamada de tensão de saturação. A FIGURA 4.11 ilustra o tipo de saída push-pull, a qual se caracteriza por grande imunidade a ruído, sendo também utilizada em ambiente industrial.

Como exemplo, seja uma rotação síncrona de 1800 rpm (MIT de 4 pólos) o que significa 30 voltas por segundo; ou seja, 30 rps (rotações por segundo). Com o encoder de 2000 pulsos por rotação tem-se então 60.000 pulsos por segundo. Esta grandeza pode também ser representada na forma de freqüência, ou seja, $60 \mathrm{kHz}$. 


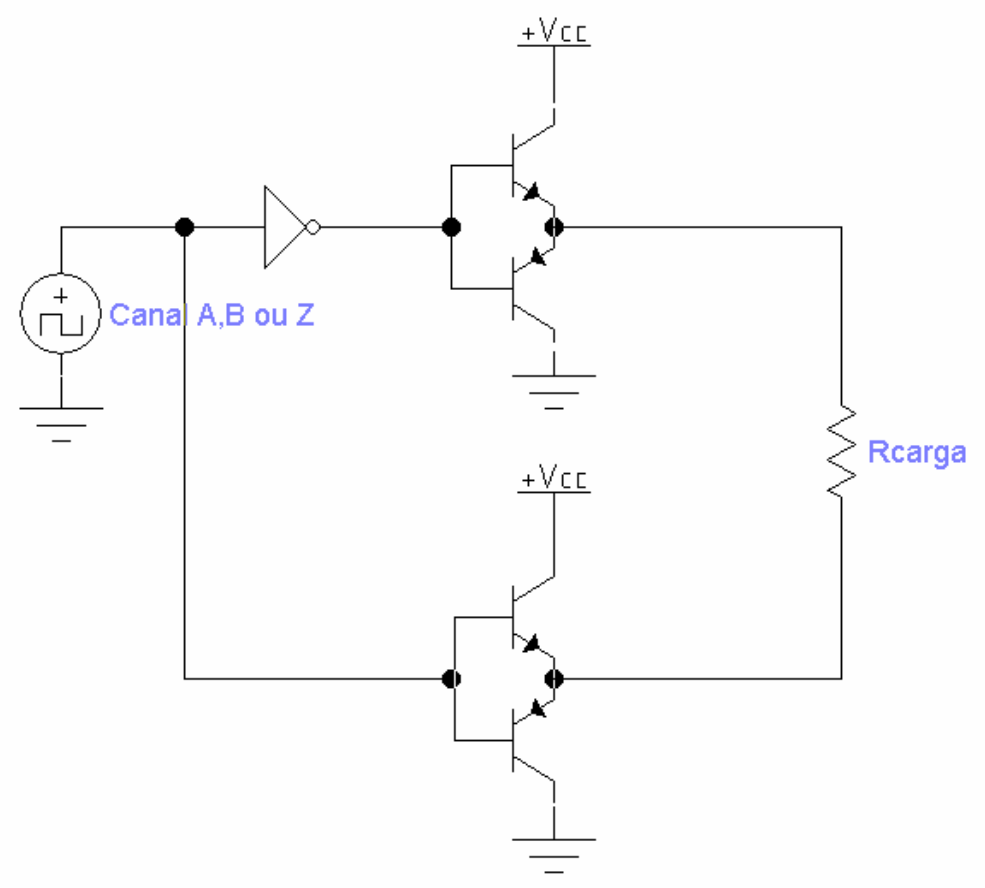

FIGURA 4.11 - Saída push-pull do encoder óptico.

A placa de aquisição suporta até 200k samples/segundo multiplexada nos diversos canais. Se a amostragem ocorrer de forma simultânea, poder-se-ia inserir mais dois canais de $60 \mathrm{k}$ samples/segundo.

A solução encontrada para esta questão foi o desenvolvimento de um divisor programável baseado em microcontrolador. A idéia principal foi retirar o sinal advindo do encoder e dividí-lo por 4, 8, 16, 32, 64, 128 ou 256 conforme uma interface externa (dip switch).

O sinal de saída do push-pull é simétrico; ou seja, +Vcc a -Vcc. Entretanto, a entrada do sistema microcontrolado é nível TTL (+5V a 0V). Há a necessidade de adaptação do sinal +/-Vcc para TTL. Escolhe-se, estrategicamente, $\mathrm{Vcc}=12 \mathrm{~V}$.

Desta forma, tem-se o padrão RS232 sobre o resistor de carga. Usa-se então o chip MAX232, que faz a conversão de RS232 para TTL, neste circuito. Usase somente a conversão RS232 para TTL nos pinos 8 e 13 do circuito integrado. Convém ressaltar que esta solução aproveita um circuito integrado disponível no 
mercado que é encontrado com facilidade e integra-se ao circuito de condicionamento.

Após a inserção deste circuito integrado e os devidos testes em protoboard, monta-se então toda a estrutura numa placa universal utilizando a técnica conhecida como wire-wrap. Esta metodologia se baseia na soldagem dos componentes e sua interconexão através de pequenos fios. A facilidade de mudanças e a rapidez com que se constrói um protótipo são as grandes vantagens deste método. Além disso, pelo processo de soldagem, diminuem-se significativamente problemas de mau contato que ocorrem com freqüência nos protodoads. A FIGURA 4.12 ilustra a estrutura para condicionamento de sinais do encoder óptico.

A verificação do funcionamento foi realizada utilizando o osciloscópio digital Tektronix em paralelo com o sinal de entrada da placa de aquisição de dados. As medidas coincidiram com as do osciloscópio cujo canal estava ajustado para efetuar as medições de período. A variação de velocidade para este ensaio foi obtida pela variação da tensão de armadura aplicada à máquina de corrente contínua operando como motor. Neste caso, mantém-se a tensão do campo constante. 


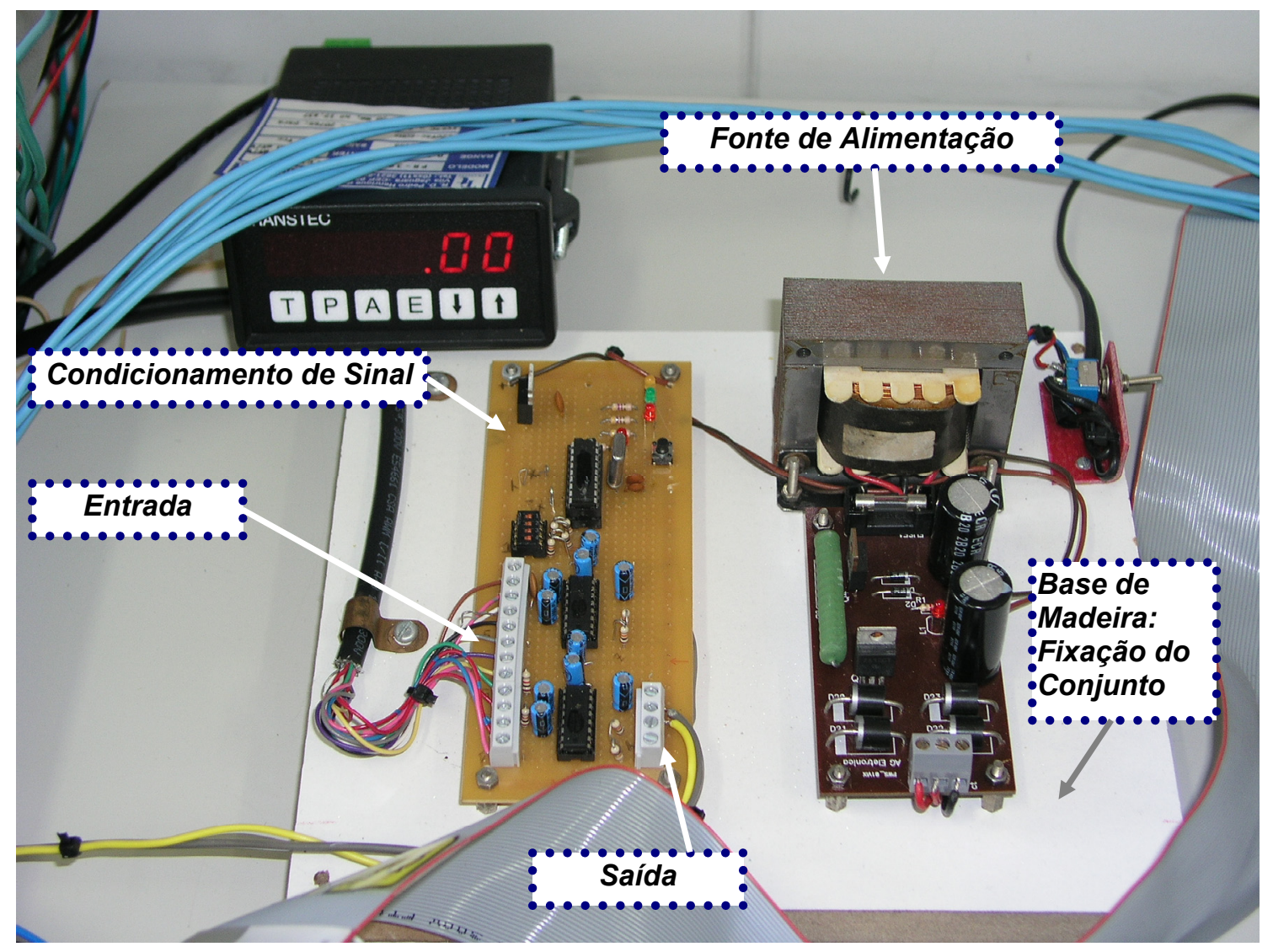

FIGURA 4.12 - Vista do conjunto: condicionamento de sinal do encoder óptico e fonte de alimentação.

\subsection{Bancada de Ensaios: Acoplando as Máquinas}

A bancada de ensaios é a plataforma sobre a qual serão fixadas as máquinas a serem ensaiadas. Esta estrutura foi concebida no sentido de possibilitar diversos tipos de ensaios de uma máquina de corrente contínua e uma máquina de corrente alternada trifásica. Entre as duas máquinas é posicionado o torquímetro girante e na ponta do motor de indução, através do alongamento do seu eixo, a fixação do encoder óptico. 


\subsubsection{Estrutura Metálica da Bancada de Ensaios}

A estrutura metálica é composta por uma chapa metálica de $1 / 4$ de polegada com $1,20 \mathrm{~m}$ de comprimento, $0,6 \mathrm{~m}$ de largura e $0,80 \mathrm{~m}$ de altura. Da chapa plana ao chão, há os pés que estão soldados na parte inferior da estrutura. A FIGURA 4.13(a) ilustra a chapa metálica ainda na oficina, na fase quer antecede a furação. A parte inferior da estrutura está em destaque mostrando a dobra da chapa e a soldagem a qual lhe confere maior rigidez mecânica.

Uma segunda estrutura metálica foi desenvolvida para fixação do encoder óptico. A altura desta estrutura faz com que coincida a altura do centro do eixo do encoder óptico e do centro do eixo da máquina de corrente contínua. Toma-se como referência a máquina de corrente contínua, pois a mesma possui a maior altura entre todas as máquinas. A FIGURA 4.13(b) apresenta a segunda estrutura.

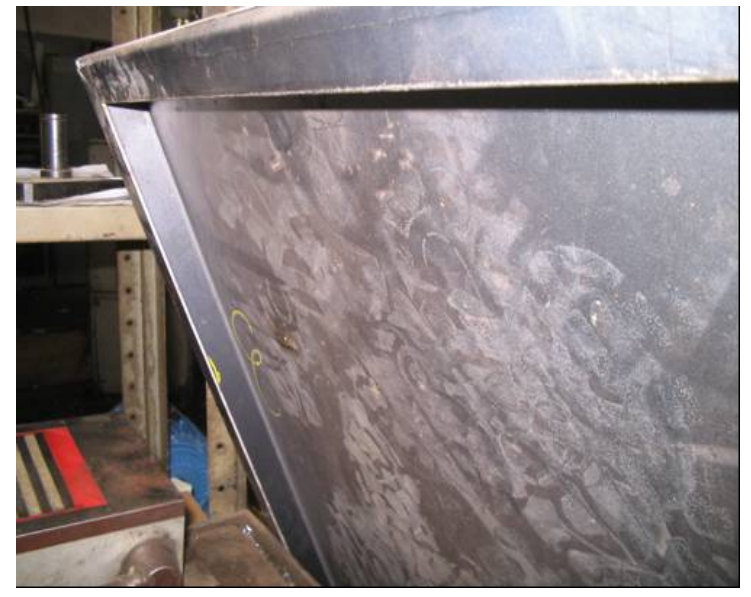

(a)

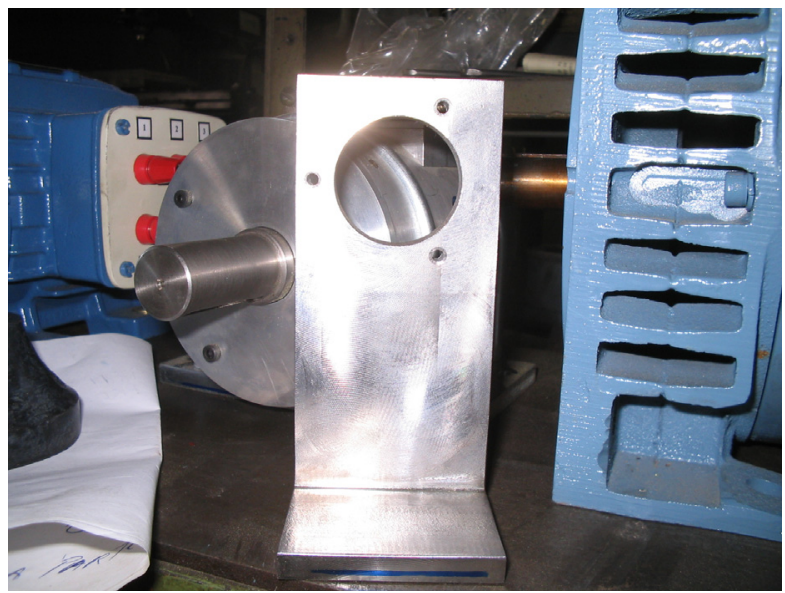

(b)

FIGURA 4.13 - Estrutura metálica: (a) Fixação das máquinas e (b) fixação do encoder.

O acoplamento do encoder óptico e do motor de indução são realizados pela construção de uma extensão no eixo. Esta extensão é fixada na parte posterior do rotor do motor de indução por um processo de soldagem e em seguida é torneado o conjunto, mantendo assim o equilíbrio de massas e evitando o desbalanceamento, o 
qual é causador de vibrações. A FIGURA 4.14(a) apresenta a extensão do eixo do MIT.

O acoplamento entre os dois eixos, do motor de indução e do encoder óptico, é realizado através de um acoplamento elástico. Tal acoplamento é responsável pela absorção de pequenas vibrações provenientes da máquina de indução e tem por objetivo o aumento da vida útil dos rolamentos do encoder óptico. A FIGURA 4.14 (b) ilustra o acoplamento elástico utilizado neste trabalho.

No acoplamento dos demais eixos foi utilizado um dispositivo de acoplamento mecânico. Este acoplamento possui dois parafusos na sua parte superior para fixar a chaveta dos eixos que são acoplados a ele. No caso desta bancada de testes, o acoplamento da máquina de corrente contínua ao torquímetro girante e do torquímetro girante ao eixo do motor de indução trifásico é realizado através deste acoplamento. No meio deles há uma borracha que absorve o esforço de um eixo contra o outro. A FIGURA 4.14 (c) mostra o acoplamento elástico e a FIGURA 4.14 (d) apresenta a conexão entre o MIT e o torquímetro girante através do acoplamento elástico.

\subsubsection{Montagem do Conjunto Completo}

A estrutura de ensaios se caracteriza num conjunto de peças, adquiridas separadamente, que quando montadas servem para testar máquinas elétricas em diversos aspectos da pesquisa. A parte final se caracteriza pela montagem do conjunto, sobre a base já pintada com pintura eletrostática, acoplando as diversas máquinas. O alinhamento das máquinas é uma das partes que envolvem um grande número de detalhes e de fundamental importância para o trabalho A Figura 4.15 apresenta o conjunto das três máquinas; a saber: o motor de indução, o torquímetro 
girante e a máquina de corrente contínua acoplados, formando um conjunto rotativo, no instante em que as máquinas estavam sendo alinhadas.

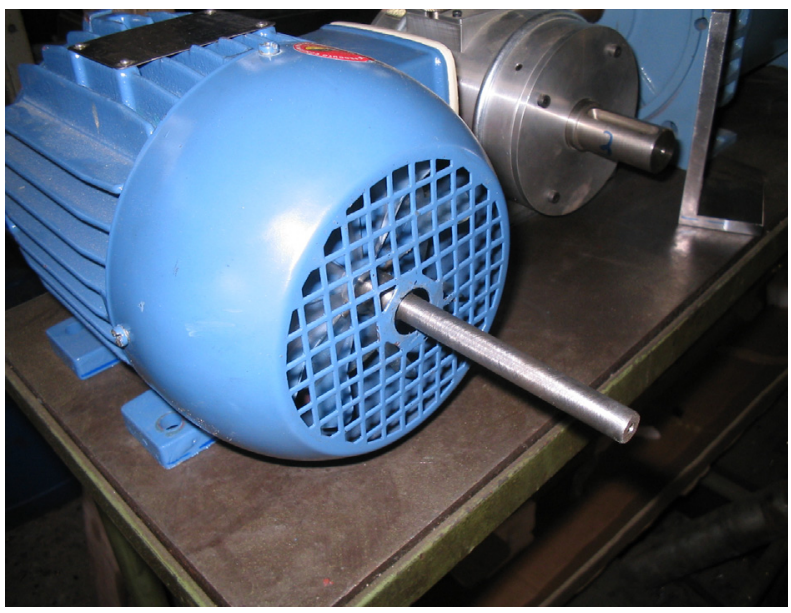

(a)

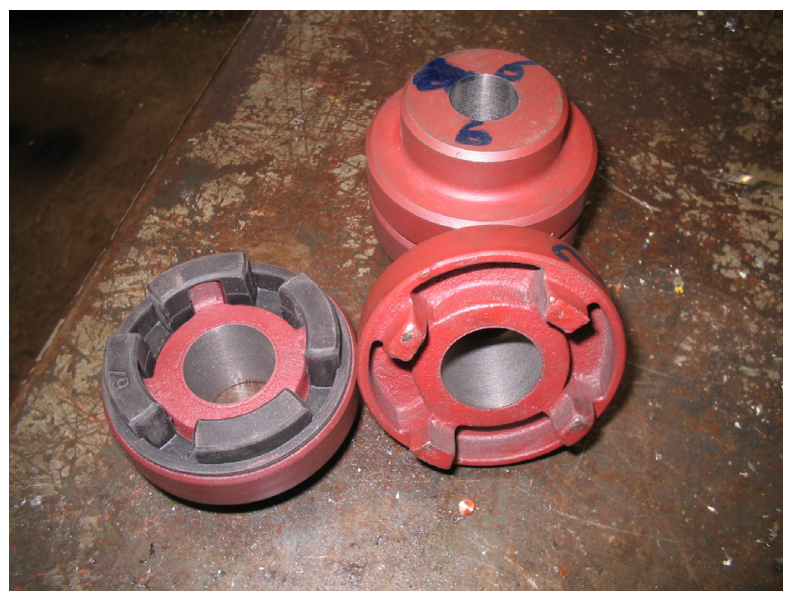

(c)

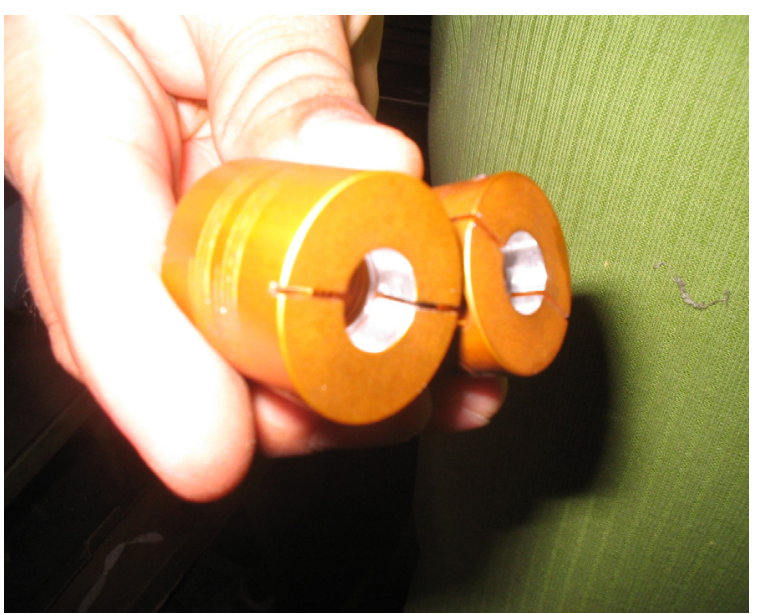

(b)

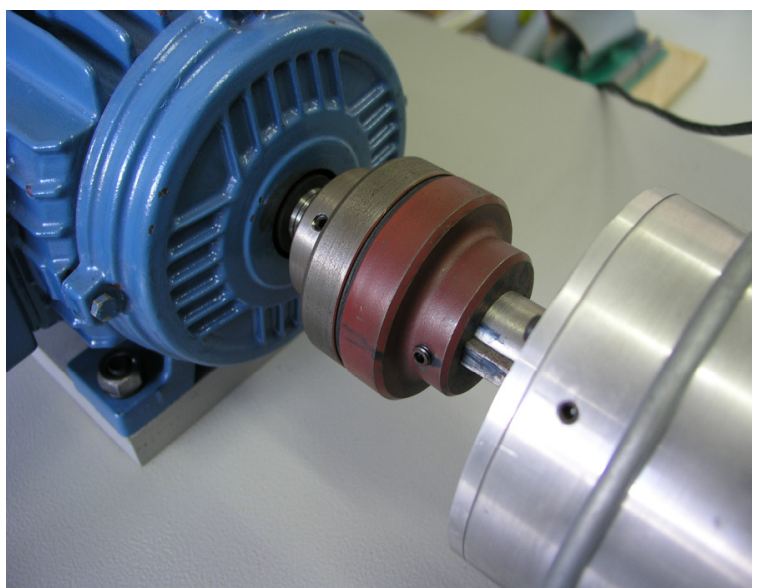

(d)

FIGURA 4.14 - Elemento de fixação: (a) extensão do eixo do MIT, (b) Acoplamento elástico do encoder, (c) acoplamento elástico das demais máquinas, (d) acoplamento do MIT com o torquímetro girante utilizando acoplamento elástico. 


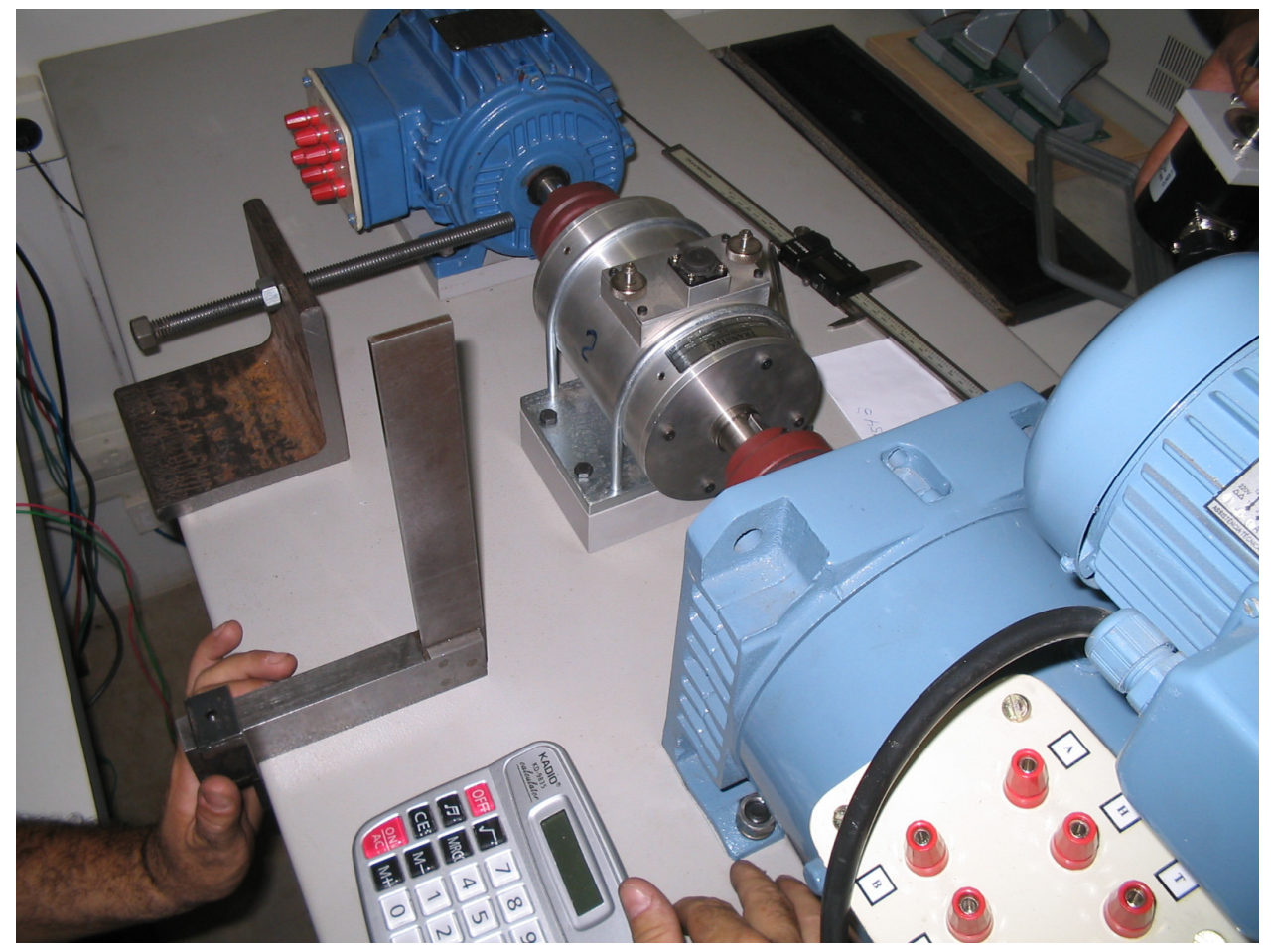

FIGURA 4.15 - Alinhamento da máquinas.

A FIGURA 4.16 apresenta uma visão geral da estrutura alinhada e montada.

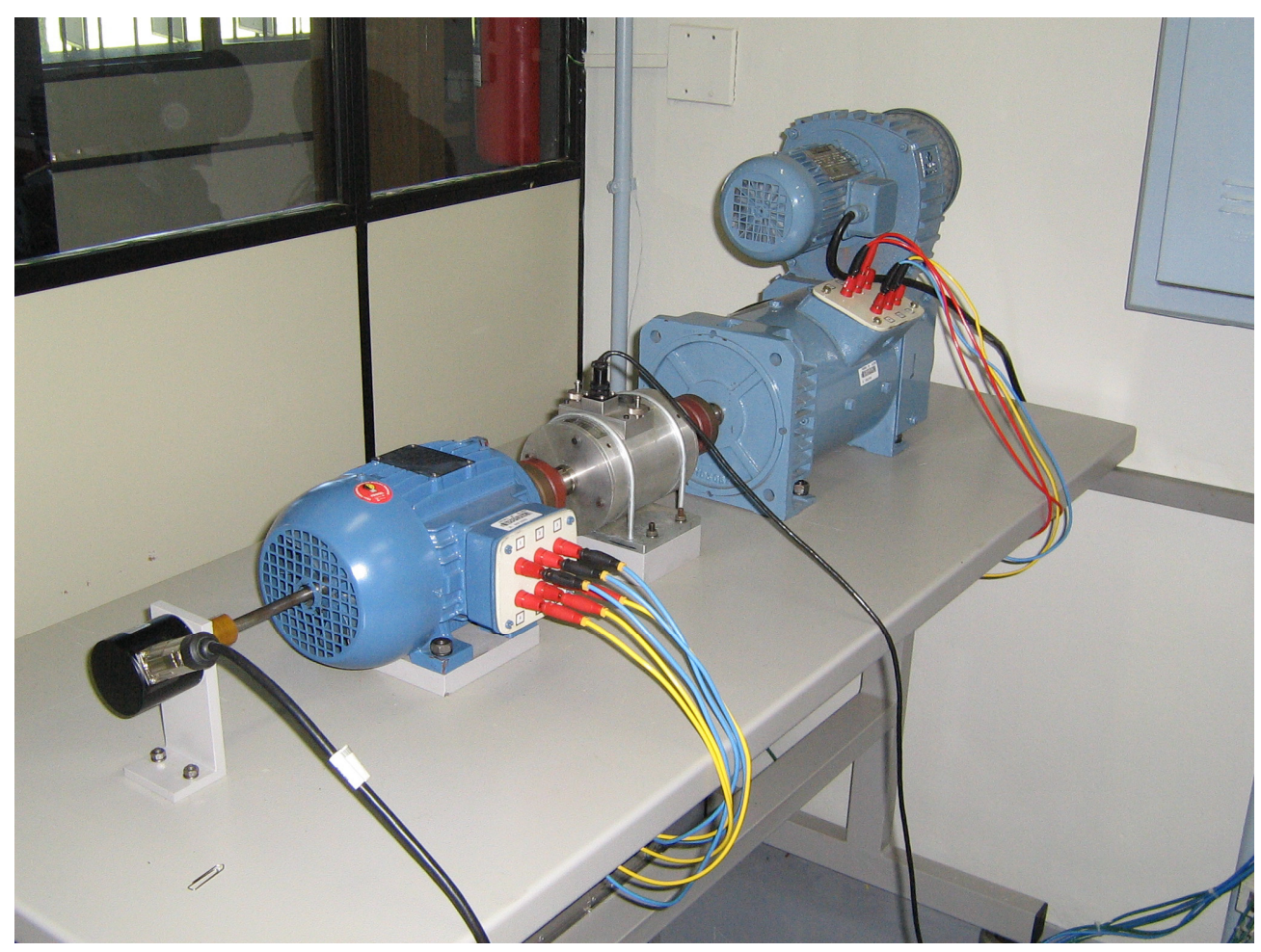

FIGURA 4.16 - Estrutura de ensaios de máquinas elétricas rotativas.

A carga conectada ao enrolamento de armadura da máquina é composta de resistências de reposição de chuveiros elétricos. A ligação delas é série ou paralelo 
conforme a necessidade de imposição de conjugado ao MIT. Este conjunto está alojado num cilindro de material plástico (tubo de PVC) e nas suas extremidades dois ventiladores, tipo cooler, auxiliam a dissipação de calor. Essa solução se caracteriza pelo baixo custo de sua montagem e implementação.

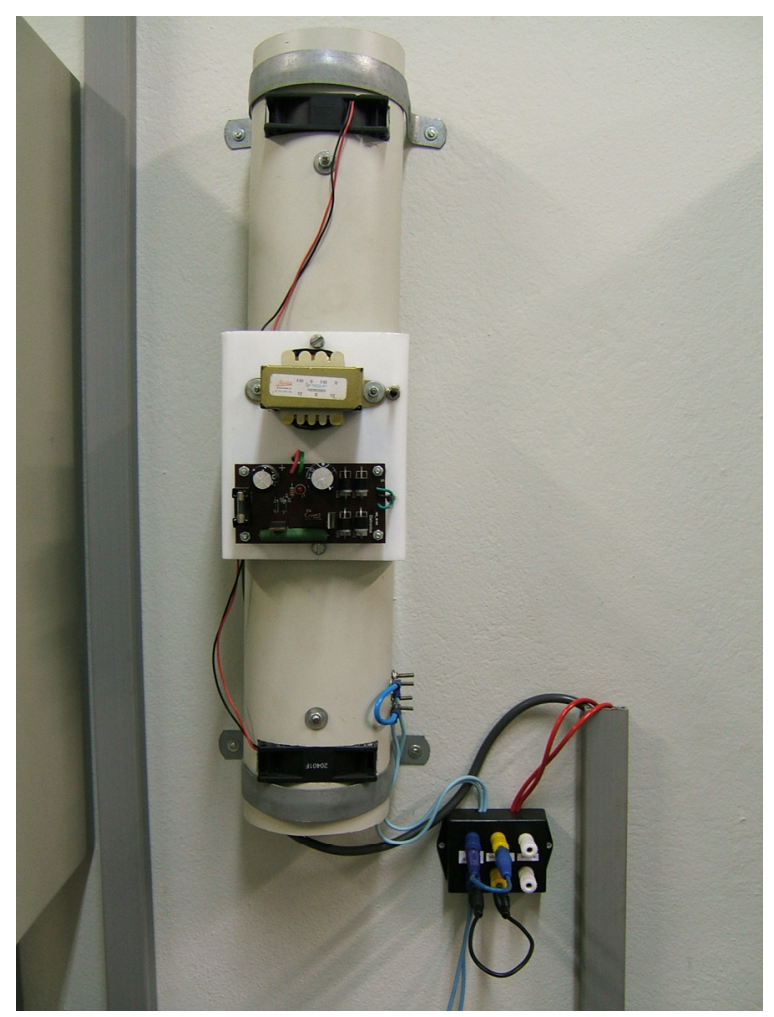

FIGURA 4.17 - Carga da máquina de corrente contínua.

A montagem desta estrutura de ensaios pode ser considerada uma contribuição aos trabalhos de pesquisa e ensino na área de máquinas elétricas rotativas. Diversos parâmetros são monitorados nesta estrutura; a saber: velocidade do eixo, torque de carga, tensão de armadura, corrente de armadura, tensão de campo, corrente de campo, tensões de linha trifásicas, correntes de linha trifásicas. A temperatura nas máquinas não é monitorada e pode ser uma implementação futura. 


\section{Uma Contribuição aos Estimadores de Velocidade Utilizando Redes Neurais Artificiais}

As aplicações de motores de indução trifásicos podem ser divididas em dois grandes grupos: o primeiro grupo é aquele em que o motor trabalha sempre a mesma velocidade, ou seja, uma vez dada sua partida, não há elemento de controle sobre sua velocidade ou regime de operação. O segundo grupo, por sua vez, é aquele onde os processos em que os motores estão acoplados necessitam a aplicação de uma metodologia de controle (escalar ou vetorial). A abordagem deste trabalho está inserida no contexto dos dois grupos de acionamento e se propõe um método para estimar velocidade do MIT em regime senoidal ou não-senoidal de alimentação.

A proposta está então focada em apresentar um modelo baseado em redes neurais artificiais para estimar velocidade no eixo do motor de indução através de medidas primárias de tensão e corrente. Dados de simulação e experimentais são apresentados para validar esta proposta.

\subsection{Aspectos da Modelagem do MIT}

O primeiro passo envolvido no treinamento de uma rede neural artificial é compilar o conjunto de padrões de entrada e saída com o objetivo do ajuste dos parâmetros internos da rede (pesos sinápticos). Este procedimento é conhecido como processo de treinamento e se deve assegurar que a rede é exposta a seqüências de padrões que descrevam de forma satisfatória o comportamento do sistema analisado (GOEDTEL, 2006a). 
Com o propósito de gerar os padrões de treinamento para estimativa de velocidade do motor de indução, quando em diferentes situações de carga e tensão de alimentação, realizaram-se várias simulações utilizando a ferramenta Matlab/Simulink.

O modelo do motor de indução usado nas simulações foi desenvolvido com base na literatura pesquisada, e é apresentado no Apêndice $A$, sendo aceito por muitos pesquisadores como um modelo muito próximo da realidade física. Este modelo leva em consideração vários aspectos envolvidos na dinâmica eletromecânica do motor, permitindo a simulação do comportamento do regime transitório ao regime permanente em diversas configurações de operação (ONG, 1998). A FIGURA 5.1 ilustra, na forma de diagrama em blocos, as entradas e saídas do modelo.

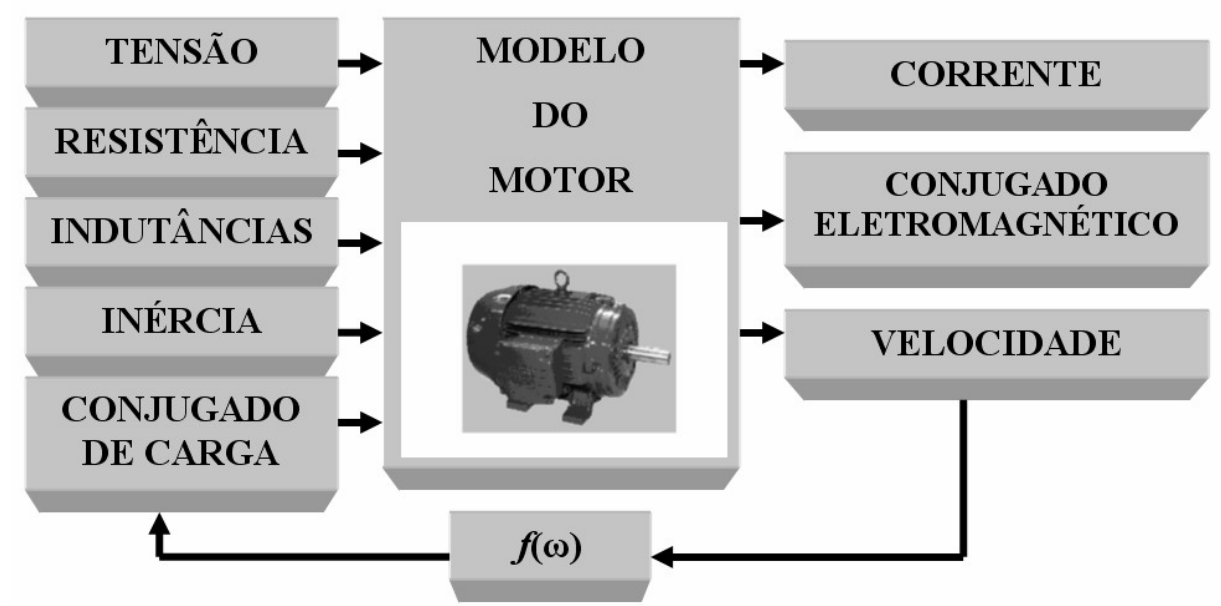

FIGURA 5.1 - Diagrama esquemático representando as configurações de entradassaídas usadas para simular o MIT.

Os parâmetros da máquina como tensão, parâmetros elétricos do rotor e estator, momento de inércia da carga e do rotor, e conjugado de carga são as entradas do modelo. A corrente elétrica, o conjugado eletromagnético e a velocidade do rotor são as saídas do modelo. Estas variáveis serão usadas no processo de treinamento das redes neurais. A função $f(\omega)$ representa a carga que está sendo 
simulada. Neste trabalho é usada uma carga com perfil linear e que se caracteriza pelo baixo conjugado de partida. Nas simulações não são consideradas as variações paramétricas devido à alteração da temperatura.

Os parâmetros utilizados na simulação foram levantados de um motor de 4 pólos, 220/380V, IP55 do fabricante WEG, conforme procedimento descrito em Kubo (2000). O levantamento dos parâmetros do MIT utilizaram a IEEE Standard Test Procedure for Polyphase Indusction Motors and Generators (IEEE Std. 112-1996) (KUBO, 2000). A Tabela 5.1 apresenta os parâmetros do motor utilizado.

TABELA 5.1 - Parâmetros do MIT.

\begin{tabular}{|c|c|}
\hline \multicolumn{2}{|c|}{ Linha Standard - IV Pólos $-60 \mathrm{~Hz}-220 / 380 \mathrm{~V}$} \\
\hline Potência & $1 \mathrm{cV}$ \\
\hline Resistência de Estator & $7,32 \Omega$ \\
\hline Resistência de Rotor & $2,78 \Omega$ \\
\hline $\begin{array}{c}\text { Indutância de Dispersão do } \\
\text { Enrolamento de Estator }\end{array}$ & $8,95.10^{-3} \mathrm{H}$ \\
\hline $\begin{array}{c}\text { Indutância de Dispersão do } \\
\text { Enrolamento de Rotor }\end{array}$ & $5,44.10^{-3} \mathrm{H}$ \\
\hline Indutância de Magnetização & $1,41.10^{-1} \mathrm{H}$ \\
\hline Momento de Inércia do Rotor & $2,71.10^{-3} \mathrm{~kg} \cdot \mathrm{m}^{2}$ \\
\hline Velocidade Síncrona & $188,49 \mathrm{rad} / \mathrm{s}$ \\
\hline Escorregamento Nominal & $3,8 \%$ \\
\hline Torque Nominal & $4,1 \mathrm{Nm}$ \\
\hline
\end{tabular}

\subsection{Metodologia e Simulação}

A metodologia proposta neste trabalho é ilustrada na FIGURA 5.2. Este diagrama em blocos ilustra uma estrutura formada entre modelagem e experimentação tendo os passos numerados de 1 a 12.

A fase inicial consiste em modelar a máquina de indução (passo 2), conforme descrito na Seção 5.1. A simulação do modelo do MIT gera os dados de treinamento e os dados de teste da estrutura neural proposta (passos 4, 5 e 6). Em seguida, a RNA é treinada (passo 7) com o algoritmo backpropagation descrito na 
Seção 3.1. A cada rede neural artificial treinada são apresentados os dados de teste (gerados no passo 4 e armazenados no passo 6). Desta forma realiza-se o processo de validação da estrutura neural verificando-se o erro entre o valor real e o valor estimado. Este processo é chamado de validação cruzada (crossvalidation) sendo descrito nos passos 8 e 9 da FIGURA 5.2.

Em seguida, propõe-se o teste da estrutura neural, treinada e validada por dados de simulação, com dados experimentais. Os dados são coletados na estrutura de ensaios de máquinas elétricas conforme FIGURA 5.2 (passos 1 e 3). Os dados experimentais são apresentados à rede neural artificial previamente treinada com dados de simulação e observam-se os resultados de generalização (passos 10, 11 e 12).

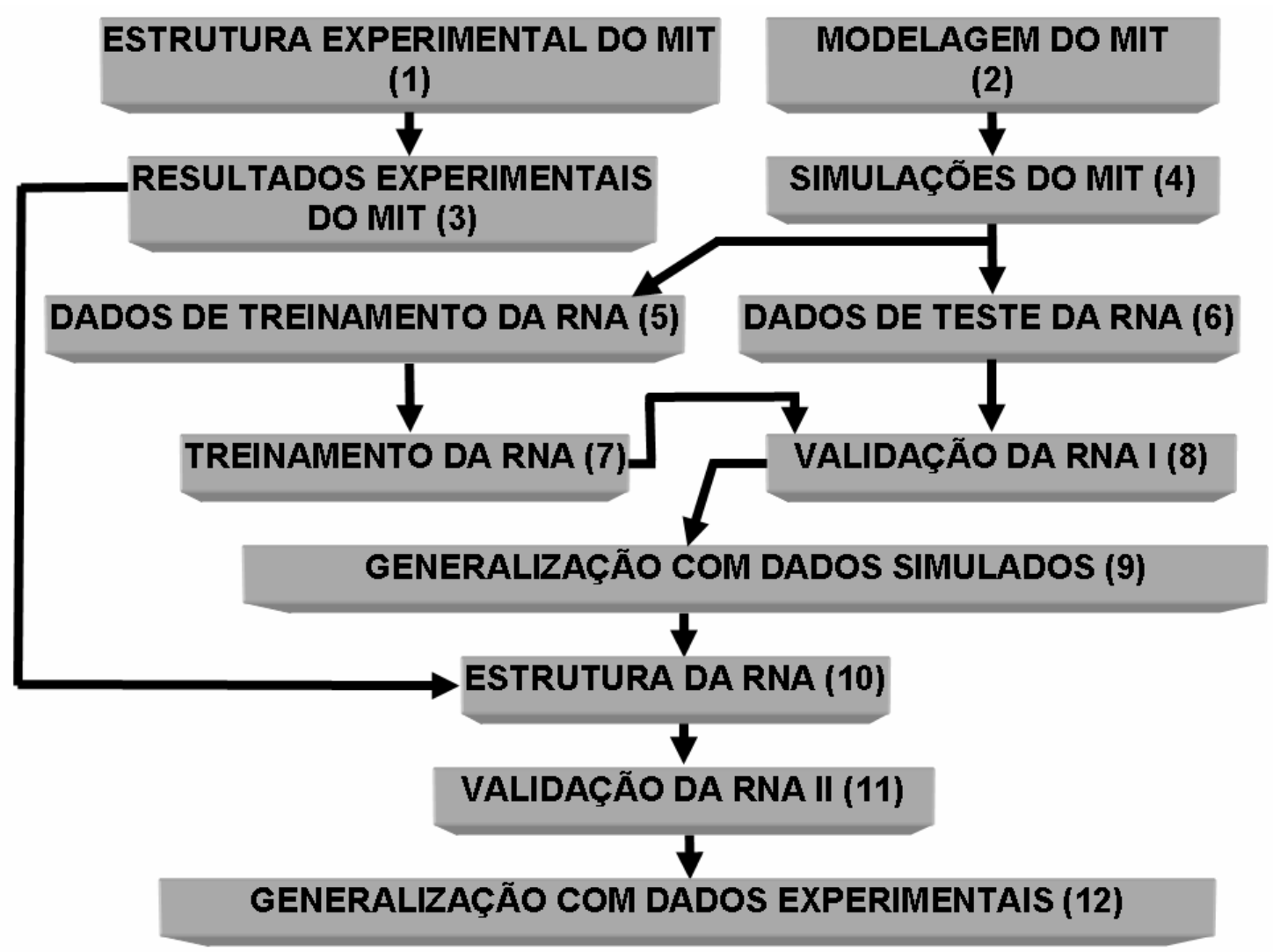

FIGURA 5.2 - Diagrama em blocos da metodologia.

É importante ressaltar que a metodologia proposta neste trabalho considera um primeiro processo de validação através de dados simulados e em seguida com 
dados experimentais. Na literatura são encontrados processos de treinamento e validação cruzada envolvendo máquinas elétricas com dados gerados a partir de modelos ou dados gerados experimentais.

A pré-validação com dados simulados e pós-validação com dados experimentais proposta neste trabalho pode ser traduzida como uma contribuição pontual nesta linha de pesquisa, validando a estrutura neural proposta para estimativa de velocidade no motor de indução trifásico com dados de simulação e dados experimentais. Propõe-se, nesta tese, a nomenclatura de bi-validação cruzada para este processo.

\subsubsection{Treinando as RNA}

Os dados de simulação gerados a partir do modelo do MIT, descrito nas seções anteriores, forneceu os dados necessários à fase de treinamento da estrutura neural. Os dados de entrada da rede Perceptron multicamadas são os valores eficazes (Root Mean Square - RMS) de tensão e corrente de linha da alimentação do MIT. A saída da rede é a velocidade. A FIGURA 5.3 ilustra a estrutura de treinamento proposta, onde $\mathrm{N}_{1}$ e $\mathrm{N}_{2}$ são os neurônios da primeira camada escondida e da segunda camada escondida, respectivamente. 



\begin{tabular}{|l|}
\hline V \\
E \\
L \\
O \\
C \\
I \\
D \\
A \\
D \\
E \\
\hline
\end{tabular}
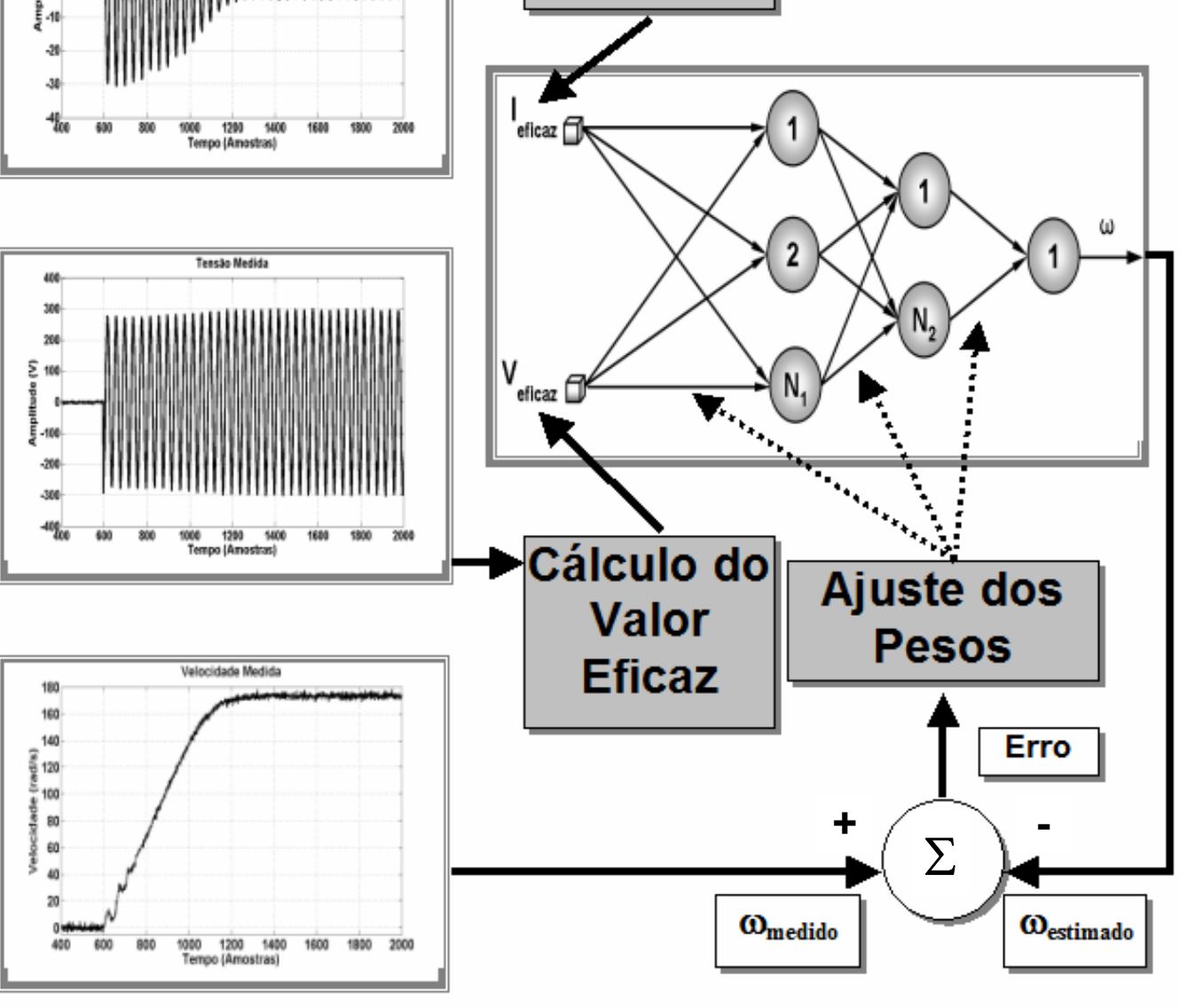

Cálculo do Valor

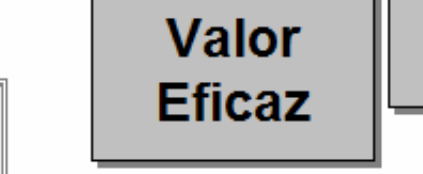

Ajuste dos Pesos

(a)

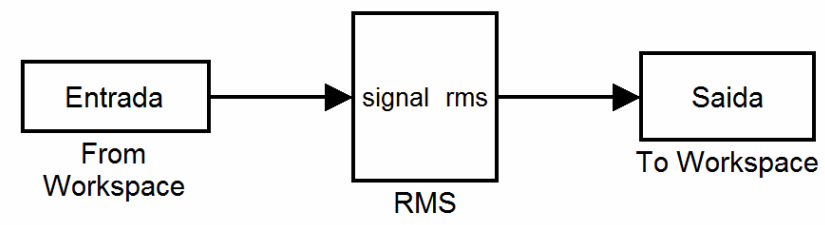

(b)

FIGURA 5.3 - (a) Estrutura de treinamento e teste da RNA e (b) detalhe do bloco para o cálculo do valor eficaz utilizando Matlab/Simulink.

A FIGURA 5.4 apresenta o procedimento de simulação para uma carga com perfil linear. Tal carga apresenta um aumento do conjugado de carga com o incremento da velocidade de forma linear, sendo bastante encontrada em aplicações 
como moinhos de rolos, bombas de pistão e serras para madeira (DIAS E LOBOSCO, 1988). Estabelece-se um conjugado inicial de $5 \%$ do conjugado nominal, simulando assim, o torque inicial exigido da carga para superar as perdas por atrito em mancais e rolamentos numa máquina real (GOEDTEL, 2003).

Quando o conjugado de carga se iguala ao conjugado eletromagnético a máquina entra em regime permanente. A partir deste ponto desaparecem as diferenças entre os perfis de carga e descreve-se o estado apenas como regime permanente enquanto não houver alteração de conjugado no eixo.

As curvas $\mathrm{C}_{1}$ a $\mathrm{C}_{26}$ apresentadas na FIGURA 5.4 representam diferentes valores de carga em diversas situações de operação. A curva $C_{26}$ representa um baixo conjugado em regime permanente e a curva $C_{1}$ um alto conjugado. Estas diferenças de conjugado simulam diversas cargas aplicadas a uma mesma máquina.

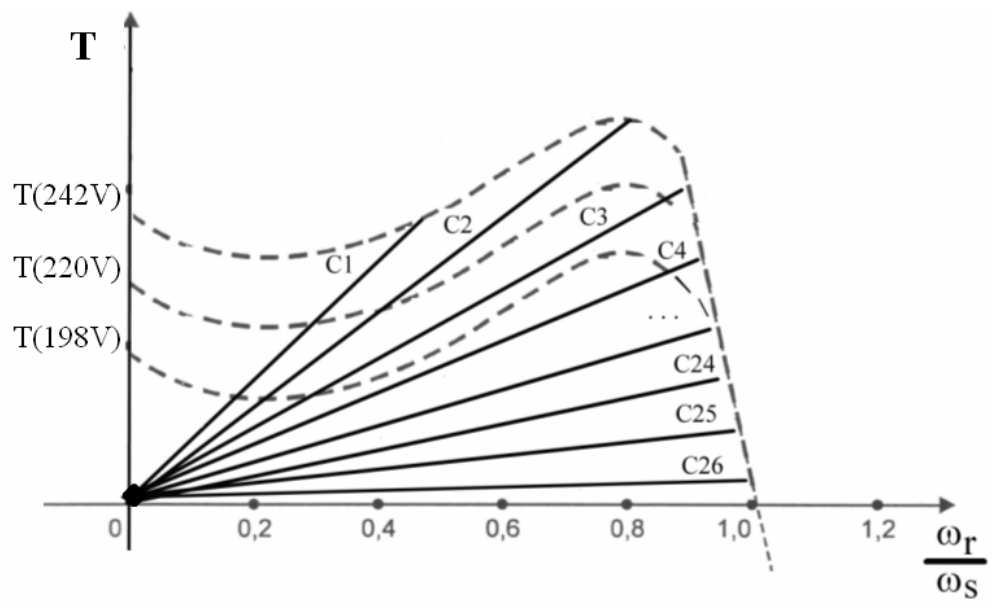

FIGURA 5.4 - Curvas de simulação do MIT as quais representam as diversas situações de carga e a faixa de tensão de operação (NBR7094/1996).

Assume-se neste trabalho uma variação na alimentação do MIT de $-9,09 \%$ a $+9,09 \%$ em relação ao valor nominal. O objetivo da variação de alimentação nos terminais do motor de indução é submeter o mesmo às condições severas em termos de alimentação ou de mau dimensionamento da rede elétrica em ambientes industriais. A faixa de variação está inserida no contexto da norma NBR7094/1996 
que admite uma variação de $-10 \%$ a $+10 \%$. Com isso, tem-se a divisão da estrutura neural que estima a velocidade em cinco faixas distintas (GOEDTEL, 2003). A Tabela 5.2 apresenta a faixa de variação de tensão utilizada neste trabalho.

Uma contribuição deste trabalho em relação a Goedtel (2003) é a inserção de faixas de operação adjacentes no treinamento da estrutura neural. Conforme descrito na Tabela 5.2, nas faixas 2,3 e 4, os limites inferior e superior da faixa de operação é inserido na camada anterior e posterior, respectivamente, em 2 Volts. Tem-se com isso a informação no treinamento da estrutura neural relativo ao limite de cada faixa e os mínimos e máximos das faixas, que se seguem e antecedem.

TABELA 5.2 - Faixas de tensão e índice da estrutura neural.

\begin{tabular}{|c|c|}
\hline Índice da Estrutura & Faixa de Tensão \\
\hline 1 & $200 \ldots 206 \mathrm{~V}$ \\
\hline 2 & $204 \ldots 216 \mathrm{~V}$ \\
\hline 3 & $214 \ldots 226 \mathrm{~V}$ \\
\hline 4 & $224 \ldots 236 \mathrm{~V}$ \\
\hline 5 & $234 \ldots 240 \mathrm{~V}$ \\
\hline
\end{tabular}

A Figura 5.5 apresenta a multi-estrutura neural para estimativa de velocidade em motores de indução trifásicos a partir dos dados de tensão e corrente (I V) coletados na bancada de ensaios. A variável $\omega_{m}$ é a velocidade medida no eixo, a qual é comparada com a velocidade estimada $\left(\omega_{e}\right)$ pela estrutura neural, gerando o sinal de erro $(\varepsilon)$. Várias situações de carga são impostas à máquina de indução através da variação da tensão de campo $(\mathrm{Vc})$ do MCC que dissipa sua energia na resistência R. As estruturas neurais obedecem ao índice apresentado na Tabela 5.2. Ilustra-se a estrutura ativada através das linhas pontilhadas; ou seja, na FIGURA 5.5 a estrutura neural de 214-226V está estimando o valor da velocidade. 


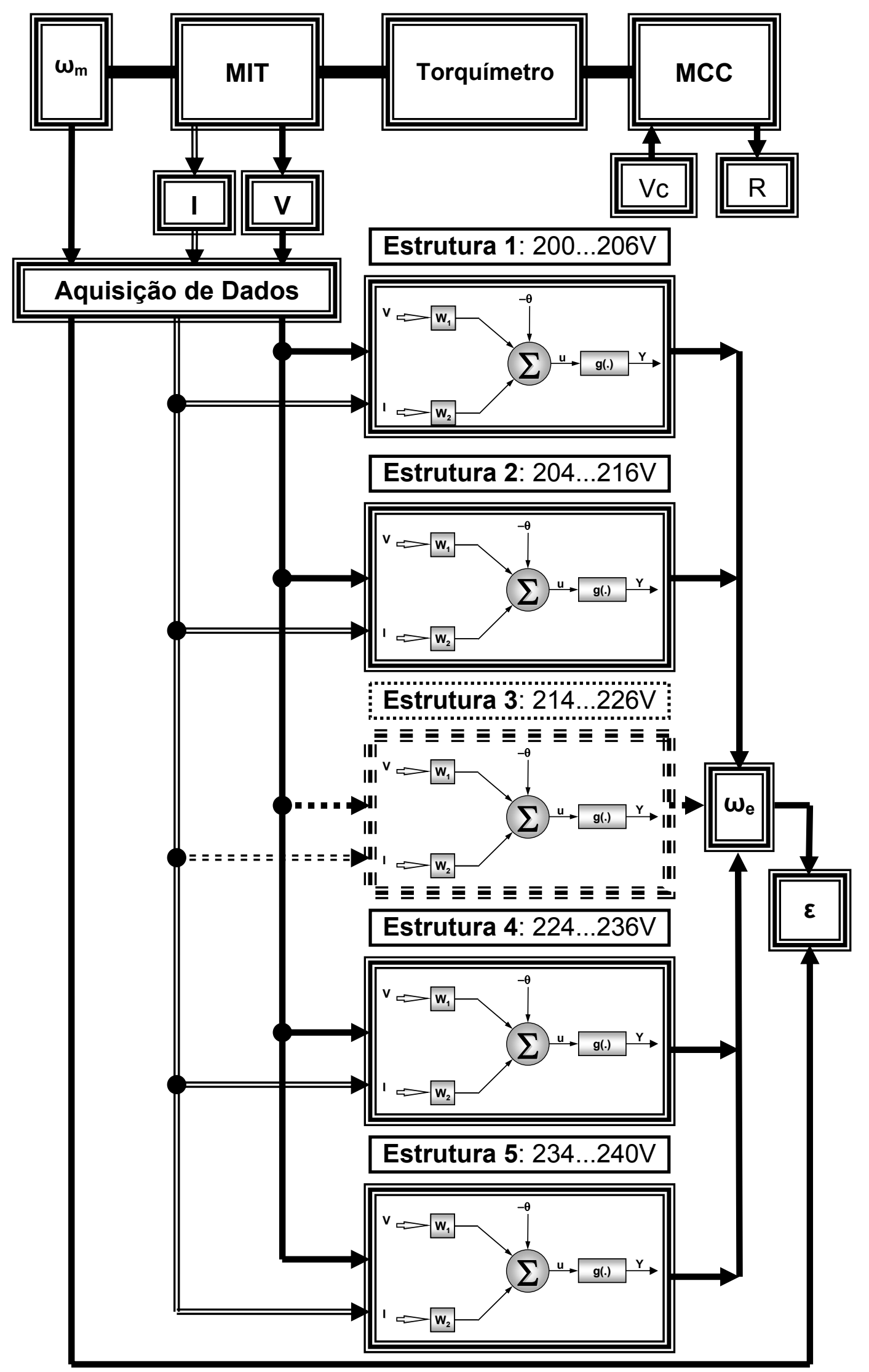

FIGURA 5.5 - Diagrama em blocos do estimador. 
Ainda, a FIGURA 5.5 ilustra as simulações computacionais responsáveis por gerar dados a partir do modelo para treinamento e validação das estruturas neurais. Entretanto, a carga mecância imposta ao modelo do MIT é gerada por um bloco denominado "Conjugado de Carga" ilustrado na FIGURA 5.1.

O bloco "Aquisição de Dados" da FIGURA 5.5 é substituído por blocos Simulink ${ }^{\circledR}$ os quais enviam os dados do ambiente Simulink ${ }^{\circledR}$ para a área de trabalho do Matlab ${ }^{\circledR}$.

\subsubsection{Resultados de Simulação: Validação Cruzada}

Resultados de simulação são apresentados nesta Seção. Deve ser ressaltado que os dados de teste (tensão e corrente) não participaram do processo de treinamento da estrutura neural. A saída da rede apresenta a estimativa de velocidade no eixo do MIT. Os resultados de simulação demonstram a capacidade da estrutura neural em aprender com os padrões de treinamento e generalizar soluções. O tempo de simulação é de 1s e reproduz o comportamento da máquina do transitório ao regime permanente.

Os conjugados de carga em regime permanente foram divididos em três valores; a saber: $1 \mathrm{Nm}, 3 \mathrm{Nm}$ e $5 \mathrm{Nm}$. Desta forma, em termos computacionais, simula-se a operação de motores superdimensionados e subdimensionados em operação nos diversos setores produtivos. Cabe ressaltar que o conjugado nominal do motor em questão é de 4,1 Nm, conforme descrito na Tabela 5.1.

A FIGURA 5.6 apresenta os resultados de generalização da RNA treinada na primeira faixa de tensão (descrito na Tabela 5.2) e submetido a um conjugado resistente de $3 \mathrm{Nm}$. A FIGURA 5.7 ilustra os resultados de generalização considerando a faixa de variação de 200V-206V e um conjugado de carga de $5 \mathrm{Nm}$ em regime permanente. 


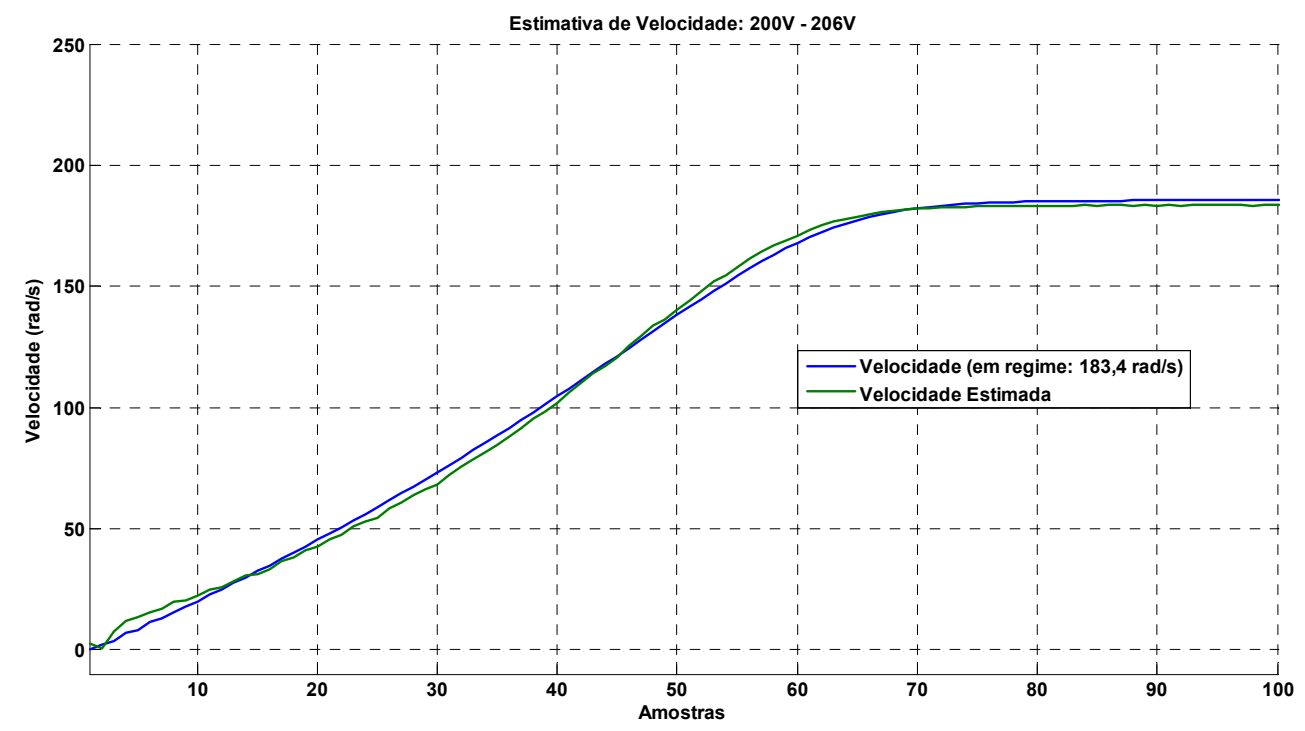

FIGURA 5.6 - Estimativa de velocidade na faixa 1 (200V-206V) e $1 \mathrm{Nm}$ de conjugado de carga em regime permanente.

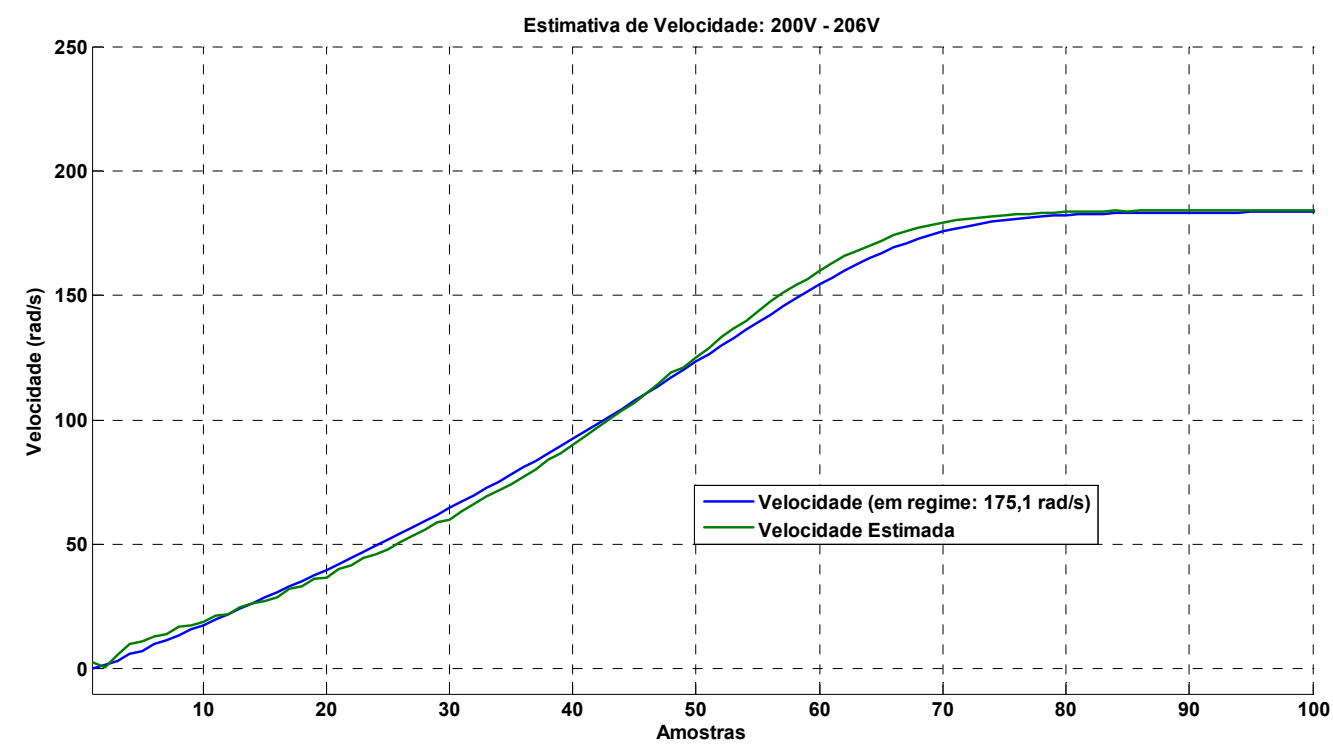

FIGURA 5.7 - Estimativa de velocidade na faixa 1 (200V-206V) e 5 Nm de conjugado de carga em regime permanente.

A FIGURA 5.8 ilustra os resultados de generalização da estrutura neural treinada na segunda faixa de tensão (204-216V) e submetido a um conjugado resistente de $1 \mathrm{Nm}$. A FIGURA 5.9 ilustra os resultados de generalização 
considerando a mesma faixa de operação da FIGURA 5.8 e um conjugado de carga de $5 \mathrm{Nm}$ em regime permanente.

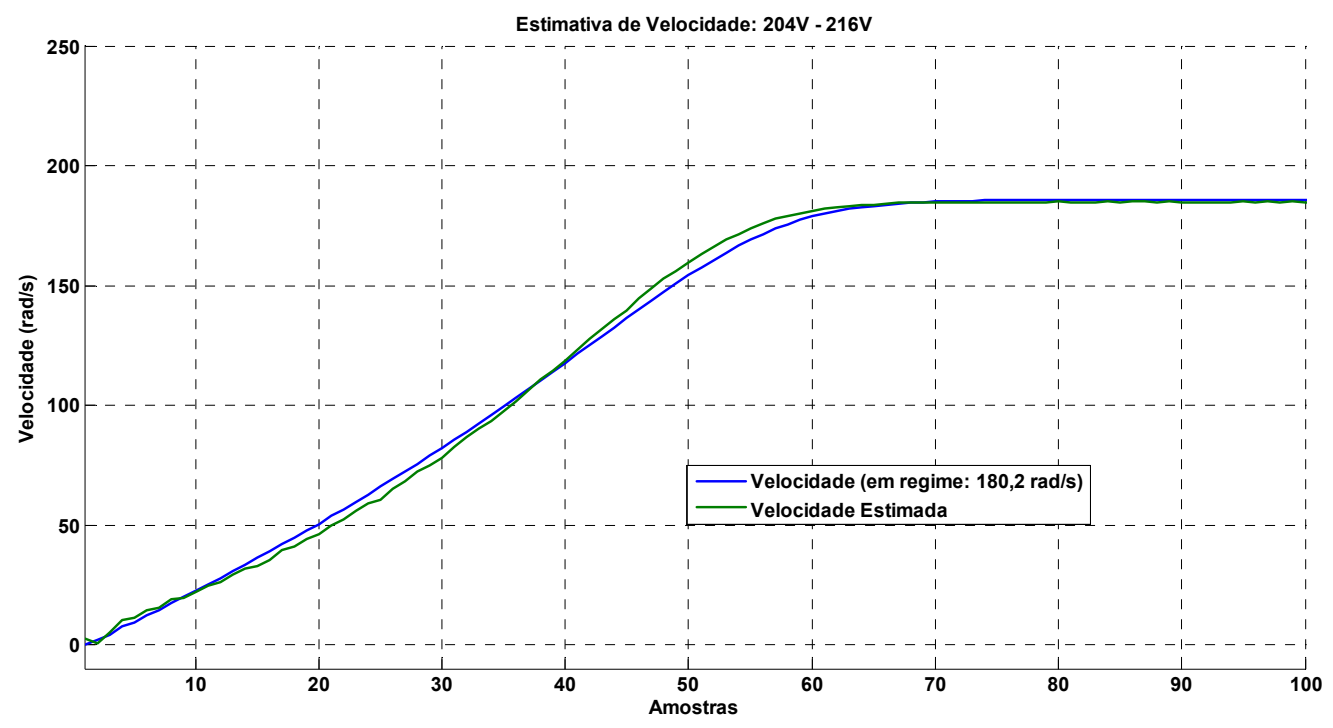

FIGURA 5.8 - Estimativa de velocidade na faixa 2 (204V-216V) e $3 \mathrm{Nm}$ de conjugado de carga em regime permanente.

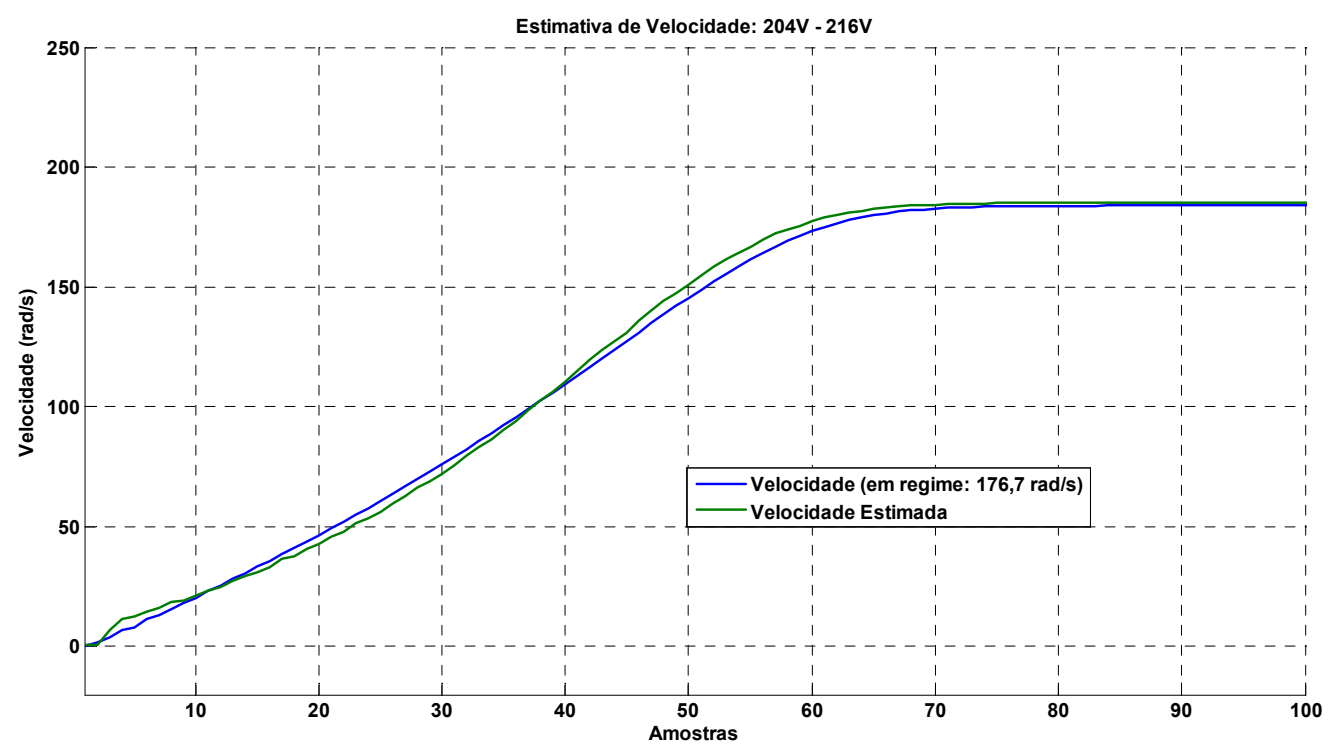

FIGURA 5.9 - Estimativa de velocidade na faixa 2 (204V-216V) e $5 \mathrm{Nm}$ de conjugado de carga em regime permanente.

As FIGURAS 5.10 e FIGURA 5.11 mostram os resultados de generalização da estrutura neural treinada na terceira faixa de tensão (214-226V). Na FIGURA 5.10 o MIT foi submetido a um conjugado resistente de $5 \mathrm{Nm}$ e, na FIGURA 5.10, o 
conjugado resistente, em regime permanente, foi de $3 \mathrm{Nm}$. Deve ser ressaltado que esta faixa de operação é de grande interesse, pois se encontra no entorno da tensão nominal da máquina de indução; a saber, $220 \mathrm{~V}$.

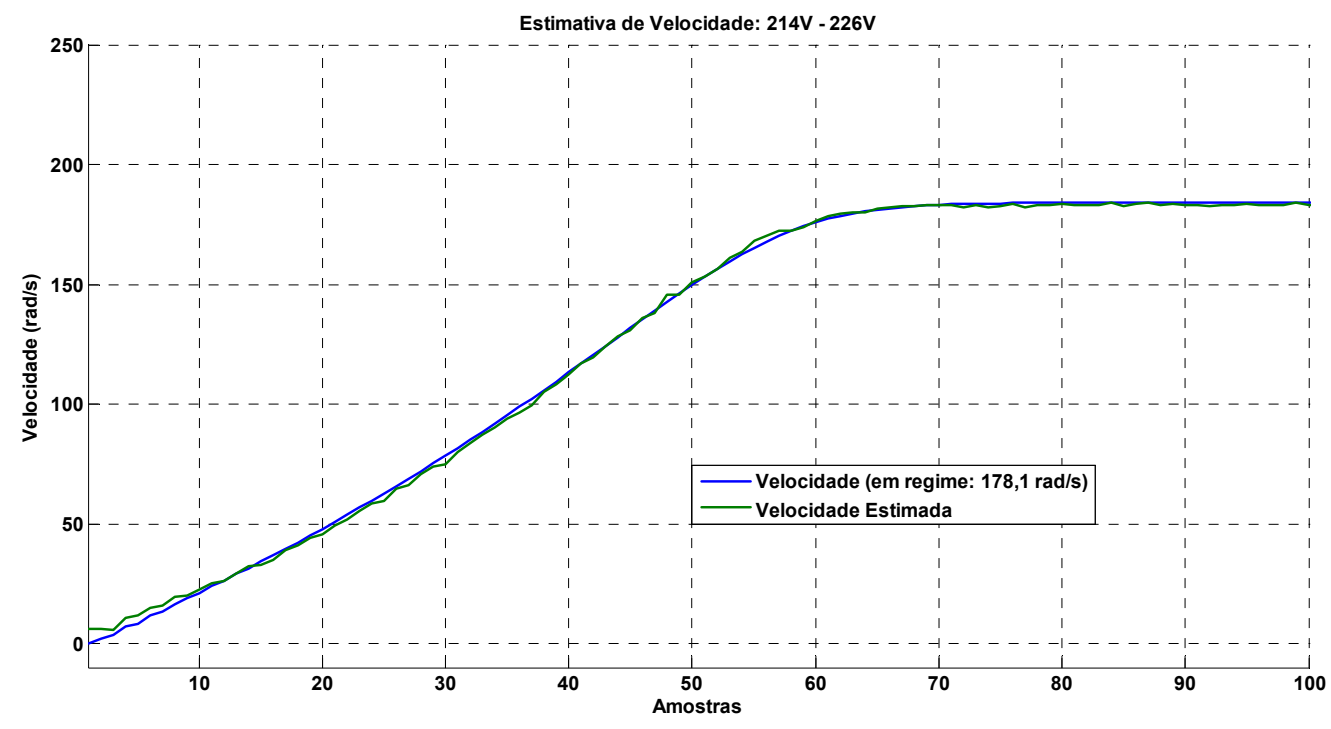

FIGURA 5.10 - Estimativa de velocidade na faixa 3 (214V-224V) e 5 Nm de conjugado de carga em regime permanente.

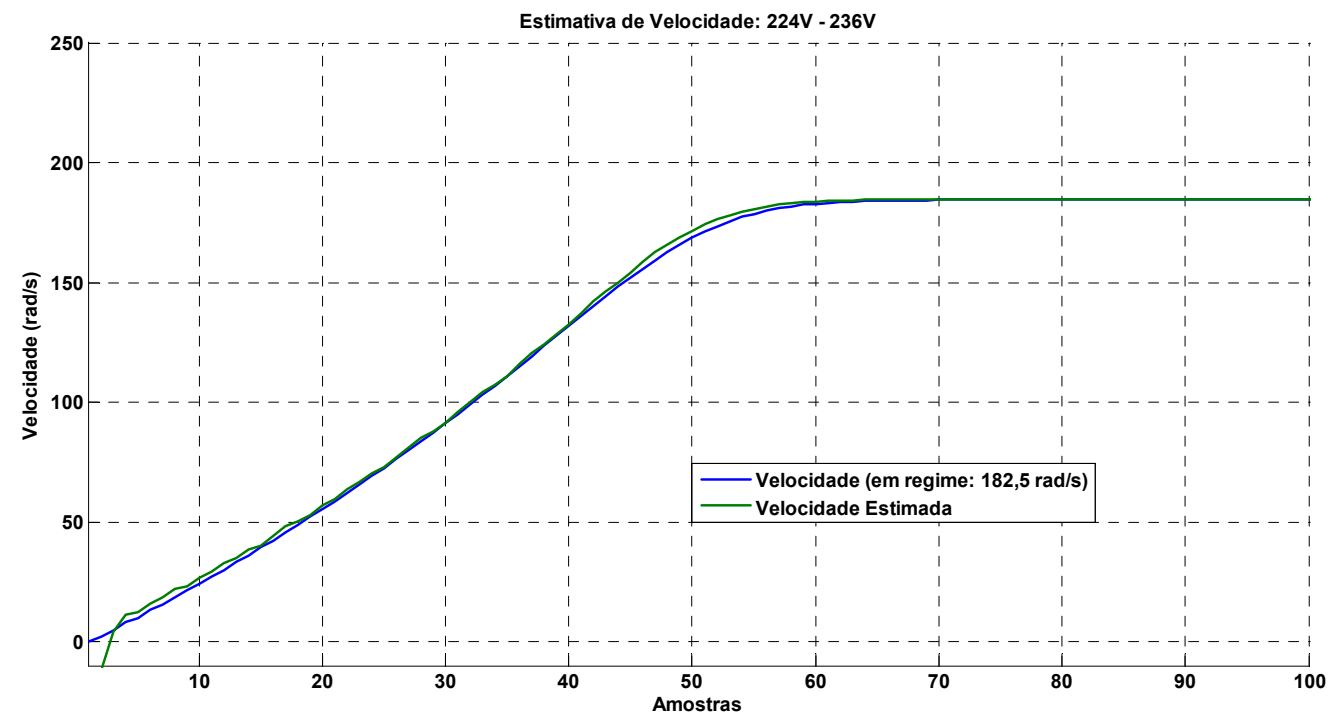

FIGURA 5.11 - Estimativa de velocidade na faixa 3 (214V-226V) e 3 Nm de conjugado de carga em regime permanente.

A quarta faixa de operação, descrito na Tabela 5.2, apresenta tensão de operação superior à tensão nominal. Em específico, nesta faixa de operação, a 
tensão varia de 224 V a 236 V. A FIGURA 5.12 ilustra o resultado de generalização na estimativa de velocidade de um MIT submetido a um conjugado de carga de 5 Nm. Na FIGURA 5.13, dentro da mesma faixa de tensão, o conjugado de carga imposto ao MIT é de $3 \mathrm{Nm}$.

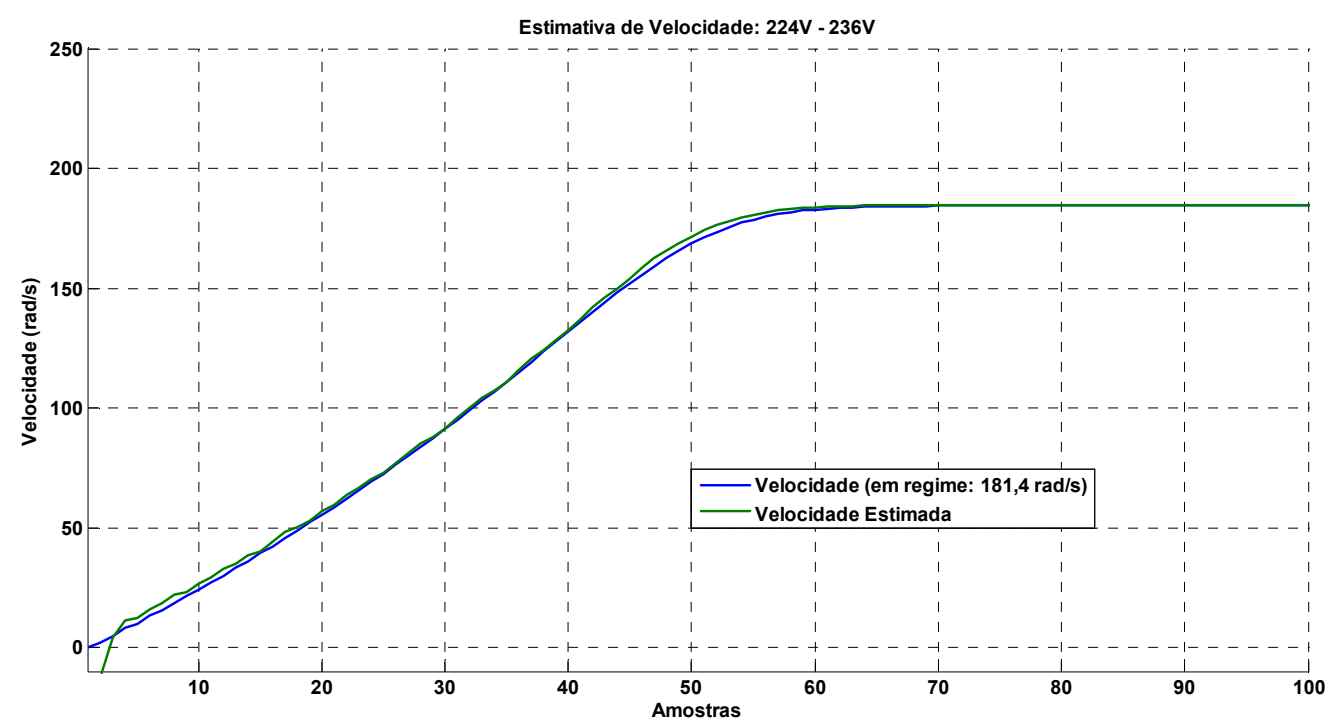

FIGURA 5.12 - Estimativa de velocidade na faixa 4 (224V-236V) e $5 \mathrm{Nm}$ de conjugado de carga em regime permanente.

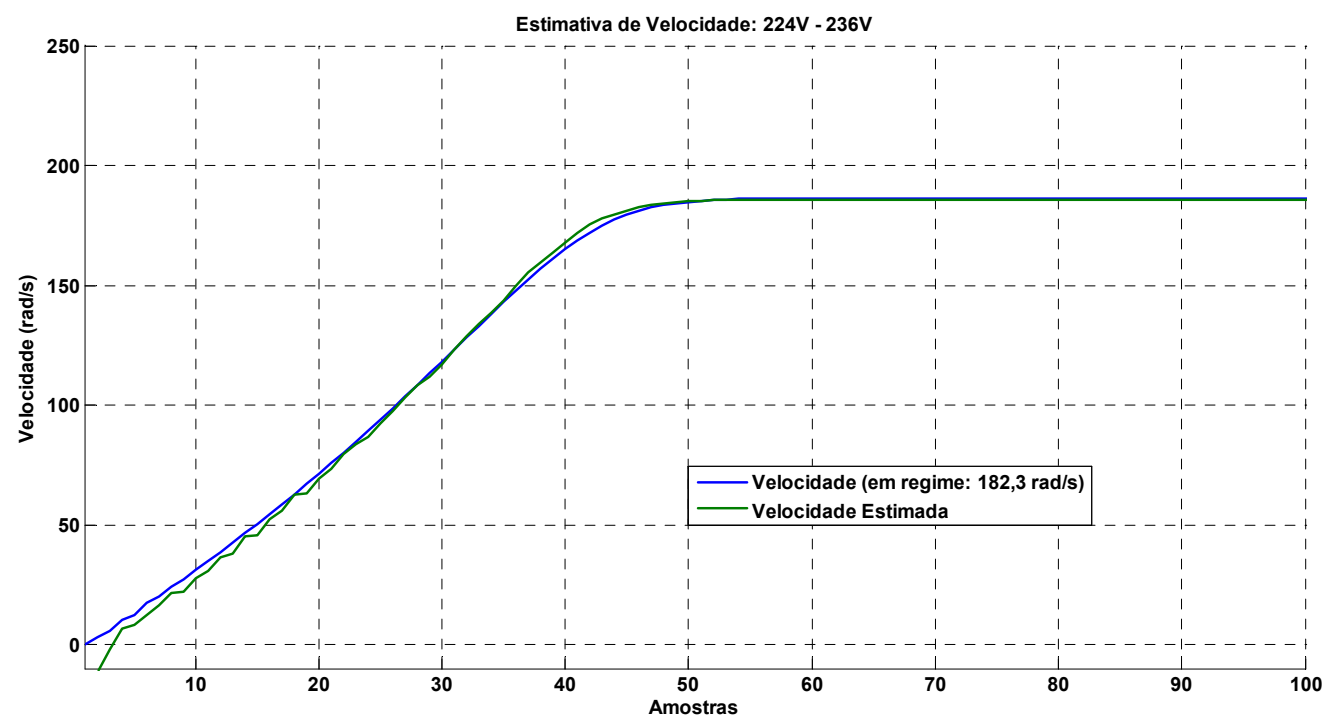

FIGURA 5.13 - Estimativa de velocidade na faixa 4 (224V-236V) e $3 \mathrm{Nm}$ de conjugado de carga em regime permanente. 
A quinta faixa de operação, conforme proposta deste trabalho, apresenta tensão de operação entre $234 \mathrm{~V}$ e 240V. A FIGURA 5.15 ilustra o resultado de generalização na estimativa de velocidade de um MIT com carga de $1 \mathrm{Nm}$ em regime permanente. Na FIGURA 5.14 o conjugado de carga imposto ao MIT é de 3 $\mathrm{Nm}$.

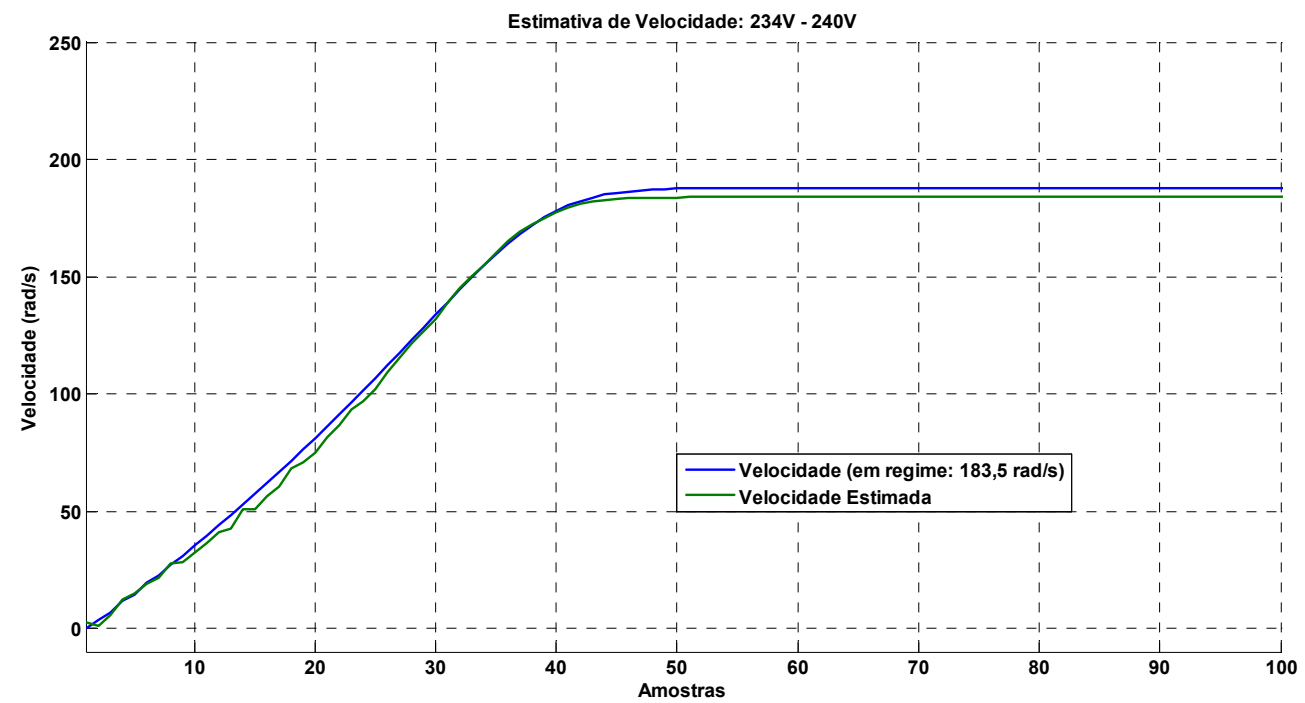

FIGURA 5.14 - Estimativa de velocidade na faixa 5 (234V-240V) e $1 \mathrm{Nm}$ de conjugado de carga em regime permanente.

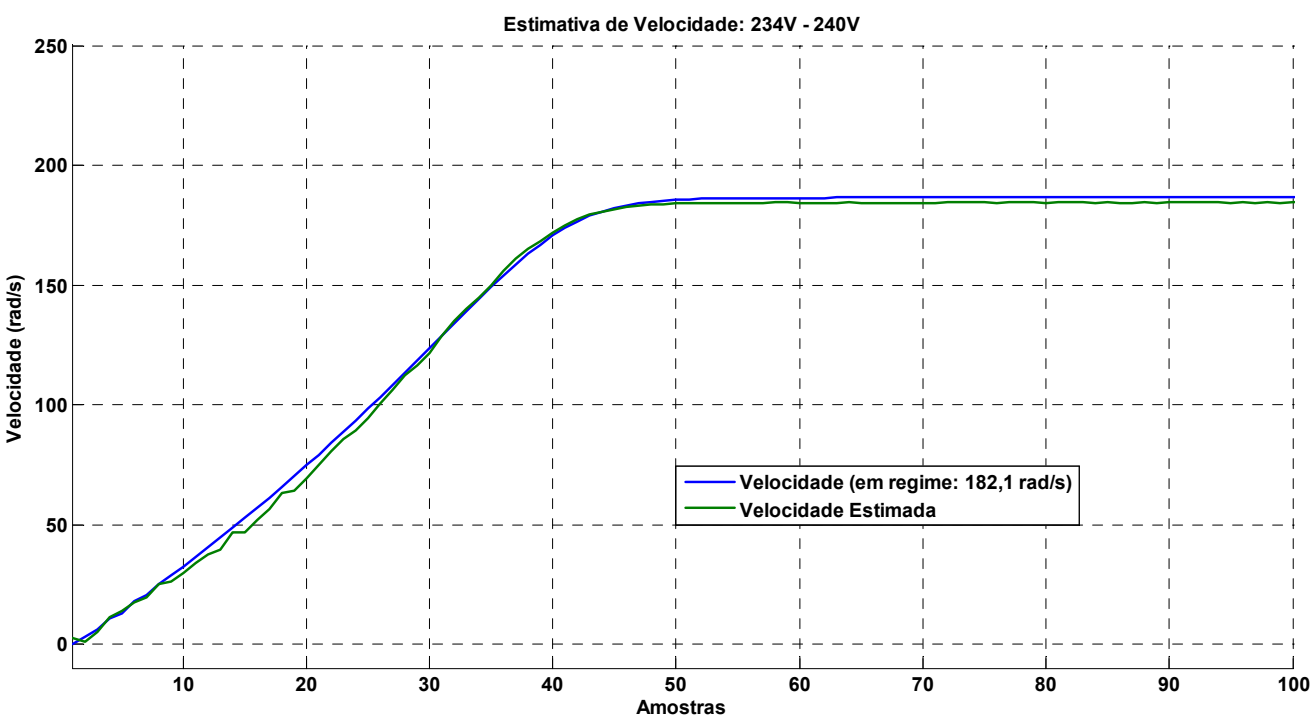

FIGURA 5.15 - Estimativa de velocidade na faixa 5 (234V-240V) e $3 \mathrm{Nm}$ de conjugado de carga em regime permanente. 
A Tabela 5.3 apresenta o erro médio e o desvio padrão do valor simulado da velocidade e o valor estimado pela estrutura neural proposta neste trabalho.

TABELA 5.3 - Erro médio e desvio padrão entre as velocidades real e estimada no eixo do motor de indução trifásico.

\begin{tabular}{|c|c|c|}
\hline Figura & Erro Médio (\%) & Desvio Padrão (\%) \\
\hline FIGURA 5.6 & 4,35 & 9,34 \\
\hline FIGURA 5.7 & 5,75 & 12,34 \\
\hline FIGURA 5.8 & 6,02 & 17,14 \\
\hline FIGURA 5.9 & 4,83 & 12,58 \\
\hline FIGURA 5.10 & 5,11 & 21,19 \\
\hline FIGURA 5.11 & 3,11 & 13,10 \\
\hline FIGURA 5.12 & 7,99 & 63,10 \\
\hline FIGURA 5.13 & 9,12 & 53,54 \\
\hline FIGURA 5.14 & 3,41 & 7,32 \\
\hline FIGURA 5.15 & 3,10 & 6,70 \\
\hline
\end{tabular}

Por inspeção das Figuras 5.6 à 5.15 é possível verificar que o maior desvio entre o valor real e estimado se encontra nas 5 primeiras amostras; ou seja, nos primeiros 50 milisegundos após a partida do motor. No sentido de investigar a influência dos primeiros três ciclos de senóide da alimentação do motor em relação ao erro de estimativa, o cálculo do erro e desvio padrão são refeitos e apresentados na Tabela 5.4 , desconsiderando para tanto as 5 primeiras amostras.

Os resultados de simulação apresentados nesta seção confirmam o uso das redes neurais artificiais para estimar a velocidade no eixo dos motores de indução, a partir de variáveis primárias como tensão e corrente, quando submetido a diferentes cargas e uma ampla faixa de tensão. A estimativa de velocidade, gerada a partir de dados de simulação do modelo dinâmico do MIT, utilizou 5 neurônios na primeira camada escondida, 10 neurônios na segunda camada escondida e um neurônio na camada de saída. A função de ativação da primeira camada escondida e da segunda camada escondida é a tangente hiperbólica enquanto que a da camada de saída é a função linear. 
TABELA 5.4 - Erro médio e desvio padrão recalculado entre as velocidades real e estimada no eixo do motor de indução trifásico.

\begin{tabular}{|c|c|c|}
\hline Figura & Erro Médio (\%) & Desvio Padrão (\%) \\
\hline FIGURA 5.6 & 2,64 & 3,21 \\
\hline FIGURA 5.7 & 3,46 & 4,83 \\
\hline FIGURA 5.8 & 2,83 & 5,24 \\
\hline FIGURA 5.9 & 2,46 & 3,58 \\
\hline FIGURA 5.10 & 1,89 & 3,70 \\
\hline FIGURA 5.11 & 1,45 & 1,60 \\
\hline FIGURA 5.12 & 1,02 & 1,66 \\
\hline FIGURA 5.13 & 1,97 & 4,38 \\
\hline FIGURA 5.14 & 2,58 & 2,55 \\
\hline FIGURA 5.15 & 1,99 & 2,54 \\
\hline
\end{tabular}

A Tabela 5.5 apresenta os diversos parâmetros usados no treinamento da rede neural proposta.

TABELA 5.5 - Parâmetros da rede neural artificial proposta.

\begin{tabular}{|c|c|}
\hline Arquitetura da rede & Perceptron multicamada \\
\hline Tipo de treinamento & Supervisionado \\
\hline Número de Camadas & 3 \\
\hline Neurônios da 1 ${ }^{\text {a }}$ camada escondida & 5 \\
\hline Neurônios da 2 ${ }^{\text {a }}$ camada escondida & 10 \\
\hline Algoritmo de treinamento & Levenberg-Marquardt backpropagation \\
\hline Taxa de Aprendizado & $1.10^{-3}$ \\
\hline Épocas & 2000 \\
\hline Erro quadrático requerido & $1.10^{-3}$ \\
\hline $\begin{array}{c}\text { Função de ativação das camadas } \\
\text { intermediárias }\end{array}$ & Tangente hiperbólica \\
\hline $\begin{array}{c}\text { Função de ativação da camada de } \\
\text { saída }\end{array}$ & Linear \\
\hline $\begin{array}{c}\text { Quantidade de amostras de } \\
\text { treinamento }\end{array}$ & 5 curvas -100 pontos por curva \\
\hline Quantidade de amostras de teste & \\
\hline
\end{tabular}

O próximo passo da investigação consiste em apresentar dados experimentais à estrutura neural que foi treinada e validada apenas com dados de simulação. 


\subsubsection{Resultados Experimentais}

Os resultados de simulação confirmam o uso das RNA para estimar velocidade dos motores de indução. A investigação deste trabalho segue no sentido de apresentar dados experimentais a uma estrutura treinada com dados de simulação.

As FIGURAS 5.16 e 5.17 mostram a bancada de testes e os sensores de tensão e corrente utilizados para monitorar o gerador CC e o painel de comando, respectivamente.

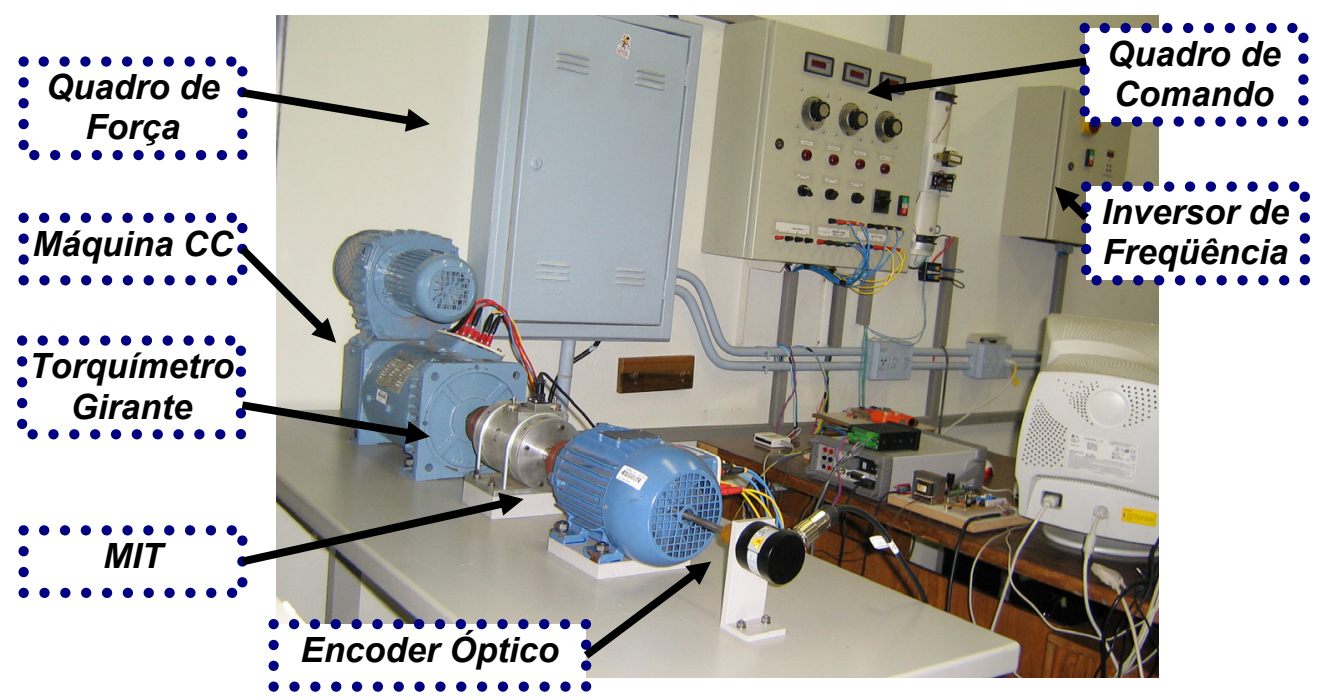

FIGURA 5.16 - Estrutura de ensaios.

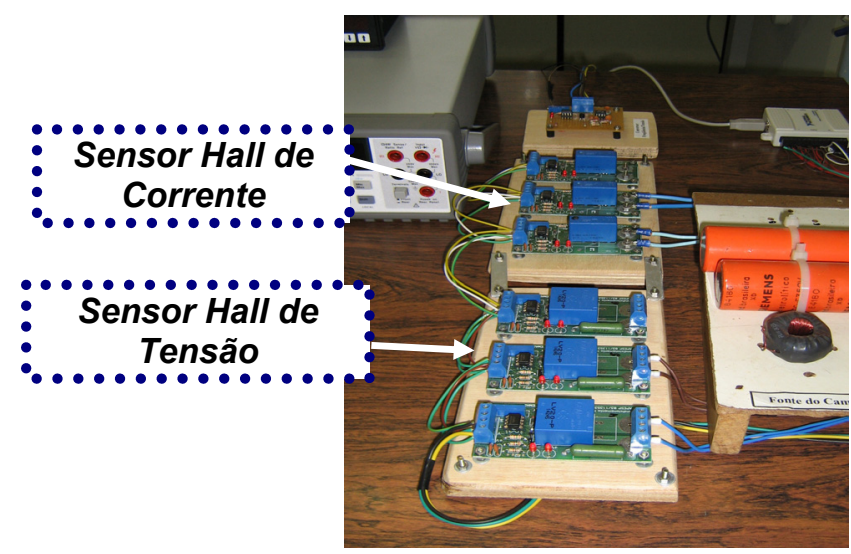

FIGURA 5.17 - Sensores Hall de corrente e tensão da máquina CC.

Os detalhes construtivos e de condicionamento de sinal são apresentados na Seção 4 deste trabalho. Os dados coletados através da placa de aquisição de 
dados são transferidos ao ambiente Matlab/Simulink através de manipulação de arquivos. O valor eficaz de tensão e corrente são calculados através dos blocos Simulink.

\subsubsection{Resultados da Bi-Validação Cruzada}

Os processos de validação cruzada (crossvalidation), aplicados à estimativa de parâmetros em máquinas elétricas, utilizam a mesma origem dos dados de treinamento. Assim, se os dados de treinamento da estrutura neural são obtidos por simulação computacional, então o processo de validação cruzada usa também dados simulados. Por outro lado, se os dados de treinamento são de origem experimental, então o processo de validação ocorre com dados igualmente experimentais. O método alternativo proposto neste trabalho, chamado de bivalidação cruzada, considera dados de simulação no treinamento e dados experimentais no teste de generalização.

Os dados experimentais coletados na estrutura de ensaios são agora apresentados à estrutura neural para as diversas faixas de tensão explicitadas na Tabela 5.2. A Figura 5.18 ilustra os resultados de generalização da estrutura neural com dados experimentais treinada para a faixa de tensão de $200 \mathrm{~V}$ a $206 \mathrm{~V}$ com dados provenientes da modelagem do MIT.

A partir de uma inspeção visual na FIGURA 5.18, observa-se que o erro no regime transitório é muito elevado, sendo, entretanto, muito baixo no regime permanente. Este padrão de erro no regime transitório e regime permanente se repete em outras faixas de tensão apresentadas na Tabela 5.2.

O transitório da tensão de alimentação, o pico de corrente na partida e a possível saturação do núcleo da máquina de indução real, além de ruídos de medição, são fatores que contribuem para o desvio encontrado no regime transitório 
apresentado na FIGURA 5.18. A FIGURA 5.19 apresenta as principais causas desta diferença.

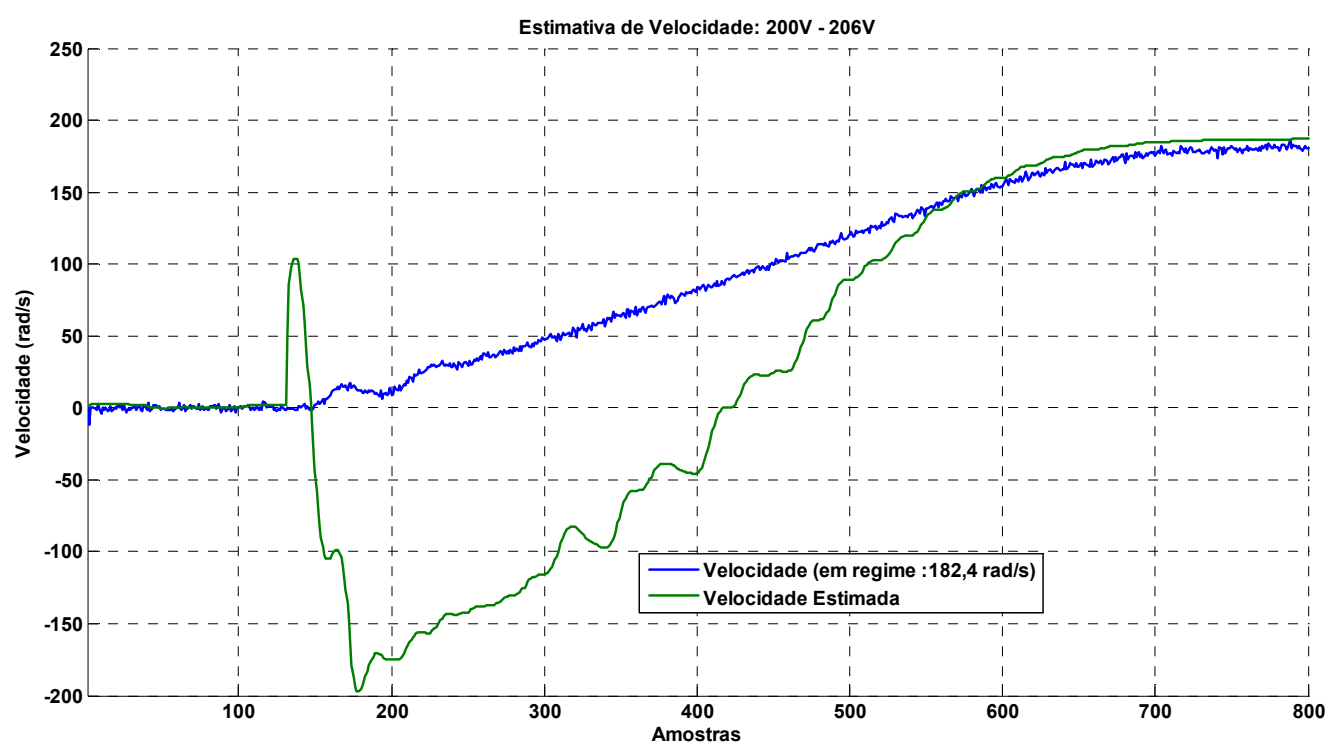

FIGURA 5.18 - Estimativa de velocidade na faixa 1 (200V-206V) e 2,5 Nm de conjugado de carga em regime permanente através do processo de bi-validação.

É possível inferir, a partir dos resultados experimentais, que o processo de bi-validação apresentado neste trabalho é válido na estimativa de velocidade do MIT em situações de regime permanente. As redes neurais artificiais são capazes de generalizar soluções a partir do aprendizado com o meio, estabelecendo uma relação entrada-saída. No caso do modelo do MIT, utilizado para gerar os padrões de treinamento, foi considerado um afundamento de tensão de $2 \%$ no instante da partida (conforme GOEDTEL, 2003). Entretanto, enquanto foi medido, durante o transitório, $5 \%$ de afundamento da tensão eficaz. As perdas por atrito e ventilação não foram também consideradas na modelagem da máquina de indução. Também deve ser mencionado que as não linearidades como saturação eletromagnética e efeito pelicular não foram consideradas na geração dos dados simulados. 


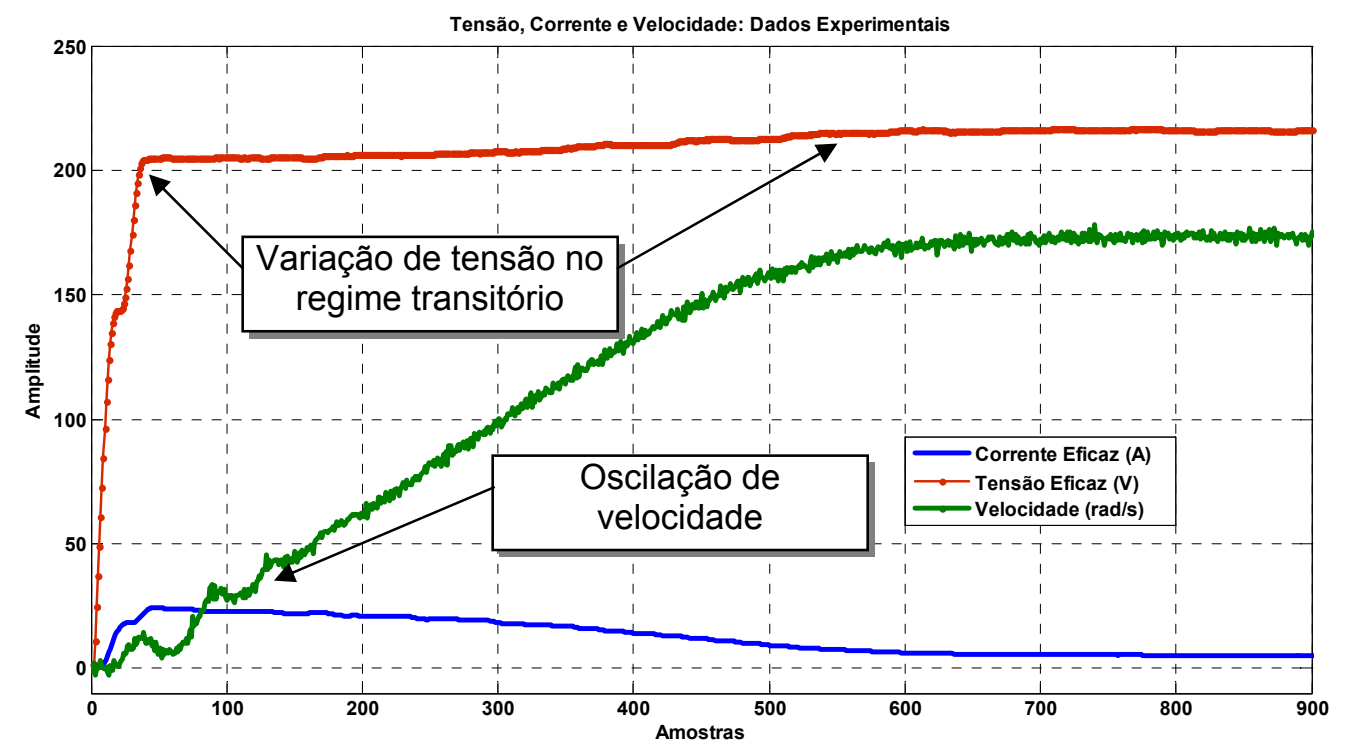

FIGURA 5.19 - Medidas de tensão, corrente e velocidade.

No sentido de aprimorar o processo de pré-validação e pós-validação proposto neste trabalho, onde os dados de treinamento são gerados a partir do modelo linear do MIT enquanto o segundo processo de validação é realizado com dados experimentais, propõe-se o processo de bi-validação modificado.

\subsubsection{O Processo de Bi-Validação Cruzada Modificado}

Nesta tese é proposto um método de bi-validação cruzada onde dados experimentais foram coletados e apresentados à RNA para verificar sua resposta de generalização quando treinada apenas com dados de simulação. Os valores de velocidade estimados e desejados são muito próximos em regime permanente, mas divergem em regime transitório.

Desta forma, no sentido de melhorar o desempenho do estimador em regime transitório, propõe-se uma modificação no processo de bi-validação cruzada; qual seja, inserir dados experimentais aos dados gerados através de simulação no processo de re-treinamento da RNA (sem alteração da estrutura), conforme faixa de 
operação descrita na Tabela 5.2. Com isso fica implícito nos pesos da estrutura neural a dinâmica do sistema no qual o estimador deve atuar.

O re-treinamento da estrutura neural, para cada faixa de operação descrito na Tabela 5.2, utilizou 10 conjuntos de dados de treinamento, sendo 8 conjuntos gerados a partir da modelagem do MIT e 2 conjuntos medidos experimentalmente. Cada conjunto representa o MIT da partida ao regime permanente.

A FIGURA 5.20 apresenta o resultado de generalização relativo à primeira faixa de operação, onde o MIT é submetido a um conjugado de carga de 2,5 Nm em regime permanente. Na FIGURA 5.21 é apresentado o resultado de generalização da estrutura neural proposta neste trabalho operando na faixa de $200 \mathrm{~V}$ a $206 \mathrm{~V}$.

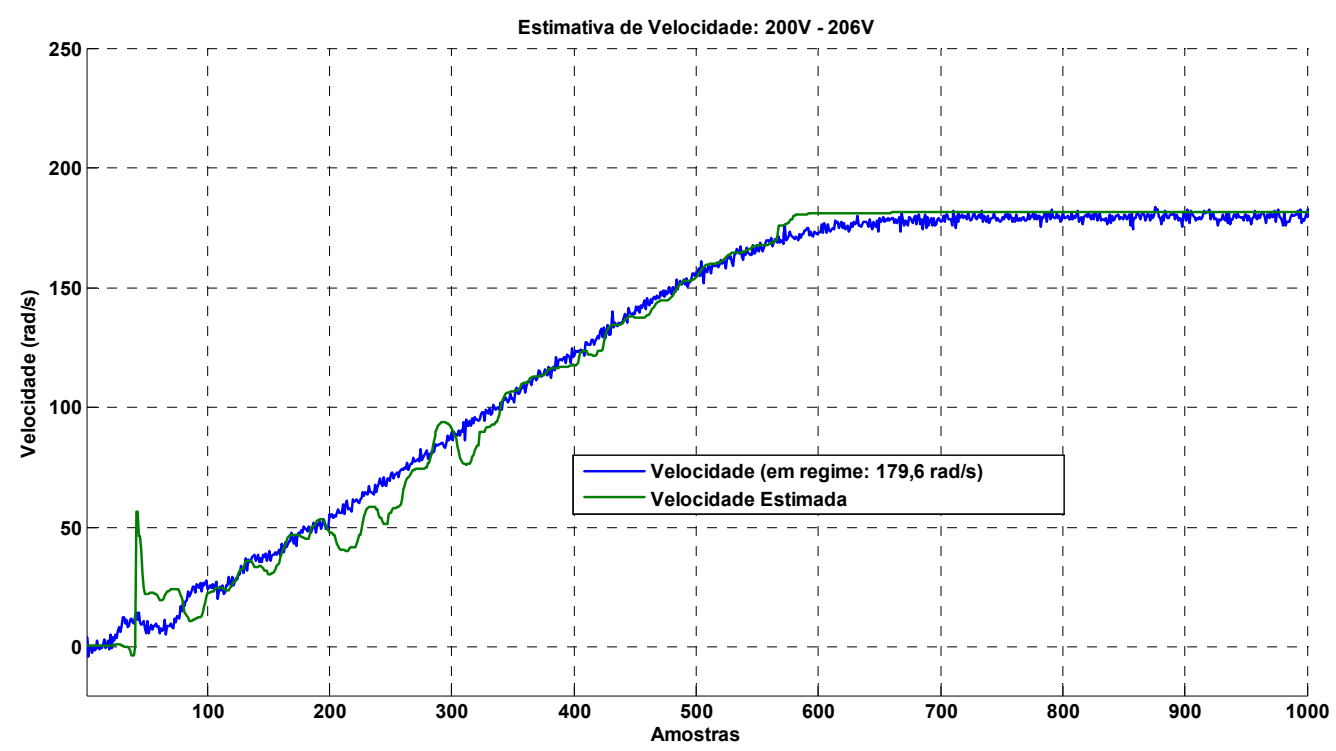

FIGURA 5.20 - Estimativa de velocidade na faixa 1 (200V-206V) e 2,5 Nm de conjugado de carga em regime permanente através do processo de bi-validação modificado. 


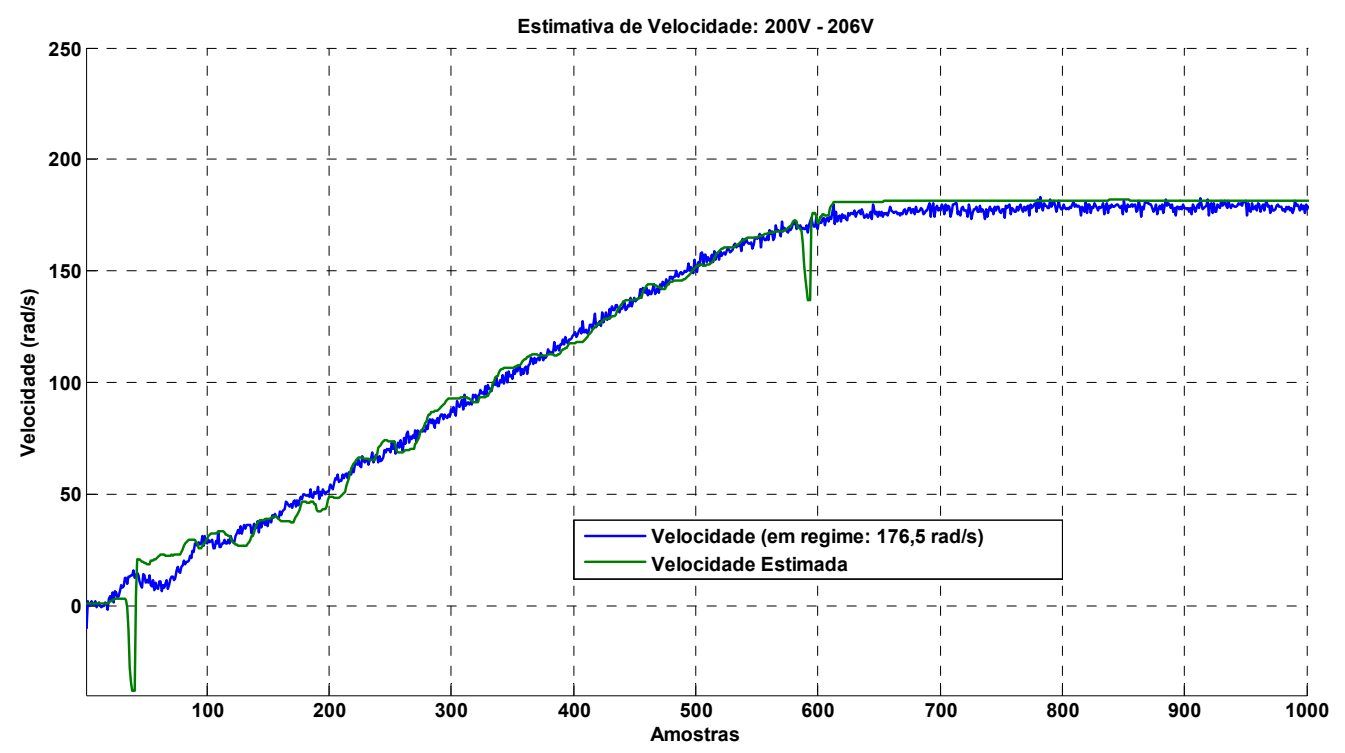

FIGURA 5.21 - Estimativa de velocidade na faixa 1 (200V-206V) e $5 \mathrm{Nm}$ de conjugado de carga em regime permanente através do processo de bi-validação modificado.

A FIGURA 5.22 apresenta os resultados de generalização para a estimativa de velocidade relativos à segunda faixa de operação $(204 \mathrm{~V}$ a $216 \mathrm{~V})$ e $3 \mathrm{Nm}$ de conjugado de carga em regime permanente. A FIGURA 5.23 a estrutura neural estima a velocidade no eixo do MIT, através de medidas primárias de tensão e corrente, quando aplicado ao seu eixo um conjugado de carga de $5 \mathrm{Nm}$.

Nas FIGURA 5.24 e FIGURA 5.25 são apresentados os resultados de generalização da RNA para a faixa de operação 3; ou seja, entre $214 \mathrm{~V}$ e $226 \mathrm{~V}$ quando submetidos ao conjugado de carga de $1 \mathrm{Nm}$ e 3,8 $\mathrm{Nm}$.

A FIGURA 5.26 e FIGURA 5.27 apresentam os resultados de generalização para a faixa 4 de operação; qual seja, $224 \mathrm{~V}$ a $236 \mathrm{~V}$. Nos resultados experimentais ilustrados na FIGURA 5.26 o conjugado de carga é de $5,5 \mathrm{Nm}$ enquanto que na FIGURA 5.27 de 3,5 Nm. 


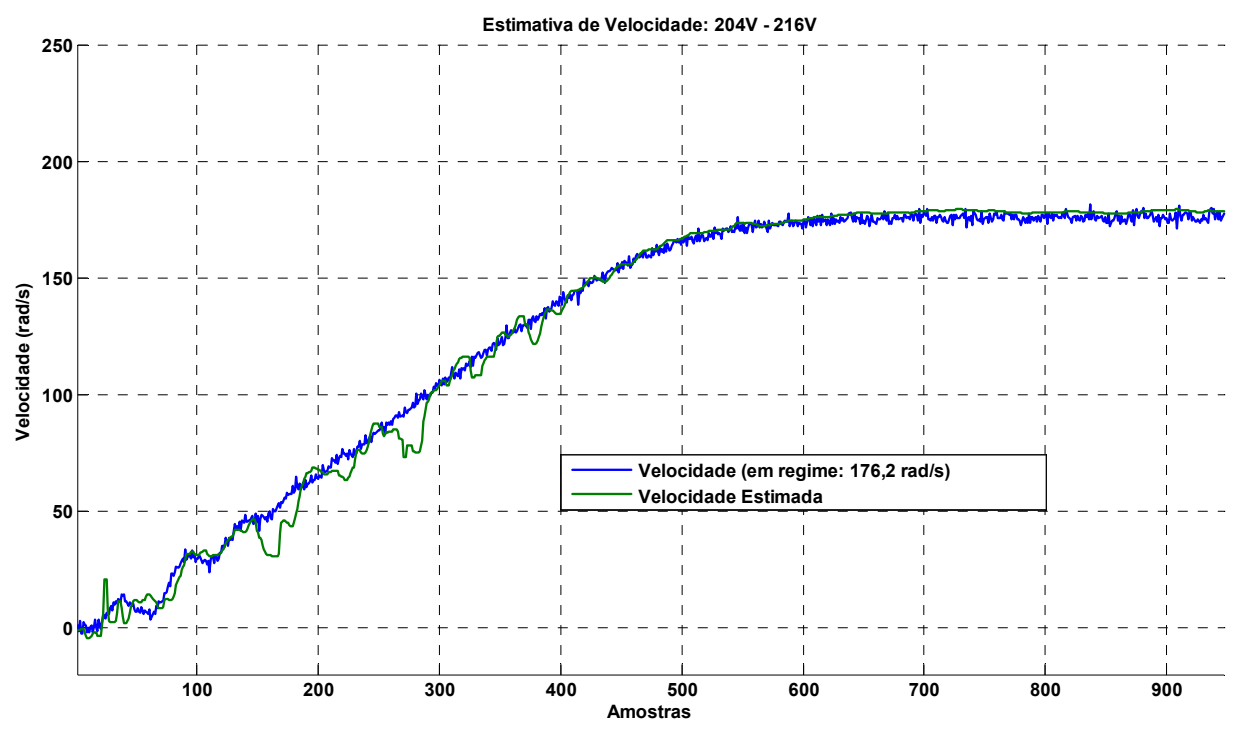

FIGURA 5.22 - Estimativa de velocidade na faixa 2 (204V-216V) e 3 Nm de conjugado de carga em regime permanente através do processo de bivalidação modificado.

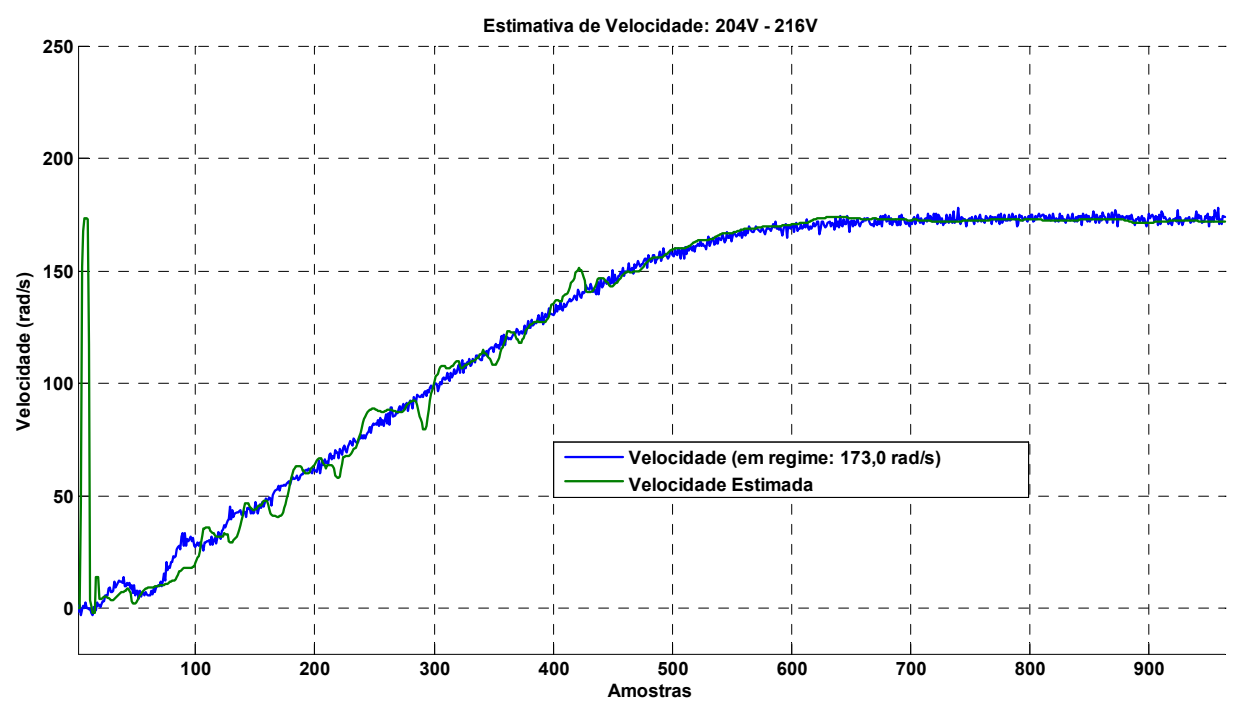

FIGURA 5.23 - Estimativa de velocidade na faixa 2 (204V-216V) e 5 Nm de conjugado de carga em regime permanente através do processo de bivalidação modificado. 


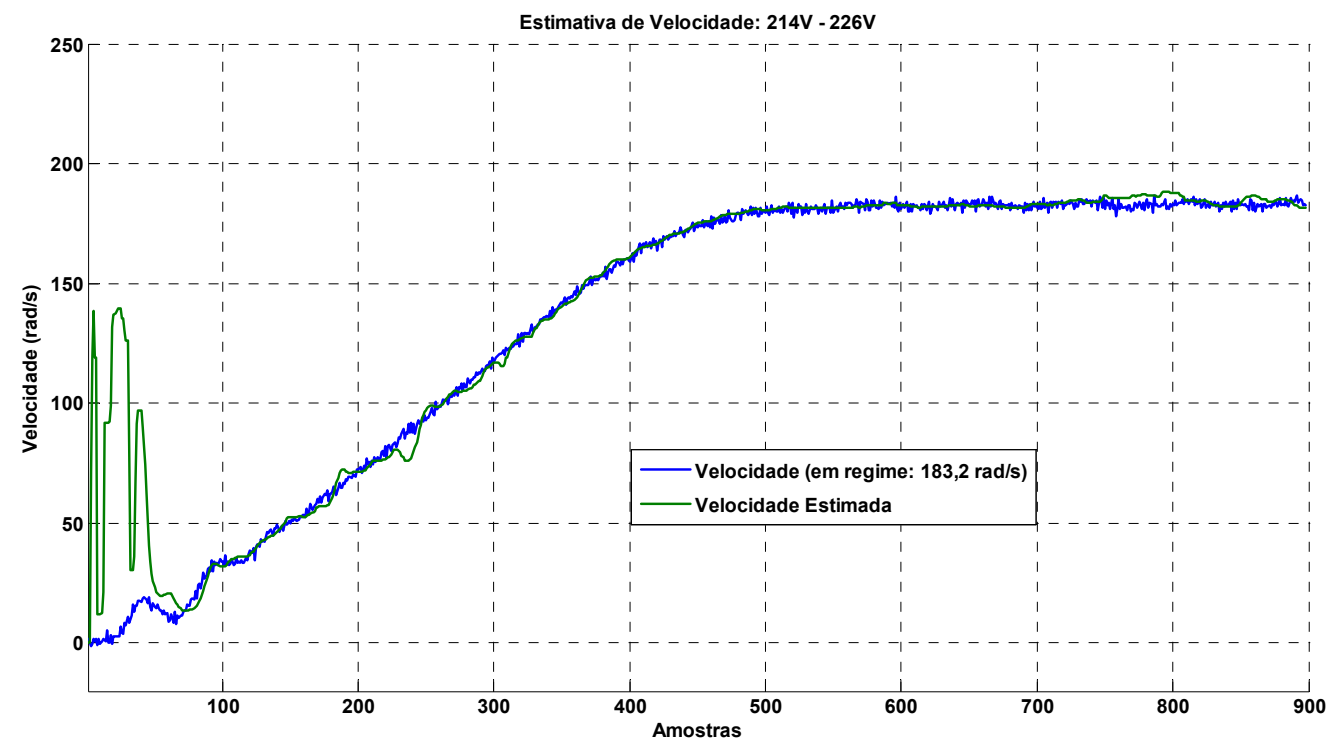

FIGURA 5.24 - Estimativa de velocidade na faixa 3 (214V-226V) e $1 \mathrm{Nm}$ de conjugado de carga em regime permanente através do processo de bi-validação modificado.

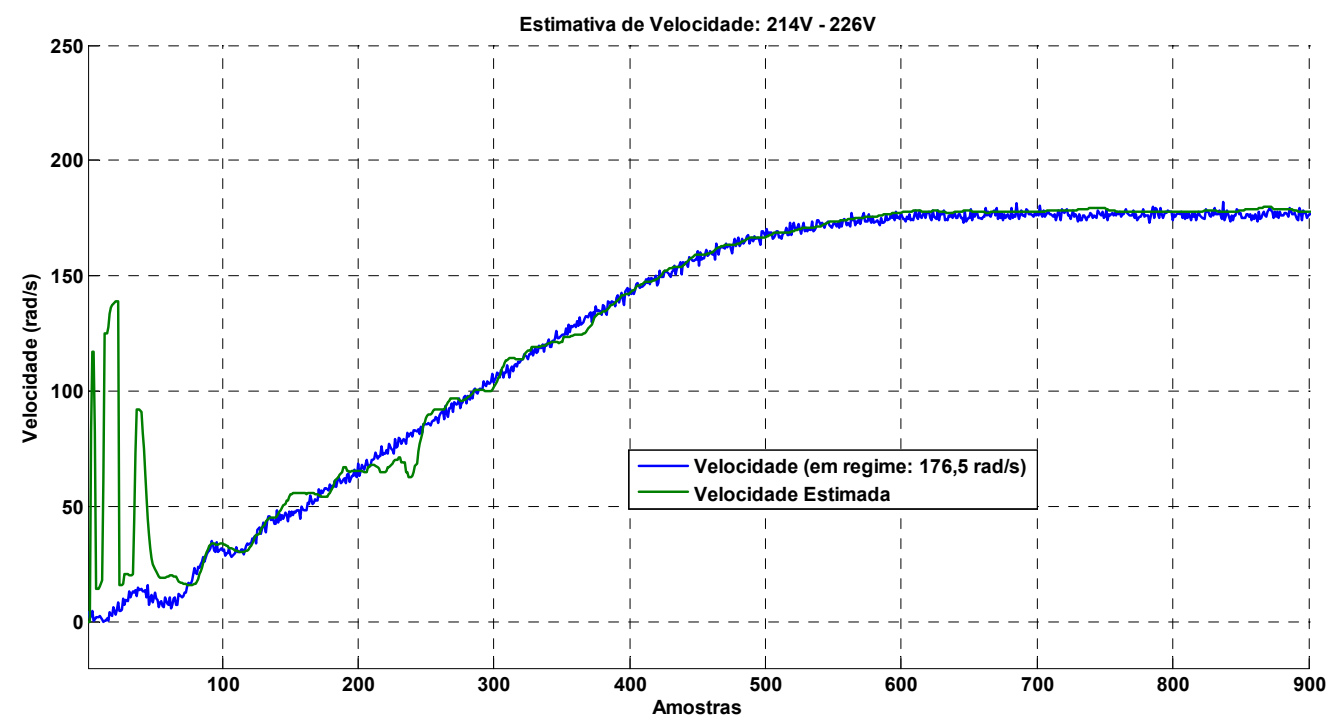

FIGURA 5.25 - Estimativa de velocidade na faixa 3 (214V-226V) e 3,8 Nm de conjugado de carga em regime permanente através do processo de bi-validação modificado. 


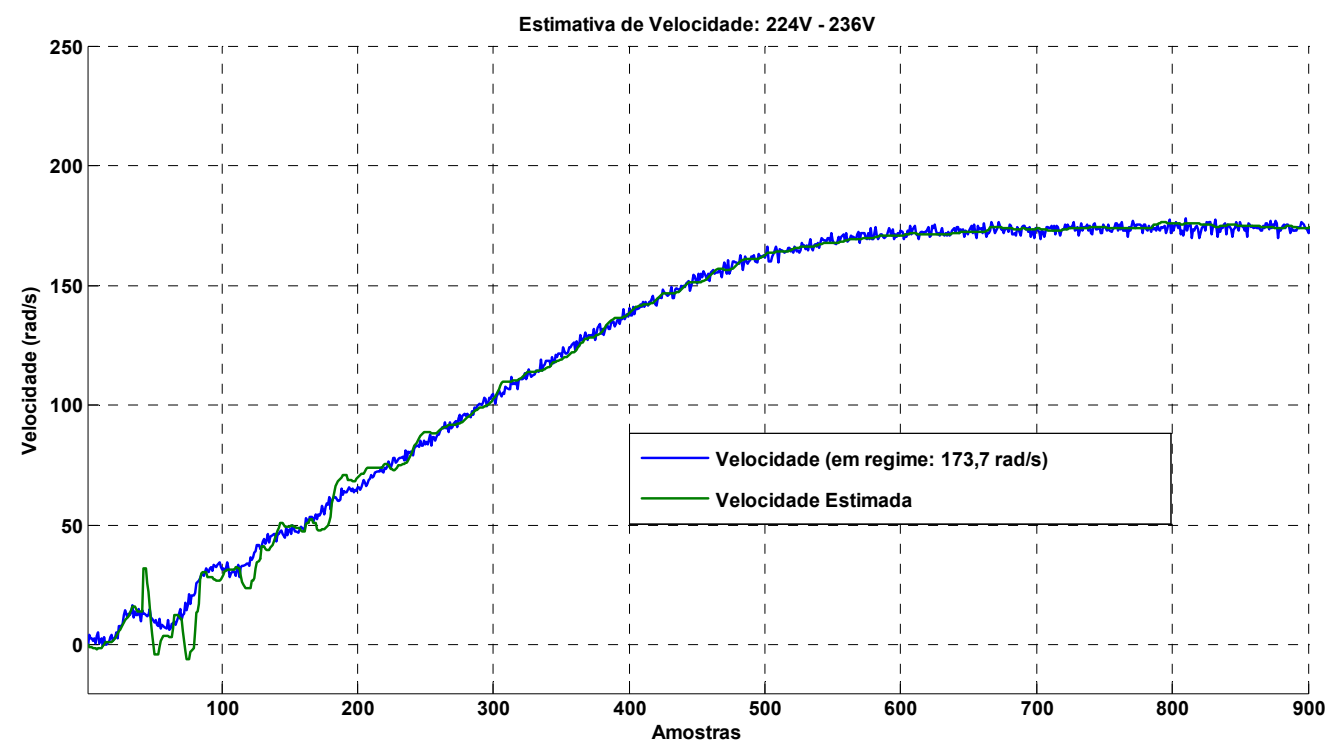

FIGURA 5.26 - Estimativa de velocidade na faixa 4 (224V-236V) e 5,5 Nm de conjugado de carga em regime permanente através do processo de bi-validação modificado.

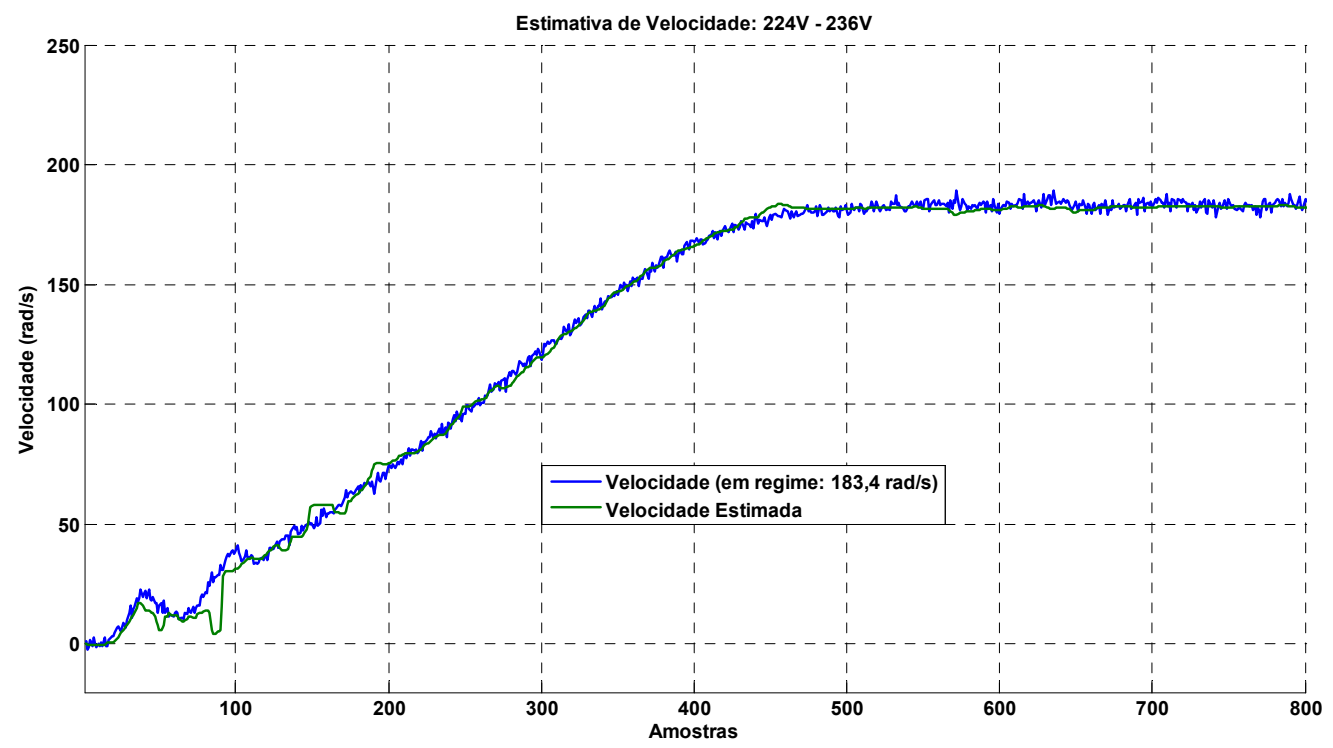

FIGURA 5.27 - Estimativa de velocidade na faixa 4 (224V-236V) e $3,5 \mathrm{Nm}$ de conjugado de carga em regime permanente através do processo de bi-validação modificado.

A Figura 5.28 apresenta os resultados de generalização do conjunto de dados obtidos experimentalmente dentro da faixa de operação 5 definido na Tabela $5.2(234 \mathrm{~V}$ a $240 \mathrm{~V})$. O conjugado de carga que o MIT é submetido tem valor de 1 
Nm. A Figura 5.29, dentro da mesma faixa de operação, o conjugado de carga é de $4 \mathrm{Nm}$.

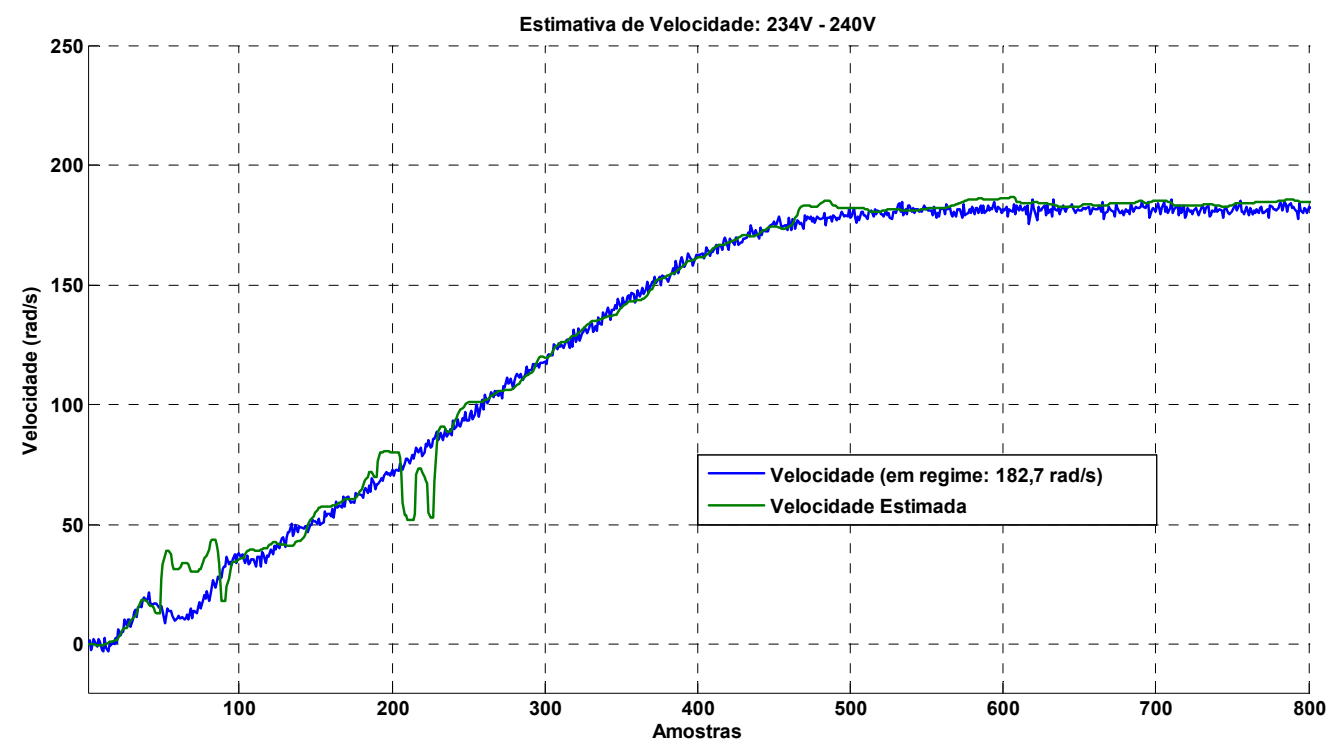

FIGURA 5.28 - Estimativa de velocidade na faixa 5 (234V-240V) e $1 \mathrm{Nm}$ de conjugado de carga em regime permanente através do processo de bi-validação modificado.

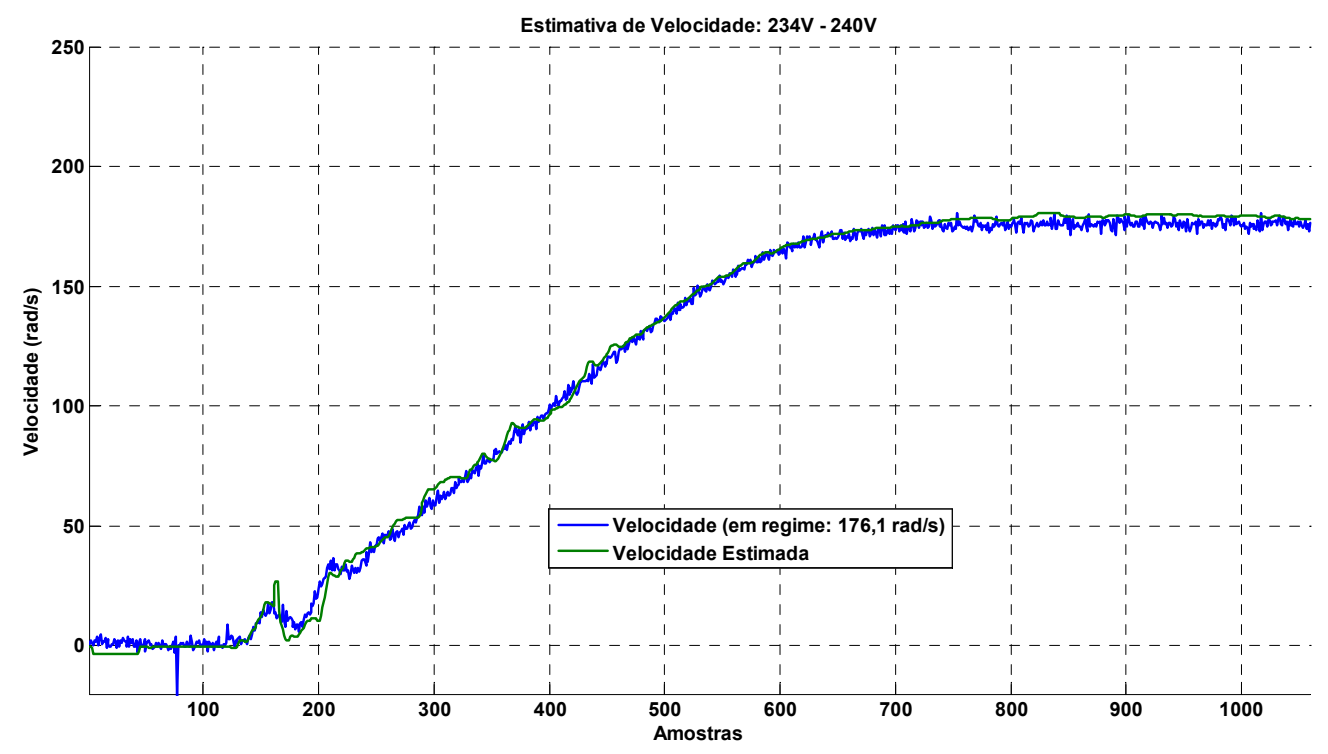

FIGURA 5.29 - Estimativa de velocidade na faixa 5 (234V-240V) e $6 \mathrm{Nm}$ de conjugado de carga em regime permanente através do processo de bi-validação modificado.

Nesta seção foram apresentados os resultados de generalização de uma estrutura neural responsável por estimar a velocidade no eixo do motor de indução 
trifásico com medidas primárias de tensão e corrente, do regime transitório ao regime permanente. A divisão por faixas de tensão, acima e abaixo da tensão nominal de operação do MIT em questão, faz desta proposta um sistema modular para estimar velocidade no MIT.

Observa-se um erro considerável de generalização nas primeiras 100 amostras após a partida no método de bi-validação modificado. Esta quantidade de amostras equivale a 6 ciclos de senóide após a partida. A Tabela 5.6 apresenta o erro médio e desvio padrão dos resultados apresentados nas FIGURA 5.20 a FIGURA 5.29.

TABELA 5.6 - Erro médio e desvio padrão entre as velocidades real e estimada no eixo do motor de indução trifásico.

\begin{tabular}{|c|c|c|}
\hline Figura & Erro Médio (\%) & Desvio Padrão (\%) \\
\hline FIGURA 5.20 & 3,14 & 4,27 \\
\hline FIGURA 5.21 & 3,73 & 5,74 \\
\hline FIGURA 5.22 & 3,30 & 5,93 \\
\hline FIGURA 5.23 & 2,73 & 4,75 \\
\hline FIGURA 5.24 & 1,52 & 2,10 \\
\hline FIGURA 5.25 & 1,21 & 1,93 \\
\hline FIGURA 5.26 & 1,95 & 3,76 \\
\hline FIGURA 5.27 & 1,62 & 2,49 \\
\hline FIGURA 5.28 & 2,83 & 4,84 \\
\hline FIGURA 5.29 & 2,36 & 4,40 \\
\hline
\end{tabular}

\subsection{Estudo Comparativo Entre RNA e Modelo de Referência}

Nesta seção a proposta baseada em redes neurais é comparada com uma metodologia onde dados experimentais de tensão são apresentados ao modelo do MIT. Este é o princípio utilizado no estimador por modelo de referência adaptativo.

Conforme Astrom e Wittenmark (1995), tal modelo consiste de um sistema onde o desempenho desejado é expresso em termos de um modelo dinâmico do sistema, o qual produz a resposta desejada a um sinal de comando. No trabalho de 
Cirrincione e Pucci (2005) foi proposto um esquema baseado no modelo de referência para estimar velocidade no eixo do motor de indução a partir das "bem conhecidas equações do motor de indução”. O mecanismo de adaptação utilizado pelos autores foi uma rede neural artificial. A partir do diagrama em blocos e pelas equações apresentadas pelos autores deste trabalho, a alimentação do modelo de referência foi à tensão e a corrente de estator, ambas decompostas nos eixos $d$ e $q$ (direto e quadratura).

No artigo de Park e Kwon (2004) é proposto um controle de velocidade baseado em metodologias sensorless para o motor de indução. Na proposta dos autores, o Controle por Modelo de Referência Adaptativo (CMRA) é realizado por alimentação do modelo de referência com tensões e correntes do estator. Este método, conforme os autores, é muito utilizado em estimadores de velocidade pela sua simplicidade de projeto e análise.

Em relação à presente tese, utiliza-se este princípio do Modelo de Referência (MR) para estimar o valor da velocidade no eixo do motor de indução a partir do modelo da máquina (Apêndice A), tendo como objetivo a comparação com os resultados do estimador neural desenvolvido.

O modelo de referência é alimentado com as tensões trifásicas, enquanto as correntes e o fluxo eletromagnético são calculados utilizando os parâmetros da máquina. A partir dos valores de fluxo e corrente se tem o conjugado eletromagnético, que aplicado à equação mecânica do MIT resulta na velocidade. O modelo utilizado nesta seção é o mesmo descrito no Apêndice A, no qual se utilizam os parâmetros da máquina de indução apresentados na Tabela 5.1.

A FIGURA 5.30 apresenta a comparação entre a velocidade medida, o modelo de referência e o estimador neural quando o MIT é submetido a uma carga 
de $1 \mathrm{Nm}$ na faixa de operação entre 214V a 226V. A FIGURA 5.31 apresenta a comparação entre os três métodos quando o MIT é submetido a um conjugado de carga de $2 \mathrm{Nm}$ e uma tensão de operação também de $214 \mathrm{~V}$ a $226 \mathrm{~V}$. A FIGURA 5.32 apresenta o MIT operando na mesma faixa de tensão das FIGURAS 5.30 e 5.31 (214V a 226V) sendo agora o MIT submetido ao conjugado resistente de $3 \mathrm{Nm}$.

A FIGURA 5.33 ilustra os resultados de estimativa de velocidade através do modelo de referência, estimador neural e medida direta da variável quando o MIT é submetido a um conjugado de carga de 4 Nm. Nas FIGURAS 5.34 e 5.35 o MIT é submetido a $5 \mathrm{Nm}$ e $6 \mathrm{Nm}$ de conjugado de carga quando aplicado à mesma faixa de tensão das figuras anteriores.

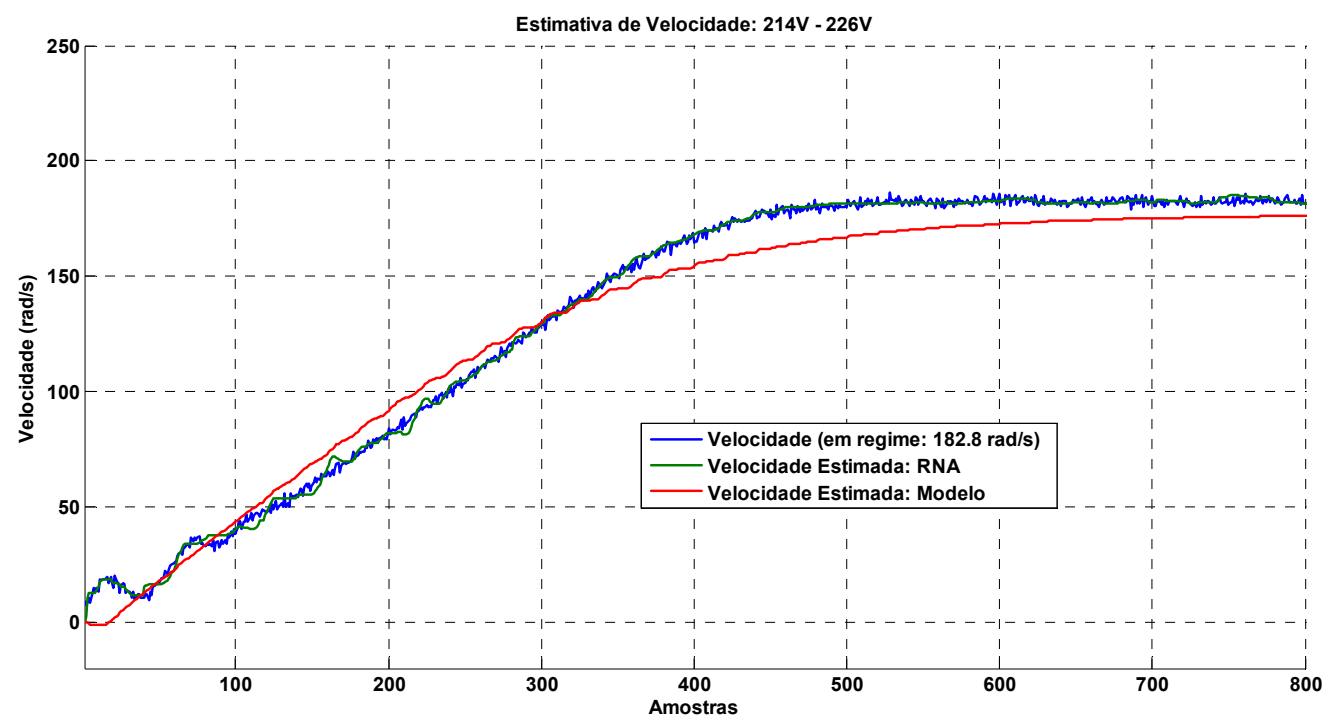

FIGURA 5.30 - Estimativa de velocidade na faixa 3 (214V-226V) e $1 \mathrm{Nm}$ de conjugado de carga em regime permanente através do processo de bi-validação modificado e o modelo de referência. 


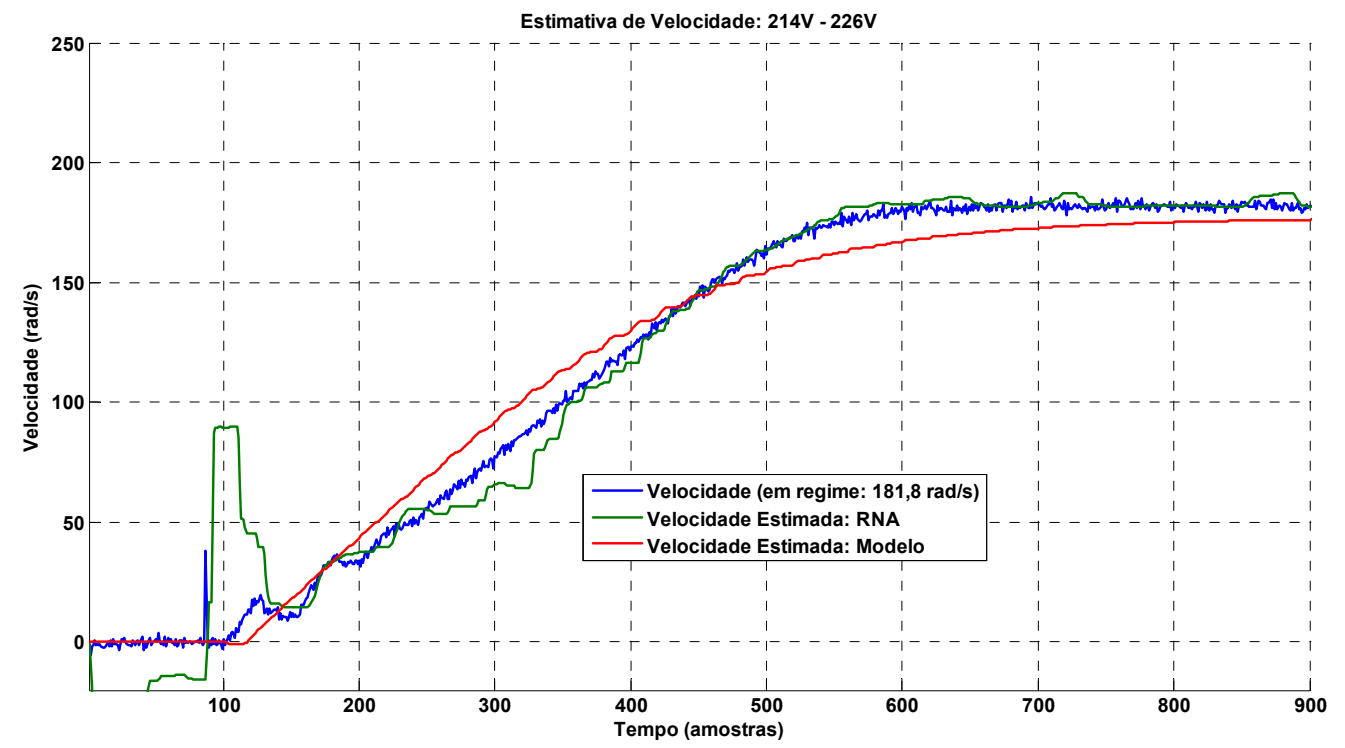

FIGURA 5.31 - Estimativa de velocidade na faixa 3 (214V-226V) e $2 \mathrm{Nm}$ de conjugado de carga em regime permanente através do processo de bi-validação modificado e o modelo de referência.

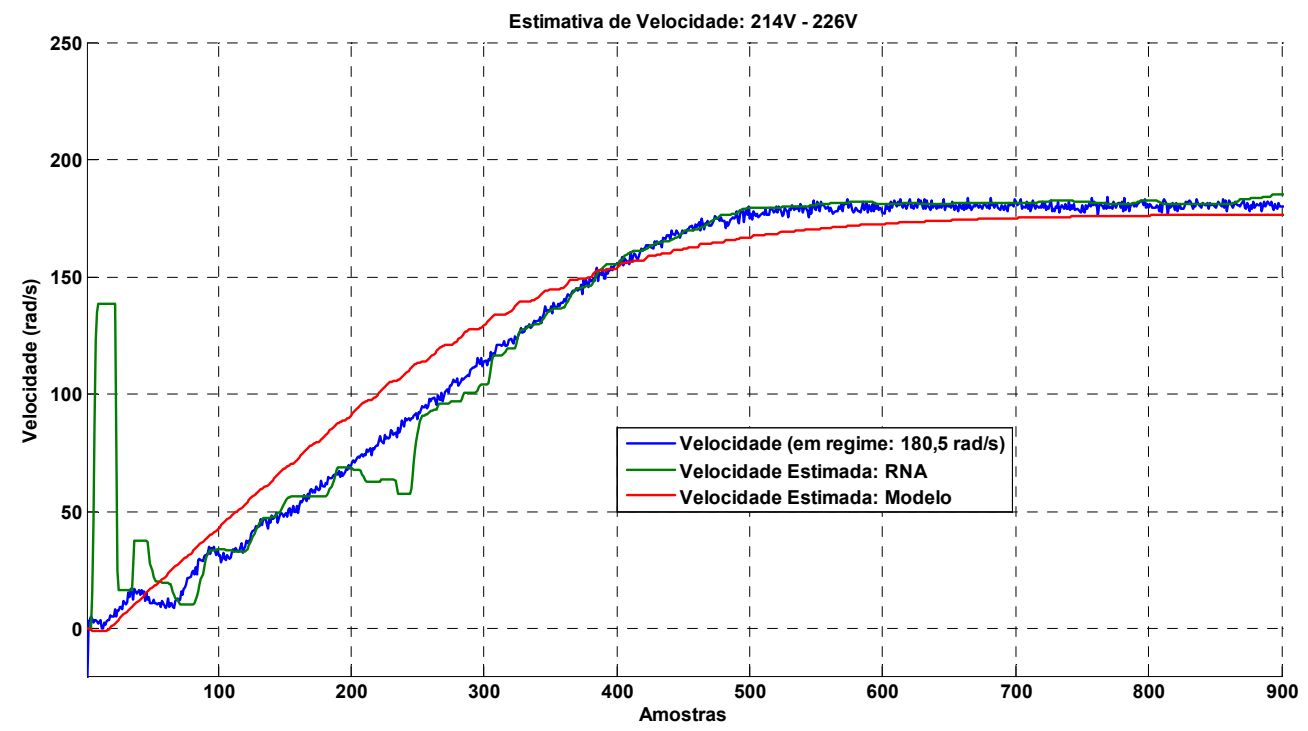

FIGURA 5.32 - Estimativa de velocidade na faixa $3(214 \mathrm{~V}-226 \mathrm{~V})$ e $3 \mathrm{Nm}$ de conjugado de carga em regime permanente através do processo de bi-validação modificado e o modelo de referência. 


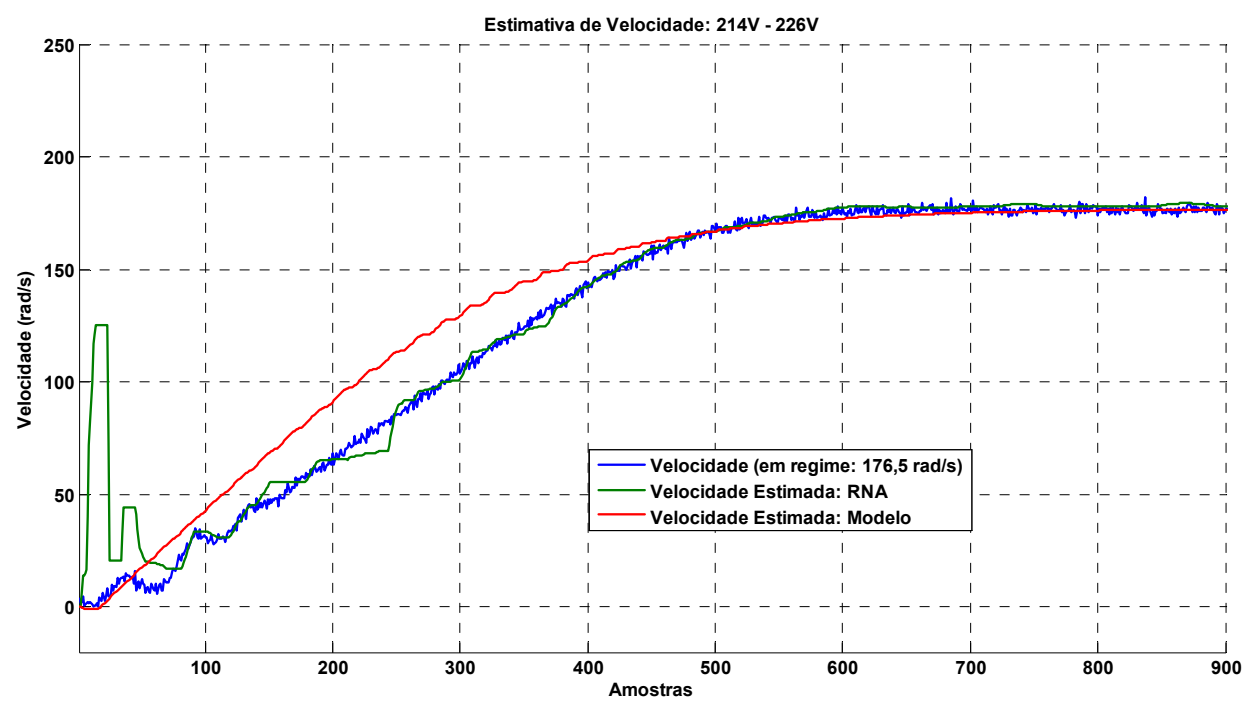

FIGURA 5.33 - Estimativa de velocidade na faixa 3 (214V-226V) e $4 \mathrm{Nm}$ de conjugado de carga em regime permanente através do processo de bivalidação modificado e o modelo de referência.

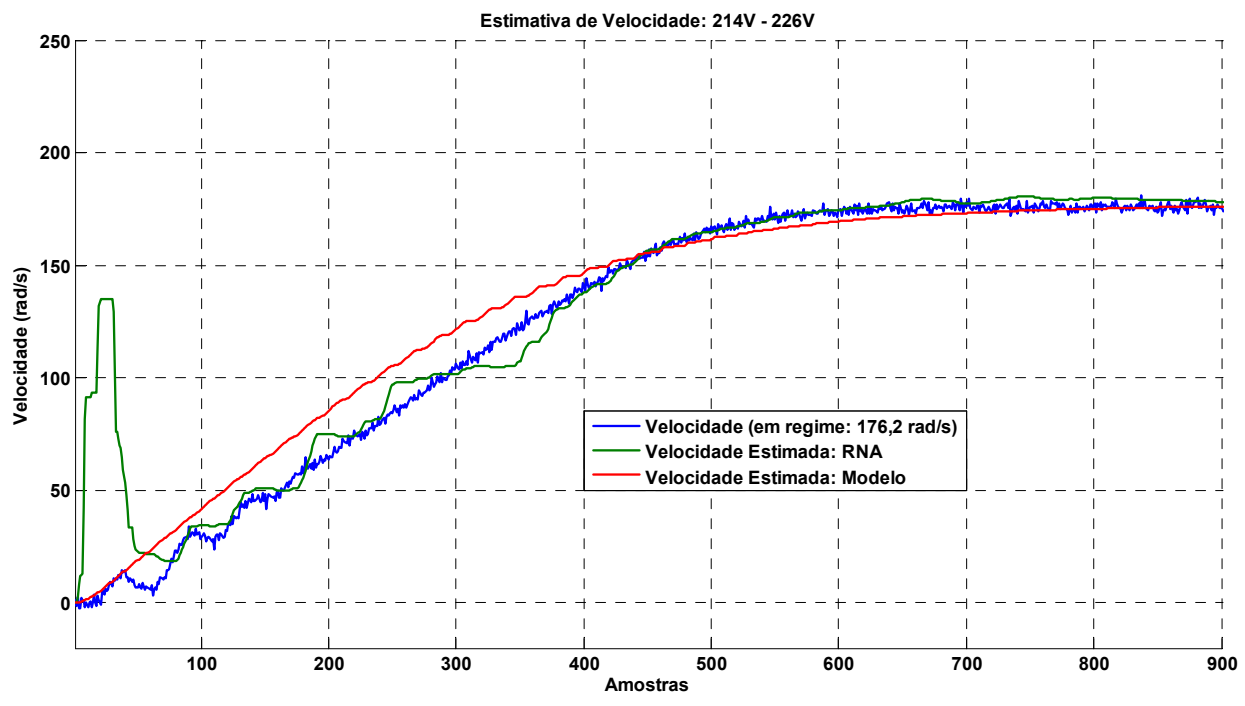

FIGURA 5.34 - Estimativa de velocidade na faixa 3 (214V-226V) e $5 \mathrm{Nm}$ de conjugado de carga em regime permanente através do processo de bivalidação modificado e o modelo de referência. 


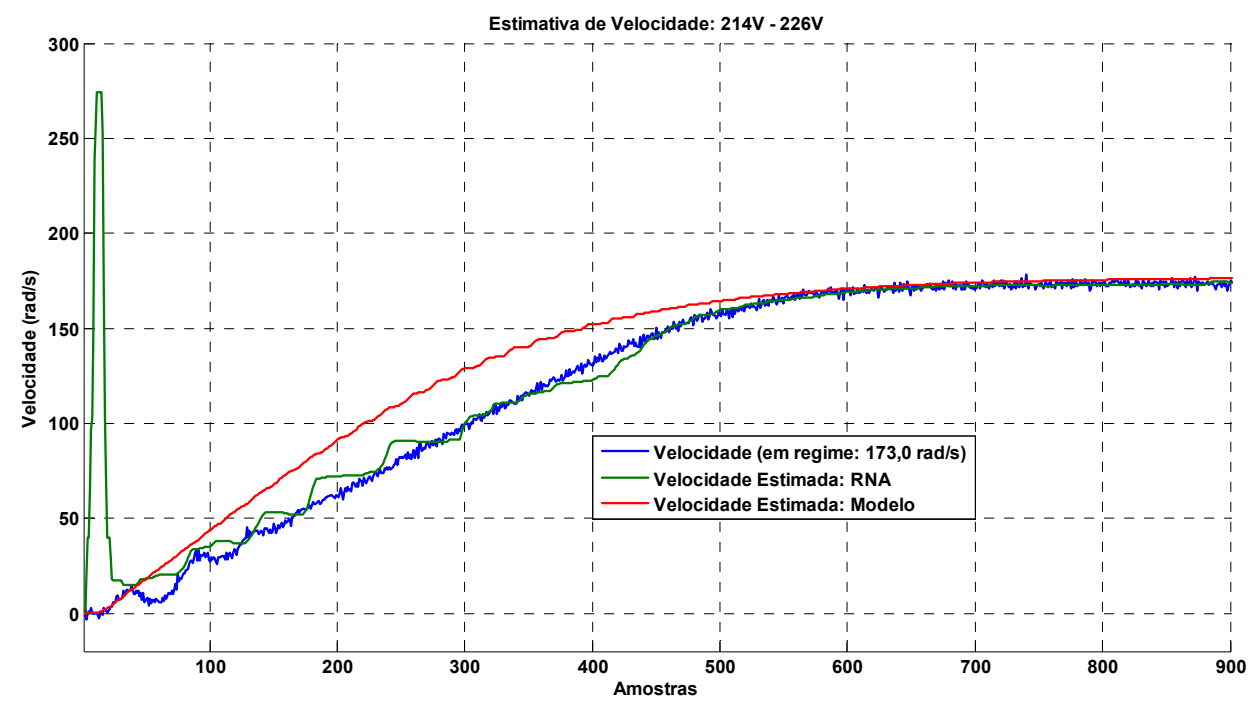

FIGURA 5.35 - Estimativa de velocidade na faixa 3 (214V-226V) e $6 \mathrm{Nm}$ de conjugado de carga em regime permanente através do processo de bivalidação modificado e o modelo de referência.

A Tabela 5.7 apresenta o erro médio e desvio padrão dos resultados apresentados na FIGURA 5.30 a FIGURA 5.35.

TABELA 5.7 - Erro médio e desvio padrão entre as velocidades real e estimada no eixo do motor de indução trifásico para o estimador neural e o modelo de referência.

\begin{tabular}{|c|c|c|c|c|}
\cline { 2 - 5 } \multicolumn{1}{c|}{} & \multicolumn{2}{c|}{ Estimador Neural } & \multicolumn{2}{c|}{ Modelo de Referência } \\
\hline Figura & $\begin{array}{c}\text { Erro Médio } \\
(\%)\end{array}$ & $\begin{array}{c}\text { Desvio Padrão } \\
(\%)\end{array}$ & $\begin{array}{c}\text { Erro Médio } \\
(\%)\end{array}$ & $\begin{array}{c}\text { Desvio Padrão } \\
(\%)\end{array}$ \\
\hline FIGURA 5.30 & 1,21 & 1,93 & 9,77 & 16,37 \\
\hline FIGURA 5.31 & 3,02 & 5,59 & 6,29 & 6,99 \\
\hline FIGURA 5.32 & 3,93 & 8,27 & 10,57 & 14,30 \\
\hline FIGURA 5.33 & 2,38 & 3,71 & 11,45 & 16,46 \\
\hline FIGURA 5.34 & 3,64 & 4,97 & 9,55 & 14,10 \\
\hline FIGURA 5.35 & 3,68 & 6,53 & 13,87 & 18,26 \\
\hline
\end{tabular}

Nesta subseção foram apresentados os resultados de um estudo comparativo entre o estimador neural proposto, o modelo de referência e os resultados medidos da velocidade no eixo do motor de indução trifásico.

O enfoque desta comparação, quando o MIT foi submetido a diferentes situações de carga, foi realizado dentro da mesma faixa de operação; a saber: 214V a 226V. Esta faixa de operação, em termos de tensão de alimentação, é de grande 
importância, pois está no entorno da tensão nominal de alimentação do motor. Logo, as características de conjugado eletromagnético e, conseqüentemente, de conjugado de aceleração não se alteram de forma significativa.

Através dos gráficos apresentados é possível observar que o modelo de referência se aproxima muito do valor medido em baixas velocidades, considerando o regime transitório e o regime permanente. Em velocidades superiores a $10 \mathrm{rad} / \mathrm{s}$, o resultado obtido por intermédio do modelo de referência diverge dos valores medidos e volta a convergir em regime permanente. Isso pode ser explicado pelo levantamento paramétrico realizado do motor de indução. Quando o modelo é obtido, considera-se a tensão nominal e a corrente nominal da máquina. Neste caso, durante o regime transitório, tem-se um afundamento de tensão de $5 \%$ em relação ao valor ajustado pelos variadores de tensão no painel. Então, durante o regime transitório, o modelo de referência não se mostra um bom estimador de velocidade devido à variação paramétrica do MIT neste período.

Em termos computacionais, o modelo de referência calculou um sistema de equações diferenciais, enquanto que o estimador baseado em redes neurais artificiais se reduziu ao cálculo matricial; aplicando-se os pesos sinápticos ajustados de forma off-line às entradas de tensão e corrente. Pode-se concluir que a estratégia baseada em redes neurais artificiais apresenta menor custo computacional para sua implementação, realizando estimativas de velocidade com erro relativamente baixo em regime transitório e regime permanente. 


\section{Conclusões Gerais e Trabalhos Futuros}

\subsection{Conclusões Gerais}

Nesta tese foi proposto um estimador de velocidade para o motor de indução trifásico baseado em redes neurais artificiais, organizada numa multi-estrutura, considerando uma ampla faixa de tensão e conjugado de carga aplicado no eixo da máquina.

No sentido de determinar a aplicabilidade da metodologia em situações reais, da partida ao regime permanente, apresentaram-se dados experimentais à estrutura neural treinada com dados de simulação através do método de bi-validação cruzada. Resultados de generalização em regime permanente mostraram-se satisfatórios, mas com erro elevado em regime transitório.

Para contornar tal inconveniente, propôs-se o método de bi-validação cruzada modificado, o qual consistiu em adicionar um pequeno conjunto de dados experimentais num conjunto de dados simulados para o treinamento da estrutura neural. A rede neural artificial apresentou a capacidade de aprender os padrões (simulados e experimentais) e generalizar soluções em regime transitório e permanente.

A metodologia de bi-validação cruzada modificada também se constituiu numa contribuição à pesquisa na área de redes neurais artificiais, uma vez que engloba dados experimentais e dados de simulação num conjunto único de treinamento. Os resultados de generalização são melhorados à medida que a estrutura neural mapeia as características da dinâmica do sistema. 
A aplicação de redes neurais artificiais em sistemas que possuem poucos dados de treinamento se torna proibitiva e, normalmente, utilizam-se outras metodologias, tal como a lógica fuzzy. Entretanto, a partir do modelo linearizado do sistema e dos seus parâmetros, tornou-se possível gerar dados adicionais que foram englobados num conjunto de treinamento juntamente com os dados experimentais. No processo de validação foram utilizados $100 \%$ de dados experimentais os quais não participaram do processo de treinamento.

A metodologia proposta foi comparada com outra baseada na modelagem do MIT; a saber, o modelo de referência. Os resultados obtidos demonstraram que o modelo de referência acompanhou a velocidade do MIT desde a partida da máquina até $20 \mathrm{rad} / \mathrm{s}$, região esta de muito baixa velocidade. Considerando esta mesma região, a estrutura neural apresentou erro elevado de generalização. À medida que o MIT acelerava, o erro do modelo de referência aumentou em relação ao valor medido da velocidade, sendo que a rede neural, por sua vez, apresentava erro inferior quando comparado à região de baixa velocidade.

Em regime permanente, ambas as propostas convergem para valores muito próximo do valor medido com erro inferior a $2 \%$. Desta forma, pode-se inferir a validade da proposta baseada em redes neurais artificiais, com divisão por faixa de tensão, para valores acima de $20 \mathrm{rad} / \mathrm{s}$, pois a mesma apresentou baixo erro de generalização considerando apenas dados experimentais quando usado o processo de bi-validação cruzada modificado.

Em suma, um resumo das principais contribuições deste trabalho de caráter inovador são elencadas como se segue: 
- Uma proposta baseada em redes neurais artificiais para estimativa de velocidade considerando diferentes faixas de tensão de operação do MIT e diversas situações de conjugado de carga.

- A proposta de bi-validação cruzada modificada, a qual melhorou os resultados de generalização da estrutura neural proposta quando apenas dados experimentais foram apresentados à rede para obter dados de generalização.

- Construção de uma estrutura de ensaios, a qual contempla o acoplamento de diversas máquinas, sua instrumentação e sistema para aquisição de dados, assim como a descrição sistemática neste trabalho, possibilitando a reprodução em outros centros de pesquisa e ensino.

\subsection{Futuras Linhas de Pesquisa}

As sugestões de futuras linhas de pesquisa são apresentadas a seguir:

- Aperfeiçoar o modelo neural para estimativa de velocidade em regiões de muito baixa velocidade (inferior a $20 \mathrm{rad} / \mathrm{s}$ ).

- Testar o método de bi-validação cruzada modificado apresentado neste trabalho em outros sistemas dinâmicos multivariáveis e variantes no tempo.

- Implementar a metodologia proposta em sistemas de controle escalar e vetorial do MIT. 
- Aperfeiçoar o sistema de controle de carga da máquina de corrente contínua com o objetivo de impor perfis de carga em regime transitório variados.

- Aplicar o método proposto para estimativa de velocidade em regimes de alimentação não senoidal.

\subsection{Publicações Relativas ao Trabalho}

A seguir, apresenta-se uma relação de publicações relativos à divulgação dos resultados das pesquisas realizadas no período de doutorado. As publicações são divididas da seguinte forma: i) publicações em revistas internacionais, ii) publicações em congressos internacionais e iii) publicações em congressos nacionais.

- Publicações em Revistas Internacionais

As principais publicações realizadas em revistas e periódicos internacionais com corpo editorial são enumeradas a seguir:

1) Alessandro Goedtel, Ivan Nunes da Silva, Paulo José Amaral Serni, Antonio Vanderlei Ortega, "A Method Based on Intelligent Systems to Estimate Speed in Induction Motors (Submitted)", Electric Power Components and Systems.

- $\quad$ Publicações em Congressos Internacionais 
As principais publicações realizadas em congressos internacionais, compreendendo o período de desenvolvimento do projeto de doutorado, são enumeradas a seguir:

1) Alessandro Goedtel, Ivan Nunes Silva, Paulo José Amaral Serni, "Torque and Speed Estimator for Sensorless Induction Motor Drive Using Cascade Neural Networks", Proceedings of the $1^{\text {st }}$ IEEE Conference on Industrial Electronics and Applications (ICIEA'2006), pp. 137-142, Cingapura, 2006.

2) Alessandro Goedtel, Ivan Nunes Silva, Paulo José Amaral Serni, "Recurrent Neural Network for Induction Motor Speed Estimation in Industry Applications", Proceedings of the $13^{\text {th }}$ IEEE Mediterranean Electrotechnical Conference (MELECON'2006), pp. 1134-1137, Málaga/Espanha, 2006.

3) Alessandro Goedtel, Ivan Nunes Silva, Paulo José Amaral Serni, Rogério Andrade Flauzino, "Uma Estratégia Eficiente Para Acionamento EstrelaTriângulo de Motores de Indução Usando Redes Neurais", Anais da VII Conferência Internacional de Aplicações Industriais (VII IEEE'INDUSCON), CD-ROM // Paper EPA-IV_3, Recife, 2006.

4) Alessandro Goedtel, Ivan Nunes Silva, Paulo José Amaral Serni, "Speed Estimation in Induction Motors Using Artificial Neural Networks", Proceedings of the $11^{\text {th }}$ IFAC Symposium on Information Control Problems in Manufacturing (INCOM'2004), CD-ROM // Paper No. 48, Salvador, 2004.

5) Alessandro Goedtel, Ivan Nunes Silva, Paulo José Amaral Serni, "An Alternative Approach to Solve Convergence Problems in the Backpropagation Algorithm", Proceedings of the IEEE International Joint Conference on Neural Networks (IJCNN'2004), pp. 1021-1026, Budapeste/Hungria, 2004. 
6) Alessandro Goedtel, Ivan Nunes Silva, Paulo José Amaral Serni, "The Torque and Speed Estimation in Induction Motors Using a Cascade Artificial Neural Networks", Proceedings of the VI Conferência Internacional de Aplicações Industriais (VI IEEE'INDUSCON), pp. 846-851, Joinville, 2004.

7) Alessandro Goedtel, Ivan Nunes Silva, Paulo José Amaral Serni, "Speed Estimation for Sensorless Technology Using Recurrent Neural Network and Single Current Sensor", Power Electronics, Drives and Energy Systems for Industrial Growth-2006 (PEDES-2006), pp. 5C-28, 2006.

8) Alessandro Goedtel, Ivan Nunes Silva, Paulo José Amaral Serni, Claudionor

Francisco Nascimento, "Neural Approach for Speed Estimation in Induction Motors (Accepted for Publication)", Seventh International Conference on Intelligent Systems Design and Applications (ISDA 2007), 2007.

9) Alessandro Goedtel, Ivan Nunes Silva, Paulo José Amaral Serni, “ Intelligent System Based Speed Estimation of Induction Motors for Industrial Sensorless Schemes (Accepted for Publication)", 2007 IEEE International Symposium on Intelligent Control (ISIC 2007), Cingapura, 2007.

- Publicações em Congressos Nacionais

As principais publicações realizadas em congressos nacionais são enumeradas a seguir:

1) Alessandro Goedtel, Ivan Nunes Silva, Paulo José Amaral Serni, "Speed Estimation Techniques in Induction Motors Using Feedback Neural Network Structure", Proceedings of the Brazilian Conference on Dynamics, Control and Their Applications (DINCON'2006), CD-ROM, Guraratingueta, 2006. 
2) Alessandro Goedtel, Ivan Nunes Silva, Paulo José Amaral Serni, "Uma Proposta Para Estimativa de Velocidade em Motores de Indução Trifásicos Utilizando Sistemas Inteligentes", Proceedings of the 4th Congresso Temático de Dinâmica, Controle e Aplicações (DINCON'2005), pp. 11601167, Bauru, 2005.

3) Alessandro Goedtel, Ivan Nunes Silva, Paulo José Amaral Serni, "Uma Proposta de Estimação Paramétrica para Motor de Indução Usando uma Estrutura Neural em Cascata", Anais do VII Simpósio Brasileiro de Automação Inteligente (VII SBAI/LARS), CD-ROM // Paper 10315, São Luis, 2005.

4) Alessandro Goedtel, Ivan Nunes Silva, Paulo José Amaral Serni, "Uma Proposta Alternativa para Estimativa de Velocidade em Motores de Indução Trifásicos Usando Redes Neurais Artificiais", Anais do XV Congresso Brasileiro de Automática (CBA'2004), CD-ROM // Paper No. 1104, Gramado, 2004.

5) Alessandro Goedtel, Ivan Nunes Silva, Paulo José Amaral Serni, Claudia Fiúza Lima Naves Souza, "Estrutura Neural Para Estimativa de Velocidade em Motores de Indução Trifásicos Baseada em Dados Experimentais e Simulados (Aceito para Publicação), VIII Simpósio Brasileiro de Automação Inteligente (SBAI 2007), Florianópolis, 2007. 


\section{Referências Bibliográficas}

ABDElBAR, A. M.; HASSAN, D. O.; TAGLIARINI, G. A.; NARAYAN, S. (2005).

Receptive field optimization for ensemble encoding. Neural Computing \& Applic., Vol. 15, p. 1-8.

AIELLO, M.; CATALIOTTI, A.; NUCCIO, S. (2005). An Induction Motor Speed Measurement Method Based on Current Harmonic Analysis With the Chirp-Z Transform. IEEE Transactions on Instrumentation and Measurement, Vol. 54, No. 5 , p. $1811-1819$

ANDERS, U.; KORN, O. (1999). Model Selection in Neural Networks. Neural Networks, Vol. 12, p. 309-323.

ASTROM, K. J.; Wittenmark, B. (1995). Adaptive Control. Addison-Wesley Publishing Company, Inc.

ANTSAKLIS, P. J. (1992). Neural networks in control systems. IEEE Control Systems Magazine, vol. 12, no. 2, p. 8-10.

ASHRAFZADEH, F.; SACHDEVA, R.; CHU, A. (2002). A novel neural network controller and its efficient DSP implementation for vector controlled induction motor drives. In: Proceedings of 37th IAS Annual Meeting in Industry Applications Conference, vol. 2, p. 1455-1462.

BATTITI, R. (1992). First and second order methods for learning: between steepest descent and Newton's method. Neural Computation, vol. 4, no. 2, pp. 141-166.

BLASCKE, F. (1972). The Principle of Field Orientation as Applied to the New Transvektor Closed-Loop Control System for Rotating Field Machines. Siemens Review Vo. XXXIX, No 5, p. 217-220. 
BOSE, B. K. (1997). Power Electronics and Variable Frequency Drives, IEEE Press.

BOSE, N. K.; LIANG, P. (1996). Neural Network Fundamentals with Graphs, Algorithms, and Applications, McGraw-Hill Inc.

BOSE, B. K. (2007). Neural Network Applications in Power Electronics and Motor Drives - An Introduction and Perspective. IEEE Transactions on Industrial Electronics, vol. 54, no. 1, p. 14-34.

BOSTANCI, M.; KOPLOWITZ, J.; Taylor, C. W. (1997). Identification of Power System Load Dynamics Using Artificial Neural Networks. IEEE Transactions on Power Systems, vol. 12, no. 4, p. 1468-1473.

BRITO, R. M. (1994). Sistema Eletro-Eletrônico para Medição de Torque em Dispositivos Girantes Utilizando Extensômetro de Resistência Elétrica. Tese (Doutorado) - Escola de Engenharia da UFRGS - Universidade Federal do Rio Grande do Sul , 1994.

CAO, C. Z.; LI, H. P. (2002). An application of fuzzy-inference-based neural network in DTC system of induction motor. Proceedings of IEEE International Conference on Machine Learning and Cybernetics, vol. 1, p. 354-359.

CAMPBELL, J. A.; SUMNER, M.; CURTIS, M. (2000). An improved sensorless vector controlled induction motor drive employing artificial neural networks for stator resistance estimation. In. Proceedings of IEE Eighth International Conference on Power Electronics and Variable Speed Drives, IEE Conf. Publ. No. 475, p. 274279.

CAMPBELL, J. A.; SUMNER, M. (2002). Practical sensorless induction motor drive employing an artificial neural network for online parameter adaptation. Proceedings of the IEE Electric Power Applications, vol. 149, p. 255-260. 
CASTOLDI, M. F. (2006). Protótipo Virtual da Estratégia DTC Aplicada a Motores de Indução Usando Linguagem VHDL. Dissertação (Mestrado) - Escola de Engenharia de São Carlos, Universidade de São Paulo, 2006.

CHATTERJEE, P.; KARAN, B. M.; SINHA, P. K. (2002). Multi-layer feed-forward modular network for induction motor. In. Proceedings of the 2002 International Joint Conference on Neural Networks, Hawaii, vol. 1, p. 339-344.

CIRRINCIONE, M.; PUCCI, M. (2003). An MRAS based speed estimation method with a linear neuron for high performance induction motor drives and its experimentation. Proceedings of IEEE International Electric Machines and Drives Conference (IEMDC'03), vol.1, p. 617-623.

CIRRINCIONE, G.; CIRRINCIONE, M.; CHUAN, L.; PUCCI, M. (2003). Direct torque control of induction motors by use of the GMR neural network. Proceedings of the International Joint Conference on Neural Networks, vol. 3, p. 2106-2111.

CIRRINCIONE, M.; PUCCI, M. (2005). An MRAS-Based Sensorless HighPerformance Induction Motor Drive With a Predictive Adaptive Model. IEEE Transactions on Industrial Electronics, vol. 52, no 2. p. 532-552.

CIRRINCIONE, M.; PUCCI, M.; CIRRINCIONE, G.; CAPOLINO, G. A (2006). An adaptive Speed Observer Based on a New Total Least-Squares Neuron for Induction Machine Drives. IEEE Transactions on Industry Applications, vol. 42, no.1, p. 89-104.

CIRSTEA, M.; AOUNIS, A.; MCCORMICK, M.; HAYDOCK, L. (2001). Induction motor drive system modelled in VHDL. In. VHDL International Users Forum Fall Workshop, vol.1, p. 113-117.

COOMBS, C. F. (1995). Electronic Instrumentation Handbook, McGraw-Hill, Inc.. 
CRUZ, P. P.; PAREDES, J. P. S. (2003). A novel speed sensorless direct torque controlled induction motor drive. In: Proceedings of IEEE International Electric Machines and Drives Conference (IEMDC'03), vol. 2, p. 971-975.

DAMASCENO, S. M.; CERQUEIRA, J.; LIMA, A. C.; OLIVEIRA, A. (2002). Uma Proposta Para Avaliação do Rendimento de Motores Elétricos de Indução em Chão de Fábrica. In: Proceedings of XIV Congresso Brasileiro de Automática (CBA 2002), p. 1136-1141.

DIAS, L. P. C.; LOBOSCO, O. S. (1998). Motores Elétricos: Seleção e Aplicação, vol. I, McGraw-Hill Inc..

EL-IBIARY, Y. (2003). An accurate low-cost method for determining electric motors' efficiency for the purpose of plant energy management. IEEE Transactions on Industry Applications, vol. 39, p.1205-1210.

FORESEE, F. D.; HAGAN, M. T. (1997). Gauss-newton approximation to Bayesian regularization. In. Proc. of. International Joint Conference on Neural Networks, p. 1930-1935.

FURTUNATO, A.; ARAÚJO, A. D.; SALAZAR, A. O. (2001). Controlador de velocidade usando modos deslizantes suaves para um motor de indução trifásico. Revista Controle \& Automação, vol. 12, no. 2, p. 148-155.

GOEDTEL, A. (2003). Estimativa de Conjugado de Carga Aplicado em Eixos de Motores de Indução Trifásicos Através de Redes Neurais Artificiais. Dissertação (Mestrado) - Faculdade de Engenharia de Bauru, Universidade Estadual Paulista, 2003.

GOEDTEL, A.; SILVA, I. N. da; SERNI, P. J. A. (2004). The Torque and Speed Estimation in Induction Motors Using a Cascade Artificial Neural Networks. In: VI 
CONFERÊNCIA INTERNACIONAL DE APLICAÇÕES INDUSTRIAIS (VI IEEE INDUSCON), p. 846-851.

GOEDTEl, A.; SILVA, I. N. da; SERNI, P. J. A.; FlAUZINO, R. A. (2006a).

Estratégia Eficiente Para Acionamento Estrela-Triângulo de Motores de Indução

Usando Redes Neurais., In: VII CONFERÊNCIA INTERNACIONAL DE APLICAÇÕES INDUSTRIAIS (VII IEEE INDUSCON), CD-ROM // Paper EPAIV_3, Recife.

GOEDTEL, A.; SILVA, I. N. da; SERNI, P. J. A. (2006b). Torque and Speed

Estimator for Sensorless Induction Motor Drive Using Cascade Neural Networks .

In: 1st IEEE CONFERENCE ON INDUSTRIAL ELECTRONICS AND APPLICATIONS (ICIEA 2006), p. 137-142.

HAGAN, M. T.; MENHAJ, M. (1994). Training feedforward networks with the Marquardt algorithm. IEEE Trans. on Neural Networks, vol. 5, p. 989-993.

HAYKIN, S. (1999). Neural Networks - A Comprehensive Foundation, Prentice Hall, Upper Saddle River, NJ.

HAYKIN, S.; LEUNG, H. (1992). Blind equalization formulated as a self-organized learning process. In. Proceedings of the Twenty-Sixth Asilomar Conference on Signals, Systems, and Computers, p. 346-350.

HOLTZ, J. (1998). Sensorless Position Control of Induction Motors - An Emerging Technology. IEEE Transactions on Industrial Electronics, Vol. 45, No. 6, p. 840852.

HOLTZ, J. (2002). Sensorless control of induction motor drives. In. Proceedings of the IEEE, vol. 90 , no. 8, p. 1359-1394.

HUBERT, C. I. (1991). Electric Machines - Theory, Operation, Applications, Adjustment and Control, Macmillan Publishing Company. 
HURST, K. D.; HABETLER, T. G. (1996). Sensorless speed measurement using current harmonic spectral estimation in induction machine drives. IEEE Transactions on Power Electronics, vol. 11, no. 1, p. 66-73.

JACOBINA, C. B.; LIMA, M. N. (2002). Acionamentos de Máquinas Elétricas de Alto Desempenho, Minicurso XIV CBA, 2002.

KARANAYIL, B.; RAHMAN, M. F.; GRANTHAM, C. (2002). Speed sensorless vector controlled induction motor drive with rotor time constant identification using artificial neural networks. In. Proceedings of the 2002 IEEE International Symposium on Intelligent Control, p. 715-720.

KOLLA, S.; VARATHARASA, L. (2000). Identifying three-phase induction motor faults using artificial neural networks. ISA Transactions, vol. 39, no. 4, p. 433-439.

KUBO, M. M. (2000). Uma contribuição ao modelamento matemático dinâmico de máquinas assíncronas trifásicas. Dissertação (Mestrado) - Faculdade de Engenharia Elétrica e Computação, Universidade de Campinas, 2000.

KUKOLJ, D.; KULIC, F.; LEVI, E. (2000). Design of speed controller for sensorless electric drives based on Al techniques: a comparative study. Artificial Intelligence in Engineering, vol. XIV, p. 165-174.

KIM, J.; NAM, K.; CHUNG, J.; H. SUNWOO, H. (2003). Sensorless Vector Control Scheme for Induction Motor Bases on a Stator Flux Estimator with Quadrant Error Compensation Rule. IEEE Transactions on Industry Applications, vol. 39, no.2, p. 492-503.

KIM, S. J.; LEE, H. J.; KIM, S. K.; KWON Y. A. (2001). ASIC design for DTC based speed control of induction motor. In. IEEE International Symposium on Industrial Electronics, vol.1, pp. 956-961, 2001. 
KRAUSE, P. C.; WASYNCZUCK, O.; SUDHOFF, S. D. (2002). Analysis of Electrical Machinery and Drive Systems, John Wiley \& Sons.

LEONHARD, W. (1991). 30 Years Space Vectors, 20 Years Filed Orientation, 10 Years Digital Signal Processing with Controlled AC-Drives, a Review (Part 1), EPE Journal, Vol. 1, No. 1, p. 13-20.

LINS, Z. D. (2001). Controle direto de torque para Motores de Indução - Estudo e Implementação. Tese (Doutorado) - Faculdade de Engenharia Elétrica e de Computação, Universidade de Campinas, Campinas, 2001.

LIXIN, T.; RAHMAN, M. F. (2001). A new direct torque control strategy for flux and torque ripple reduction for induction motors drive-a Matlab/Simulink model. IEEE International Conference on Electric Machines and Drives, p. 884-890.

LOPEZ, J. C.; ROMERAL, L.; ARIAS, A.; ALDABAS, E. (2006). Novel Fuzzy Adaptive Sensorless Induction Motor Drive. IEEE Transactions on Industrial Electronics, Vol. 53, No. 4, p. 1170-1178.

LU, B.; HABETLER, T. G.; HARLEY, R. G. (2006). A Survey of Efficiency-Estimation Methods for In-Service Induction Motors. IEEE Transactions on Industry Applications, vol. 42, no. 4, 2006.

MARINO, R.; TOMEI, P.; VERRELI, C. M. (2004). A global tracking control for speed-sensorless induction motors. Automatica, 40, p. 1071-1077.

MURAT, B.; BOGOSYAN, S.; GOSAKAN, M. (2004). Speed sensorless direct torque control of IMs with rotor resistance estimation. Energy Conversion and Management, vol. 46, no 3, p. 335-349.

MUNOZ-GARCIA, A.; LIPO, T. A.; NOVOTNY, D. W. (1998). A new induction motor V/f control method capable of high-performance regulation at low speeds. IEEE Transactions on Industry Applications, vol. 34, no. 4, p. 813-821. 
NOVOTNY, D. W.; LIPO, T. A. (1996). Vector Control and Dynamics of AC Drives, Oxford University Press.

OLIVEIRA, V. A.; AGUIAR, M. L.; VARGAS, J. B. (2005). Sistemas de Controle Aulas de Laboratório, Publicação EESC-USP.

ONG, C. M. (1997). Dynamic Simulation of Electric Machinery Using Matlab/Simulink, Prentice Hall.

PARK, C. W.; KWON, W. H. (2004). Simple and Robust Sensorless Vector Control of Induction Motor Using Stator Current Based MRAC. Electric Power Systems Research, no. 71, p. 257-266.

SERNI, P. J. A. (1999). Uma Contribuição ao Estudo do Motor de Indução Linear Acionado por Inversor (VSI) Com Corrente Controlada. Tese (Doutorado) Faculdade de Engenharia Elétrica e de Computação, Universidade de Campinas, Campinas, 1999.

SHAO, J. (1993). Linear Model Selection by Cross-Validation. Journal of the American Statistical Association, Vol. 88, no. 422, p. 486-492.

VAS, P. (1990). Vector Control of AC Machines, Oxford Science Publications.

VAS, P. (1998). Sensorless Vector and Direct Torque Control, Oxford University Press.

VAS, P. (1999). Artificial Intelligence Based Electrical Machines and Drives, Oxford University Press.

SHI, D.; UNSWORTH, P. J.; GAO, R. X. (2006). Sensorless Speed Measurement of Induction Motor Using Hilbert Transform and Interpolated Fast Fourier Transform, IEEE Transactions on Instrumentation and Measurement, Vol. 55, No. 1, p. 290299. 
XEPAPAS, S.; KALETSANOS, A.; XEPAPAS, F.; MANIAS, S. (2003). Sliding-mode observer for speed-sensorless induction motor drives. IEE Proc. of Control Theory Application, vol. 150, no. 6, p. 611-617. 


\section{Apêndice A}

\section{A1. Modelagem Matemática do MIT}

A modelagem matemática é iniciada pelas equações de tensão do estator e do rotor. A Figura A.1 representa o rotor e estator de um MIT, e as correntes de rotor e estator são apresentadas com índices "r" e "s" respectivamente (ONG, 1997).

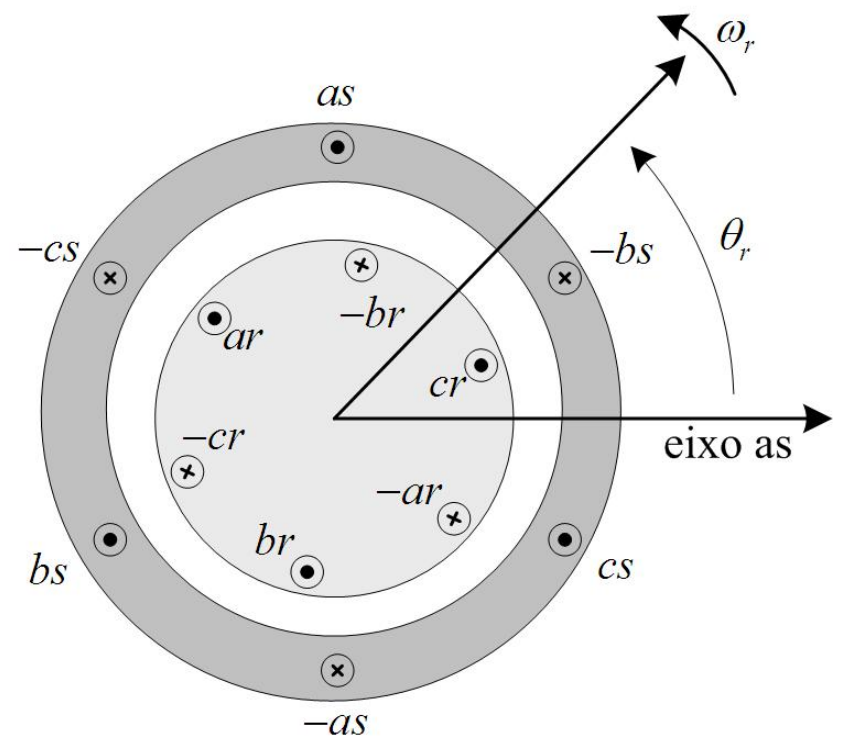

FIGURA A.1 - Corrente de rotor e estator.

As equações de tensão de linha do estator são dadas por:

$$
\begin{aligned}
& v_{a s}=i_{a s} r_{s}+\frac{\mathrm{d} \lambda_{a s}}{\mathrm{~d} t} \\
& v_{b s}=i_{b s} r_{s}+\frac{\mathrm{d} \lambda_{b s}}{\mathrm{~d} t} \\
& v_{c s}=i_{c s} r_{s}+\frac{\mathrm{d} \lambda_{c s}}{\mathrm{~d} t}
\end{aligned}
$$

onde:

$V_{a s}, V_{b s}, V_{c s}$ são as tensões trifásicas do estator em Volt . 
$i_{a s}, i_{b s}, i_{c s}$ são as correntes trifásicas do estator em Ampere .

$\lambda_{a s}, \lambda_{b s}, \lambda_{c s}$ são os fluxos os fluxos magnéticos concatenados trifásicos do estator em Weber .

$r_{s}$ é a resistência do estator em Ohms.

Com relação ao rotor, as equações de tensão do mesmo são descritas por:

$$
\begin{aligned}
& V_{a r}=i_{a r} r_{r}+\frac{d \lambda_{a r}}{d t} \\
& v_{b r}=i_{b r} r_{r}+\frac{d \lambda_{b r}}{d t} \\
& v_{c r}=i_{c r} r_{r}+\frac{d \lambda_{c r}}{d t}
\end{aligned}
$$

onde:

$V_{a r}, V_{b r}, V_{c r}$ são as tensões trifásicas do rotor em Volt.

$i_{a r}, i_{b r}, i_{c r}$ são as correntes trifásicas do rotor em Ampere.

$\lambda_{a r}, \lambda_{b r}, \lambda_{c r}$ são os fluxos magnéticos concatenados trifásicos do rotor em Weber.

$r_{r}$ é a resistência do rotor em Ohms.

As equações de fluxo concatenado entre os enrolamentos de rotor e estator são representadas na forma matricial como se segue:

$$
\left[\begin{array}{c}
\boldsymbol{\Lambda}_{s}^{a b c} \\
\boldsymbol{\Lambda}_{r}^{a b c}
\end{array}\right]=\left[\begin{array}{ll}
\mathbf{L}_{s s}^{a b c} & \mathbf{L}_{s r}^{a b c} \\
\mathbf{L}_{r s}^{a b c} & \mathbf{L}_{r r}^{a b c}
\end{array}\right]\left[\begin{array}{l}
\mathbf{i}_{s}^{a b c} \\
\mathbf{i}_{r}^{a b c}
\end{array}\right]
$$

onde:

$$
\begin{aligned}
& \lambda_{s}^{a b c}=\left[\begin{array}{lll}
\lambda_{a s} & \lambda_{b s} & \lambda_{c s}
\end{array}\right]^{T} \text { é o fluxo concatenado do estator. } \\
& \lambda_{r}^{a b c}=\left[\begin{array}{lll}
\lambda_{a r} & \lambda_{b r} & \lambda_{c r}
\end{array}\right]^{T} \text { é o fluxo concatenado do rotor. } \\
& \mathbf{i}_{S}^{a b c}=\left[\begin{array}{lll}
i_{a s} & i_{b s} & i_{c s}
\end{array}\right]^{T} \text { é o vetor de corrente do estator. }
\end{aligned}
$$




$$
\mathbf{i}_{r}^{a b c}=\left[\begin{array}{lll}
i_{a r} & i_{b r} & i_{c r}
\end{array}\right]^{T} \text { é o vetor de corrente do rotor. }
$$

As matrizes de indutância mútua e de indutância própria são descritas pelas seguintes equações:

$$
\begin{aligned}
& \mathbf{L}_{s s}^{a b c}=\left[\begin{array}{ccc}
L_{/ s}+L_{s m} & L_{s m} & L_{s m} \\
L_{s m} & L_{/ s}+L_{s m} & L_{s m} \\
L_{s m} & L_{s m} & L_{/ s}+L_{s m}
\end{array}\right] \\
& \mathbf{L}_{r r}^{a b c}=\left[\begin{array}{ccc}
L_{l r}+L_{r m} & L_{r m} & L_{r m} \\
L_{r m} & L_{l r}+L_{r m} & L_{r m} \\
L_{r m} & L_{r m} & L_{l r}+L_{r m}
\end{array}\right] \\
& \mathbf{L}_{r s}^{a b c}=L_{s r}\left[\begin{array}{ccc}
\cos \left(\theta_{r}\right) & \cos \left(\theta_{r}+\frac{2 \pi}{3}\right) & \cos \left(\theta_{r}-\frac{2 \pi}{3}\right) \\
\cos \left(\theta_{r}-\frac{2 \pi}{3}\right) & \cos \left(\theta_{r}\right) & \cos \left(\theta_{r}+\frac{2 \pi}{3}\right) \\
\cos \left(\theta_{r}+\frac{2 \pi}{3}\right) & \cos \left(\theta_{r}-\frac{2 \pi}{3}\right) & \cos \left(\theta_{r}\right)
\end{array}\right]^{T} \\
& \mathbf{L}_{s r}^{a b c}=\left[\mathbf{L}_{r s}^{a b c}\right]^{T}
\end{aligned}
$$

onde:

$L_{l s}$ é a indutância de dispersão do estator $(H)$.

$L_{\text {r }}$ é a indutância de dispersão do rotor $(H)$.

$L_{s s}$ é a indutância própria de estator $(H)$.

$L_{r r}$ é a indutância própria de rotor $(H)$.

$L_{s m}$ é a indutância mútua de estator $(H)$.

$L_{r m}$ é a indutância mútua de $\operatorname{rotor}(H)$.

$L_{s r}$ é a indutância mútua entre rotor e estator $(H)$.

$N_{s}$ e $N_{r}$ são o número de espiras no enrolamento do rotor e estator, respectivamente.

Desconsiderando as perdas no ferro, é possível expressar estas indutâncias em termos do número de espiras dos enrolamentos de rotor e estator, e a 
permeância do entreferro. As relações entre as indutâncias são expressas pelas seguintes equações:

$$
\begin{gathered}
L_{s s}=N_{s}^{2} P_{g} \\
L_{s m}=N_{s}^{2} P_{g} \cos \left(\frac{2 \pi}{3}\right) \\
L_{s r}=N_{s} N_{r} P_{g} \\
L_{r r}=N_{r}^{2} P_{g}
\end{gathered}
$$

onde $P_{g}$ é a permeância magnética.

\section{A2. O Modelo "qd0" do Motor de Indução}

Uma máquina idealizada é descrita por seis equações diferenciais de primeira ordem, uma para cada enrolamento. Estas equações são acopladas devido às indutâncias mútuas entre os enrolamentos. Em particular, os termos de acoplamento entre rotor e estator são função da posição do rotor. À medida que o rotor gira, estes termos de acoplamento variam com o tempo. Transformações matemáticas, como a de Park ("qd0") e Clark ("ab0"), facilitam o cálculo da solução transitória, transformando as equações diferenciais variantes no tempo em equações de indutâncias constantes (ONG, 1997).

Conforme descrito por Reginatto e Rico (1993), a transformação de coordenadas consiste em referenciar as variáveis do motor (Tensão, Corrente e Fluxo Eletromagnético) descrito num sistema original para outro sistema de coordenadas, o qual será tomado como referência. A fundamentação deste processo está baseada no princípio da similaridade eletromagnética. A possibilidade 
de reproduzir o fluxo magnético no entreferro, bem como a distribuição de correntes no rotor e estator no sistema de coordenadas adotado como referência, tem o mesmo efeito do sistema de coordenadas original.

O sistema de coordenadas arbitrárias é formado pelo eixo q(quadratura), d(direto) e zero. Uma variável representada por uma relação biunívoca entre as variáveis dos dois sistemas de referência é expressa por:

$$
f_{q d 0}=K^{-1} f_{a b c}
$$

onde $K$ é a relação entre as variáveis dos dois sistemas de coordenadas.

Na Figura A.2 é representada graficamente esta ação de transformação onde $a_{s}, b_{s}$ e $c_{s}$ são os eixos de coordenadas referenciadas ao estator e $a_{r}, b_{r}$ e $c_{r}$ são os eixos de coordenadas referenciadas ao rotor.

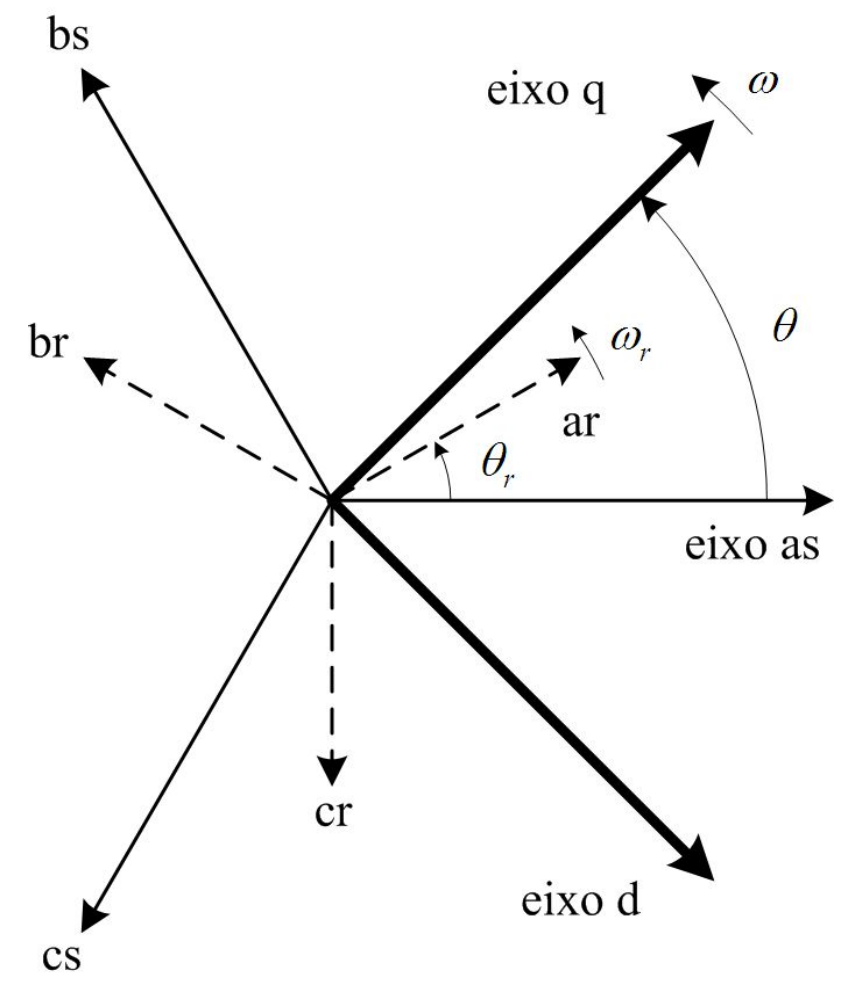

FIGURA A.2 - Corrente de rotor e estator.

A equação de transformação do sistema "abc" para "qd0" é descrita como segue: 


$$
\left[\begin{array}{c}
f_{q} \\
f_{d} \\
f_{o}
\end{array}\right]=\left[\boldsymbol{T}_{q d 0}(\theta)\right] \cdot\left[\begin{array}{c}
f_{a} \\
f_{b} \\
f_{c}
\end{array}\right]
$$

onde $f$ pode representar a Tensão, Corrente ou Fluxo Eletromagnético de cada fase. A matriz de transformação $T_{q d o}(q)$ é dada por:

$$
\left[\mathbf{T}_{q d 0}(\theta)\right]=\frac{2}{3}\left[\begin{array}{ccc}
\cos \theta & \cos \left(\theta-\frac{2 \pi}{3}\right) & \cos \left(\theta+\frac{2 \pi}{3}\right) \\
\sin \theta & \sin \left(\theta-\frac{2 \pi}{3}\right) & \sin \left(\theta+\frac{2 \pi}{3}\right) \\
\frac{1}{2} & \frac{1}{2} & \frac{1}{2}
\end{array}\right]
$$

E a matriz de transformação inversa $\left[T_{q d 0}(q)\right]^{-1}$ é expressa por:

$$
\left[\mathbf{T}_{q d 0}(\theta)\right]^{-1}=\left[\begin{array}{ccc}
\cos (\theta) & \sin (\theta) & 1 \\
\cos (\theta-2 \pi / 3) & \sin (\theta-2 \pi / 3) & 1 \\
\cos (\theta+2 \pi / 3) & \sin (\theta+2 \pi / 3) & 1
\end{array}\right]
$$

O MIT idealizado tem entreferro simétrico. O sistema de coordenadas "qd0" é usualmente selecionado tomando-se por base a conveniência ou compatibilidade com a representação de outros componentes como descrito em Ong (1997). Os dois sistemas de referência usados na análise do MIT são o estacionário e o síncrono. Para estudos de regime transitório é usualmente mais conveniente o uso de sistemas de coordenadas fixo, tanto para a simulação do MIT como do sistema de controle e acionamento, enquanto que para estudos em regime permanente o referencial síncrono é o mais recomendado (ONG, 1997).

O interesse do trabalho é a simulação da máquina do instante da partida ao regime permanente. "Para estudos transitórios é usual a simulação da máquina de indução num sistema de coordenadas estacionário" (ONG, 1997). Desta forma fica escolhido o sistema de coordenadas fixo para simulação. As equações são deduzidas para o sistema de coordenadas síncrono, que gira a uma velocidade 
$\omega=\omega_{e}$, como ilustrado na Figura A.2. Fazendo-se $\omega$ igual a zero obtém-se o sistema de coordenadas fixo. Esse modelo é genérico para simular tanto o regime transitório como permanente da máquina.

\section{A3. Equações de Tensão "qd0"}

$\mathrm{Na}$ notação matricial, a tensão do enrolamento de estator no sistema de coordenadas "abc" pode ser expresso pela seguinte equação:

$$
\mathbf{v}_{S}^{a b c}=\mathbf{i}_{S}^{a b c} \mathbf{r}_{S}^{a b c}+\frac{\mathrm{d} \lambda_{s}^{a b c}}{\mathrm{~d} t}
$$

Aplicando a matriz de transformação $\mathrm{K}^{-1}=\left[\mathrm{T}_{\mathrm{qd} 0}(\mathrm{q})\right]$ em (A.20), tem-se:

$$
\mathbf{v}_{s}^{q d 0}=K^{-1} \cdot \frac{\mathrm{d}(K)}{\mathrm{d} t} \cdot \lambda_{s}^{q d 0}+K^{-1} \cdot \mathbf{r}_{S}^{a b c} \cdot K \cdot \mathrm{i}_{S}^{q d 0}
$$

Usando o valor da derivada de $\left\{\mathbf{T}_{q d 0}(\theta)^{-1} \cdot \lambda_{s}^{q d 0}\right\}$ com relação a variável $t$ em (A.21), obtém-se:

$$
\mathbf{v}_{s}^{q d 0}=\omega\left[\begin{array}{ccc}
0 & 1 & 0 \\
-1 & 0 & 0 \\
0 & 0 & 0
\end{array}\right] \lambda_{S}^{q d 0}+\frac{d\left(\lambda_{s}^{q d 0}\right)}{\mathrm{d} t}+\mathbf{r}_{S}^{q d 0_{i} q d 0}
$$

onde a variável $\omega e \mathbf{r}_{s}^{q d 0}$ são definidas por:

$$
\begin{gathered}
\omega=\mathrm{d} \theta / \mathrm{d} t \\
\mathbf{r}_{S}^{q d 0}=\mathbf{r}_{S}\left[\begin{array}{lll}
1 & 0 & 0 \\
0 & 1 & 0 \\
0 & 0 & 1
\end{array}\right]
\end{gathered}
$$

De forma similar aos procedimentos anteriores, a equação referente ao rotor é descrita como segue: 


$$
\mathbf{V}_{r}^{q d 0}=\left(\omega-\omega_{r}\right)\left[\begin{array}{ccc}
0 & 1 & 0 \\
-1 & 0 & 0 \\
0 & 0 & 0
\end{array}\right] \lambda_{r}^{q d 0}+\frac{d\left(\lambda_{r}^{q d 0}\right)}{d t}+\mathbf{r}_{r}^{q d 0} \mathbf{i}_{r}^{q d 0}
$$

\section{A4. Equações de Fluxo "qd0"}

As equações de fluxo do estator expressas em coordenadas "qd0" são obtidas aplicando a seguinte matriz de transformação:

$$
\lambda_{\mathrm{s}}^{\mathrm{qd} 0}=\mathbf{T}_{q d 0}(\theta) \cdot\left(\mathbf{L}_{s s}^{a b c} i_{s}^{a b c}+\mathbf{L}_{s r}^{a b c} i_{r}^{a b c}\right)
$$

Como conseqüência direta, as equações de fluxo do rotor e estator são expressas por:

$$
\begin{gathered}
\lambda_{s}^{q d 0}=K^{-1} L_{s s}^{a b c} K i_{s}^{q d 0}+K^{-1} L_{s r}^{a b c} T_{q d 0}\left(\theta-\theta_{r}\right)^{-1} i_{r}^{q d 0} \\
\lambda_{r}^{q d 0}=G . L_{r s}^{a b c} \cdot K ._{i}^{q d 0}+G . L_{r r}^{a b c} \cdot G^{-1} \cdot \mathrm{i}_{r}^{q d 0}
\end{gathered}
$$

onde $G$ é dado por $\mathrm{T}_{q d 0}\left(\theta-\theta_{r}\right)$.

\section{A5. Equação de Torque "qd0"}

Considerando o equacionamento previamente descrito, as equações de torque eletromagnético envolvidas com a modelagem matemática devem levar em consideração a transferência de potência nos seis enrolamentos (rotor e estator). Esta consideração resulta na seguinte equação:

$$
\mathbf{T}_{e m}=\frac{3}{2} \frac{p}{2}\left(\lambda_{q r}^{\prime} i_{d r}^{\prime}-\lambda_{d r}^{\prime} i_{q r}^{\prime}\right)
$$


onde $T_{\text {em }}$ é o torque eletromagnético, $p$ o número de pólos do motor de indução, e as variáveis $\lambda_{q r}^{\prime}, \lambda_{d r}^{\prime}, i_{q r}^{\prime}$ e $i_{d r}^{\prime}$ são as grandezas de rotor referenciadas ao estator $\mathrm{e}$ definidas por:

$$
\begin{aligned}
& \dot{\lambda}_{q r}^{\prime}=\frac{N_{s}}{N_{r}} \lambda_{q r} \\
& \dot{\lambda}_{d r}^{\prime}=\frac{N_{s}}{N_{r}} \lambda_{d r} \\
& i_{q r}^{\prime}=\frac{N_{s}}{N_{r}} i_{q r} \\
& i_{d r}^{\prime}=\frac{N_{s}}{N_{r}} i_{d r}
\end{aligned}
$$

\section{A6. Equação de Torque "qd0"}

Como mencionado em Ong (1997), é desejado que as equações sejam expressas em termos do fluxo concatenado por segundo, $\psi$ e pelas reatâncias $x$, no lugar de $\lambda$ e $L$. Estas variáveis estão relacionadas pela freqüência angular $\omega_{b}$, ou seja:

$$
\begin{gathered}
\psi=\omega_{b} \lambda \\
x=\omega_{b} L \\
\omega_{b}=2 \pi f_{r}
\end{gathered}
$$

onde $f_{r}$ é a freqüência relativa entre rotor e estator medida em $\mathrm{Hz}$.

De forma resumida, as equações de rotor e estator podem ser escritas, em termos de $\psi$ e $x$, e são descritas a seguir: 


$$
\begin{aligned}
& \mathbf{v}_{S}^{q d 0}=\frac{\omega}{\omega_{b}}\left[\begin{array}{ccc}
0 & 1 & 0 \\
-1 & 0 & 0 \\
0 & 0 & 0
\end{array}\right] \psi_{S}^{q d 0}+\frac{1}{\omega_{b}} \cdot \frac{\mathrm{d}\left(\psi_{s}^{q d 0}\right)}{\mathrm{d} t}+\mathbf{r}_{S}^{q d 0_{\mathbf{i}_{S}} q d 0} \\
& \mathbf{V}_{r}^{q d 0}=\frac{\left(\omega-\omega_{r}\right)}{\omega_{\mathrm{b}}}\left[\begin{array}{ccc}
0 & 1 & 0 \\
-1 & 0 & 0 \\
0 & 0 & 0
\end{array}\right] \psi_{r}^{q d 0}+\frac{1}{\omega_{b}} \frac{d\left(\psi_{r}^{q d 0}\right)}{d t}+\mathbf{r}_{r}^{q d 0} \mathbf{i}_{r}^{q d 0} \\
& {\left[\begin{array}{c}
\psi_{q s} \\
\psi_{d s} \\
\psi_{0 s} \\
\psi_{q r}^{\prime} \\
\psi_{d r}^{\prime} \\
\psi_{0 r}^{\prime}
\end{array}\right]=\left[\begin{array}{cccccc}
x_{l s}+x_{m} & 0 & 0 & x_{m} & 0 & 0 \\
0 & x_{l s}+x_{m} & 0 & 0 & x_{m} & 0 \\
0 & 0 & x_{l s} & 0 & 0 & 0 \\
x_{m} & 0 & 0 & x_{l r}^{\prime}+x_{m} & 0 & 0 \\
0 & x_{m} & 0 & 0 & x_{l r}^{\prime}+x_{m} & 0 \\
0 & 0 & 0 & 0 & 0 & x_{l r}^{\prime}
\end{array}\right]\left[\begin{array}{c}
i_{q s} \\
i_{d s} \\
i_{0 s} \\
i_{q r}^{\prime} \\
i_{d r}^{\prime} \\
i_{0 r}^{\prime}
\end{array}\right]} \\
& \mathbf{T}_{e m}=\frac{3}{2} \frac{p}{2 \omega_{r}}\left[\frac{\omega}{\omega_{b}}\left(\psi_{d s} i_{d s}-\psi_{q s} i_{d s}\right)+\frac{\omega-\omega_{r}}{\omega_{b}}\left(\psi_{d r}^{\prime} i_{q r}^{\prime}-\psi_{q r}^{\prime} i_{d r}^{\prime}\right)\right]
\end{aligned}
$$

onde

$$
x_{l r}^{\prime}=\omega_{b} L_{l r}^{\prime}
$$

e

$$
L_{l r}^{\prime}=\left(\frac{N_{s}}{N_{r}}\right)^{2} L_{l r}
$$

Destas equações é possível simular o comportamento elétrico e mecânico do motor de indução trifásico. $O$ objetivo do presente trabalho é simular 0 comportamento do motor da partida ao regime permanente. Sendo este período extremamente curto não serão então consideradas variações térmicas as quais fica submetida à máquina.

Considera-se que as três fases que alimentam o motor são equilibradas e cujas senóides não apresentam distorção harmônica. A freqüência das senóides segue o padrão brasileiro de fornecimento de energia, ou seja, $60 \mathrm{~Hz}$. A partida do 
motor simulará a partida direta com tensão plena sendo aplicada aos enrolamentos de estator. A Figura A.3 apresenta o modelo desenvolvido no Matlab/Simulink ${ }^{\circledR}$.

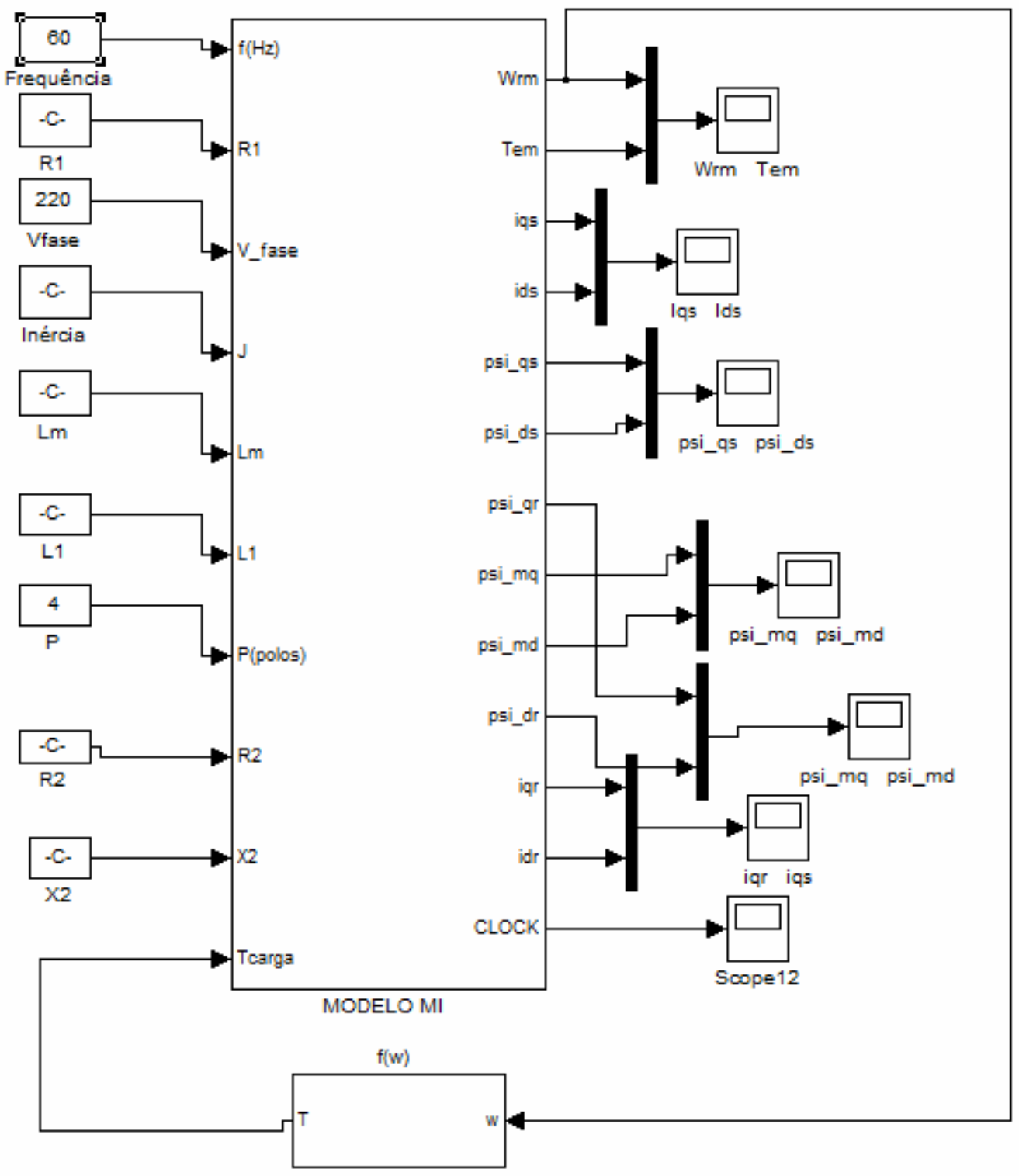

FIGURA A.3 - Modelo do MIT implementado no Simulink ${ }^{\circledR}$. 